\title{
Material versus psychosocial explanations of socioeconomic differences in health-related functioning in older people
}

Citation for published version (APA):

Groffen, D. A. I. (2011). Material versus psychosocial explanations of socioeconomic differences in healthrelated functioning in older people. [, Maastricht University]. Universitaire Pers Maastricht. https://doi.org/10.26481/dis.20110629dg

Document status and date:

Published: 01/01/2011

DOI:

10.26481/dis.20110629dg

Document Version:

Publisher's PDF, also known as Version of record

Please check the document version of this publication:

- A submitted manuscript is the version of the article upon submission and before peer-review. There can be important differences between the submitted version and the official published version of record.

People interested in the research are advised to contact the author for the final version of the publication, or visit the DOI to the publisher's website.

- The final author version and the galley proof are versions of the publication after peer review.

- The final published version features the final layout of the paper including the volume, issue and page numbers.

Link to publication

\footnotetext{
General rights rights.

- You may freely distribute the URL identifying the publication in the public portal. please follow below link for the End User Agreement:

www.umlib.nl/taverne-license

Take down policy

If you believe that this document breaches copyright please contact us at:

repository@maastrichtuniversity.nl

providing details and we will investigate your claim.
}

Copyright and moral rights for the publications made accessible in the public portal are retained by the authors and/or other copyright owners and it is a condition of accessing publications that users recognise and abide by the legal requirements associated with these

- Users may download and print one copy of any publication from the public portal for the purpose of private study or research.

- You may not further distribute the material or use it for any profit-making activity or commercial gain

If the publication is distributed under the terms of Article $25 \mathrm{fa}$ of the Dutch Copyright Act, indicated by the "Taverne" license above, 
Material versus psychosocial explanations of socioeconomic differences in health-related functioning in older people 
The studies presented in this thesis were performed at CAPHRI School for Public Health and Primary Care of Maastricht University. CAPHRI participates in the Netherlands School of Primary Care Research (CaRe), acknowledged by the Royal Dutch Academy of Science (KNAW).

Financial support by the Faculty of Health, Medicine, and Life Sciences of Maastricht University for printing this thesis is gratefully acknowledged.

\section{ISBN 9789052789675}

Cover art by Horia Varlan (Flickr.com)

Printed by Datawyse / Universitaire Pers Maastricht

(C) Copyright, Daniëlle A.I. Groffen, Maastricht 2011

All rights reserved. No part of this thesis may be reproduced, stored in a retrieval system, or transmitted, in any form or by any means, electronic, mechanical, photocopying, recording, or otherwise, without permission from the author or from the publisher holding the copyright of the published articles. 


\title{
Material versus psychosocial explanations of socioeconomic differences in health-related functioning in older people
}

\author{
Proefschrift \\ Ter verkrijging van de graad van doctor \\ aan de Universiteit Maastricht \\ op gezag van de Rector Magnificus, \\ Prof. mr. G.P.M.F. Mols, \\ volgens het besluit van het College van Decanen, \\ In het openbaar te verdedigen op \\ woensdag 29 juni 2011 om 14.00 uur \\ door \\ Daniëlle Adriana Irene Groffen
}

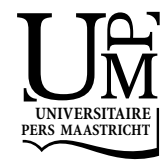




\section{Promotores}

Em. prof. dr. J.Th.M. van Eijk

Prof. dr. G.I.J.M. Kempen

\section{Copromotores}

Dr. H. Bosma

Dr. M. van den Akker

\section{Beoordelingscommissie}

Prof. dr. N.K. de Vries (voorzitter)

Prof. dr. D.J.H. Deeg (Vrije Universiteit, Amsterdam)

Prof. dr. F.J.M. Feron

Prof. dr. J.P. Mackenbach (Erasmus Medisch Centrum, Rotterdam)

Em. prof. dr. H. Philipsen 
"Het gras lijkt altijd groener bij de buren. . . . ."

Voor Elin* 



\section{Contents}

Chapter 1 General introduction $\quad 9$

Chapter 2 Material deprivation and health-related dysfunction in older Dutch 21 people; Findings from the SMILE study

Chapter 3 Lack of basic and luxury goods and health-related dysfunction in older persons; Findings from the longitudinal SMILE study

Chapter 4 Beyond socioeconomic status: the influence of early life and midlife material factors on old age function; Findings from the AGES-Reykjavik Study

Chapter 5 Personality and health as predictors of income decrease in old age; Findings from the longitudinal SMILE study

Chapter 6 Socioeconomic adversity and incident depressive symptoms in older persons: mediating effects of an unhealthy lifestyle; Findings from the Health $A B C$ study

Chapter 7 Material versus psychosocial explanations of old-age educational differences in physical and mental functioning; Findings from the longitudinal SMILE study

Chapter 8 General discussion

Chapter 9 Summary

Samenvatting

Co-authors and affiliations

Dankwoord

About the author

Publications 



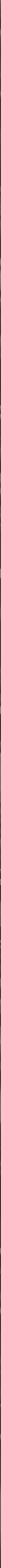




\section{SOCIOECONOMIC HEALTH DIFFERENCES}

Socioeconomic status (SES) is an economic and sociological summary measure of a person's position in the social hierarchy relative to others. The classic indicators of SES typically include income, education and occupation. ${ }^{1}$ However, depending on a person's age and position in the life course, different (alternative) ways of measurement might be of interest. For example, in childhood, parent's education might be the best indicator of SES, while in old age accumulation of wealth might be a more suitable indicator. ${ }^{2,3}$ Because of inter- and intra-generational social mobility, it is also possible to move up or down on the socioeconomic ladder over time. ${ }^{4,5}$

There is ample evidence that SES influences health outcomes: poorer socioeconomic circumstances lead to poorer health. ${ }^{1,6}$ In the Netherlands, life-expectancy of men with only primary education is $\mathbf{7 2 . 2}$ years, while men with higher vocational or university education live on average 79.1 years. Lower educated women have a lifeexpectancy of 78.1, whereas higher educated women live on average 83.8 years. These differences are also present in healthy life-expectancy. Lower educated men and women live their lives on average 18.8 and 16.4 years longer in poor health, compared with higher educated men and women. ${ }^{7}$ In addition, we know that there are not only health differences between the lower educated and the higher educated or between the poor and the rich, but that socioeconomic health differences exist across the whole socioeconomic spectrum: there is an improvement in health status at each successive step on the socioeconomic ladder up to the very top. ${ }^{6}$

Socioeconomic health differences are consistent across different physical and mental health outcomes, countries and settings. They are, however, less well studied in older people. Taking into account our rapidly aging population, older people are of particular interest in studying health inequalities. ${ }^{8}$ In addition, we know that the rate of functional decline is significantly higher in older age groups ${ }^{9}$ and that older people are sensitive to changes in income, for example because of retirement and a vulnerable position in the labour market. Some studies have shown stabilization or narrowing of health inequalities in old age. ${ }^{10}$ This might be due to the 'healthy survivor effect', in which the most disadvantaged individuals may have died earlier. ${ }^{11}$ On the other hand, it is argued that older people are more vulnerable to health inequalities, compared with younger people, because of an accumulation of disadvantages over the life course. ${ }^{12}$ From a life course perspective, the origins of health inequalities in old age may not only be related to circumstances in old age, but may also be traced back to early life circumstances and experiences. ${ }^{12,13}$

According to the World Health Organisation (WHO), health is defined as "a state of complete physical, mental and social well-being and not merely the absence of disease or infirmity". ${ }^{14}$ Self-reported physical and mental functioning might thus be an important indicator of health. The onset of physical and mental diseases often results in functional limitations. ${ }^{15}$ Moreover, consistent evidence exists that self- 
reported functional limitations itself are a good predictor of future morbidity and mortality. ${ }^{16,17}$ While health is considered to be a cumulative state, "to be promoted throughout life in order to maintain an acceptable quality of life in older individuals", ${ }^{14}$ it is important to identify and understand the ways SES affects functional limitations in older people.

\section{EXPLANATIONS OF SOCIOECONOMIC HEALTH DIFFERENCES}

In 1980, the Black Report was published. ${ }^{18}$ This report showed in great detail the extent to which poor health and mortality are unequally distributed among the British population. The report recommended a wide strategy of social policy measures to combat inequalities in health, based on four theoretical explanations, i.e. artefact explanations, theories of (natural) selection, behavioural explanations, and material explanations. ${ }^{18}$ Over the last few decades, it has become clear that the relationship between SES and health is not likely to be explained by measurement artefact $^{6}$. Hence, it is very likely that there exist a true relation between socioeconomic status and health (i.e. social causation). Other explanations of this relation were replicated in later international studies, ${ }^{19-21}$ drawing additional attention to psychosocial factors as fifth explanation of socioeconomic health differences.

\section{Causation and selection}

Two main directions of the relationship between SES and health are distinguished. One direction suggests that health influences SES and social mobility, i.e. the social selection perspective. In this perspective, healthy people are believed to reach higher positions on the social hierarchy than people who are less healthy. ${ }^{22}$ Social selection is more likely for diseases with early onset that have more profound effects on life trajectories (e.g. psychiatric illnesses, such as schizophrenia). It has, however, also been suggested that other qualities of an individual, for example personality (e.g. social inadequacy and sense of control) and $1 Q,{ }^{23,24}$ affect both where one ends up in the social hierarchy as well as future health status. This perspective is called 'indirect selection'. ${ }^{25}$

In general, more evidence exists for the causation perspective on socioeconomic health differences. In this perspective, SES is causally related to future health outcomes. Based on the causation mechanism, behavioural, material, and psychosocial explanations provide pathways in which SES may affect health outcomes. 


\section{Behavioural factor explanation}

The behavioural factor explanation of SES differences in health implies that people from lower SES groups have poorer health because of their higher rates of unhealthy lifestyles, for example smoking, poor diet, or being physical inactive. ${ }^{26,27}$ Indeed, considerable evidence has accumulated that lower SES is generally associated with higher rates of smoking, ${ }^{28}$ poor diet, ${ }^{29}$ and lower levels of physical activity. ${ }^{30}$ These unhealthy behaviours are negatively related to physical ${ }^{31}$ and mental functioning. ${ }^{32}$ Behavioural factors are, however, generally not able to explain all of the socioeconomic health differences. ${ }^{27,33}$

The behavioural factor explanation has been criticised because it might -inadvertently- 'blame the victim' (i.e. people harm themselves by adopting healthdamaging lifestyles). ${ }^{26,34,35}$ Individual decision-making may, however, also be seen in the context of the social structure (e.g. material factors) and constraints that impede these behaviours (e.g. psychosocial factors). Hence, it is important to clarify these underlying structures and to look for the fundamental explanation of socioeconomic health differences. These groups of factors will be discussed below.

\section{Material versus psychosocial explanations}

Material factors include factors related to the physical (living and working) environment, the possession of goods and the household's financial situation. In relatively wealthy countries such as the Netherlands, absolute poverty is assumed to be relatively rare. However, the growing number of food banks might indicate that material deprivation and the inability to buy healthy food is still a major challenge for public health even in developed countries. ${ }^{36-39}$ Consequently, material factors are often argued to be the main explanation of socioeconomic differences in health. ${ }^{40}$ These material factors can have a direct effect on health. For example, the lack of a refrigerator (i.e. the inability to store fresh food) has been shown to increase the risk of stomach cancer. ${ }^{41}$ The lack of qualitatively good food and poor housing conditions (e.g. cold and draught) might also affect health and functioning. $^{40}$

If material factors are the main explanation of socioeconomic health differences, why are there still socioeconomic health differences in the absence of absolute poverty and deprivation? In this respect, psychosocial factors might also be of interest. Psychosocial factors generally include both psychological factors (e.g. personality), as well as factors related to the social environment (e.g. social network, social support and life events), that determine individual susceptibility to chronic stress. The psychosocial factor hypothesis implies that socioeconomic inequalities are due to the direct or indirect effects of chronic stress. ${ }^{42}$ It has been suggested that the higher prevalence of health problems in lower SES groups may be attributed to a higher exposure to psychosocial stressors in these groups. ${ }^{43}$ The health 
impact of these stressors may partly be explained by individual vulnerability. People in lower SES groups are suggested to be less well equipped to cope with stressors, hindered by, for example, a lack of social support or a lower sense of control. ${ }^{43}$ While material disadvantages, job strain and life events may already be considered as considerable stressors, being in a lower position in the socioeconomic hierarchy itself might even be a more important chronic source of stress. ${ }^{44}$ Comparisons with other individuals, being higher or lower in the socioeconomic hierarchy, are argued to be a central phenomenon within human societies. ${ }^{45}$ The need for social comparison stems from the adaptive significance of assessing one's status in the group, ${ }^{46}$ and a desire for higher status and prestige. ${ }^{47}$ Generally, people make social comparisons on the basis of territory and possession (e.g. the size of one's house or car or the possession of luxury goods). Negative social comparisons in lower SES groups might result in feelings of shame ${ }^{48}$ and inferiority and consequently in a lower sense of control and self-esteem. Via unhealthy lifestyle ${ }^{26}$ and stress-induced neuroendocrine or immunological pathways, these adverse psychosocial characteristics may eventually lead to poor physical and mental functioning. ${ }^{49}$

During recent years there is an ongoing debate about whether the effects of SES on health are due to material or to psychosocial factors. ${ }^{40,50-52}$ Although the dichotomy has been questioned, ${ }^{53}$ this debate ${ }^{50,53,54}$ remains crucial, particularly in terms of the choice of interventions intended to reduce inequalities in health. Traditionally, advocates of the material factor hypothesis focus on changing the material and physical environmental causes of health inequalities. While psychosocial stressors often have a material base, advocates of the psychosocial factor hypothesis do not think that the problem is solved when focussing solely on these material factors. Although they are sometimes accused of 'victim blaming', ${ }^{50,53}$ psychosocial researchers generally do not have the intention to blame people from low SES of irresponsible behaviours. ${ }^{52}$ In order to reduce socioeconomic health differences, their main aim is to enable all persons to maximize their capabilities and control over their lives. ${ }^{20}$

\section{Targeted interventions}

The existence and reduction of socioeconomic health differences is a recurring issue in Dutch policy. In December 2008, the Ministry of Public Health, Welfare and Sports has set out a new policy plan to reduce socioeconomic health differences in the Netherlands. ${ }^{55}$ This plan mainly focuses on stressing the citizen's own responsibility. A wide range of possible interventions and policies has been proposed and sometimes implemented. ${ }^{7,56}$ Despite these efforts, socioeconomic health differences still exist and are even increasing. ${ }^{7}$

One problem with interventions is that they are mostly based on descriptive epidemiological studies that are only implicitly able to suggest possible interven- 
tions. What is lacking is further evidence about the amenability to change the specific factor of interest, what sort of interventions might be required, for whom, and whether they will actually be effective in reducing the socioeconomic gradient in health. Still, most interventions are based on promoting a healthy lifestyle and making well-informed choices and are mainly targeted to specific low SES groups (e.g. "krachtwijken"). Lifestyles are often thought to be easy to identify and to treat. Evidence on tackling the more fundamental determinants of socioeconomic health differences is generally less apparent and less accessible to policy makers and practitioners. 57

Identifying and understanding the pathways and mechanisms that contribute to socioeconomic health differences in generally wealthy Western countries might provide more insight in the possible factors that offer the most important startingpoint for action. This information could then be used to identify priorities for future intervention, implementation, and evaluation research.

\section{AIM OF THIS THESIS}

This thesis aims to explore the explanations of socioeconomic health differences in older people. To gain more insight into the more fundamental determinants of socioeconomic health differences, the individual contribution of material and psychosocial factors to the relation between SES and health-related functioning in older people will be studied in particular. For this purpose, four main research questions were formulated:

1. What is the influence of socioeconomic status on physical and mental functioning in older people?

2. What is the influence of material factors on physical and mental functioning in older people?

3. What is the influence of psychosocial factors on physical and mental functioning in older people?

4. What is the relative contribution of psychosocial factors and material factors to the relation between SES and physical and mental functioning in older people?

In addition, the reversed influence of health-related dysfunction on low socioeconomic status (i.e. direct selection) and between psychosocial factors and low socioeconomic status (i.e. indirect selection), as well as the mediating role of behavioural factors (i.e. behavioural factor hypothesis) will be considered to gain more insight in the underlying relations and explanations of socioeconomic differences in healthrelated function.

Figure 1 gives an overview of the pathways that will be studied. To answer the first research question of this thesis, the direct pathway from low SES to healthrelated dysfunction will be examined. This direct pathway indicates a causation 
perspective on socioeconomic health differences. Research questions two and three will be addressed by studying the pathways from material factors to health-related dysfunction and from psychosocial factors to health-related dysfunction, respectively. For the purpose of answering the fourth research question, material factors and psychosocial factors are considered as independent mediators in the relation between SES and health-related dysfunction.

In addition to the four main research questions, the selection perspective on socioeconomic health differences will be studied. In Figure 1, this is indicated by the reversed pathway from health-related dysfunction to low SES. The pathway from psychosocial factors to low socioeconomic status indicates an indirect selection hypothesis. Finally, the mediating role of behavioural factors to the relation between SES and health-related dysfunction will be studied to obtain a complete insight in the explanations of socioeconomic health differences.

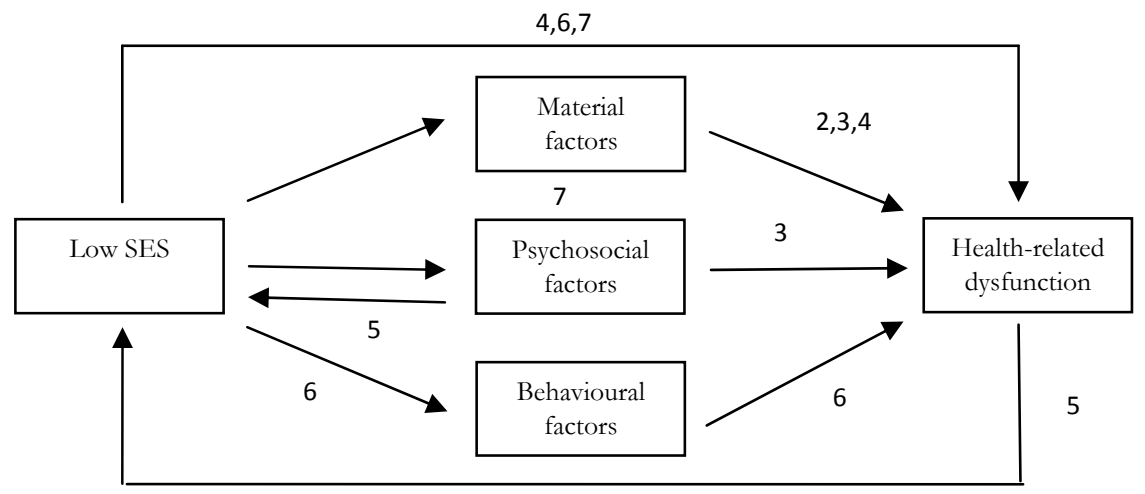

Figure 1 Research model of this thesis. Numbers indicate the chapters in this thesis.

\section{Data}

Data from three different longitudinal cohort studies will be used. Making use of different international older populations allows us to cross-validate answers on the four main research questions. In this thesis, older people were defined as having an age of at least 55 years at the follow-up measurements.

The first study is the Study on Medical Information and Lifestyles Eindhoven (SMILE). ${ }^{58}$ This large dynamic cohort study started in November 2002 as a joint project of Maastricht University and the Eindhoven Corporation of Primary Health Care Centres. General practitioner's registers and annual postal questionnaires were used to collect data on health, lifestyles, and health care use. People aged 55 years and older were considered as a separate population within SMILE. From May 2003 onwards, these people received biannual questionnaires on health-related function- 
ing, socioeconomic status, material factors and psychosocial factors. For the purpose of the present thesis, data of approximately 5,000 men and women of 55 years and older were used. These people were followed over an average period of 3.5 years.

The second study is the Age, Gene/Environment Susceptibility (AGES)-Reykjavik Study. ${ }^{59}$ This study was drawn from the Reykjavik Study, a population-based cohort established in 1967 by investigators at the Icelandic Heart Association (IHA). As part of the Reykjavik Study, participants completed questionnaires and participated in a standardised medical examination. Follow-up examination for AGES-Reykjavik started in 2002. As part of the AGES-Reykjavik Study, participants completed interviews about functional health status and disability, health conditions, health behaviours, and family history and had a series of standardised health examinations. For the purpose of the present thesis, the study sample consisted of 5,764 survivors from the Reykjavik Study who participated in the AGES-Reykjavik Study. These people were followed over an average period of 30 years time. At baseline, these people were aged between 33 and 65 years. At follow-up, participants were aged between 66 and 93 years.

The third study is the Health, Aging and Body Composition (Health $A B C$ ) Study. The Health $A B C$ study is a longitudinal cohort study consisting of 3,075 wellfunctioning 70- to 79-year old, black and white men and women from Memphis, Tennessee and Pittsburgh, Pennsylvania in the United States. Baseline data were collected between April 1997 and June 1998 and included an in-person interview and a clinic-based examination, with evaluation of, amongst others, socioeconomic status and material adversity, body composition, lifestyle, clinical and subclinical diseases, and depressive symptoms. Yearly follow-up measurements were performed. For the purpose of the present thesis, nine years of follow-up data were used.

\section{OUTLINE OF THIS THESIS}

Chapter 2 of this thesis describes the association between material deprivation and health-related dysfunction in Dutch older people. Cross-sectional data from the SMILE study were used.

Chapter 3 elaborates on the previous chapter by examining the possession of basic goods and the possession of luxury goods and their effects on health-related dysfunction in Dutch older people. Cross-sectional and longitudinal data from the SMILE study were used.

Chapter 4 describes the independent relations of classic SES measures as well as of early life and midlife material factors on old age functioning in an Icelandic popu- 
lation. An average of almost 30 years of follow-up data from the AGES-Reykjavik data was used.

Chapter 5 addresses the reversed relation between health-related dysfunction and subsequent decreases in income and between personality factors and decreases in income in Dutch older people. Three years of follow-up data from the SMILE study were used.

Chapter 6 reports on the relation between socioeconomic status and depressive symptoms and the mediating role of lifestyle factors in this relation in American older people. Nine years of follow-up data from the Health ABC study were used.

Chapter 7 describes the relation between educational level and changes in health-related functioning over a period of 5 years time in Dutch older people. Moreover, the relative contribution of material and psychosocial factors to this relation is assessed.

Finally, the findings of the previous chapters are summarised and discussed in Chapter 8. Policy implications and recommendations for future research are provided. 


\section{REFERENCES}

1. Adler NE, Ostrove JM. Socioeconomic status and health: what we know and what we don't. Ann N Y Acad Sci. 1999;896:3-15.

2. Galobardes B, Shaw M, Lawlor DA, Lynch JW, Davey Smith G. Indicators of socioeconomic position (part 2). J Epidemiol Community Health. 2006;60:95-101.

3. Galobardes B, Shaw M, Lawlor DA, Lynch JW, Davey Smith G. Indicators of socioeconomic position (part 1). J Epidemiol Community Health. 2006;60:7-12.

4. Van de Mheen HD, Stronks K, Schrijvers CT, Mackenbach JP. The influence of adult ill health on occupational class mobility and mobility out of and into employment in The Netherlands. Soc Sci Med. 1999;49:509-18.

5. Cardano M, Costa G, Demaria M. Social mobility and health in the Turin longitudinal study. Soc Sci Med. 2004;58:1563-74.

6. Marmot MG, Shipley MJ, Rose G. Inequalities in death specific explanations of a general pattern? Lancet. 1984;8384:1003-6.

7. RIVM. National atlas for public health and health care. Bilthoven, the Netherlands: National Institute for Public Health and Environment; 2009.

8. Artazcoz L, Rueda S. Social inequalities in health among the elderly: a challenge for public health research. J Epidemiol Community Health. 2007;61:466-7.

9. Stuck AE, Walthert JM, Nikolaus T, Bula CJ, Hohmann C, Beck JC. Risk factors for functional status decline in community-living elderly people: a systematic literature review. Soc Sci Med. 1999;48:44569.

10. Herd P. Do functional health inequalities decrease in old age? Educational status and functional decline among the 1931-1941 birth cohort. Res Aging. 2006;28(3):375-92.

11. Beckett M. Converging health inequalities in later life--An artifact of mortality selection. J Health Soc Behav. 2000;41(2):106-19.

12. Kuh D, Ben-Shlomo Y, Lynch JW, Hallqvist J, Power C. Life course epidemiology. J Epidemiol Community Health. 2003;57:778-83.

13. Van de Mheen HD, Stronks K, Mackenbach JP. A lifecourse perspective on socio-economic inequalities in health: the influence of childhood socio-economic conditions and selection processes. Sociol Health IIIn. 1998;20 (5):754-77.

14. WHO. Ageing - exploding the myths. Geneva: World Health Organization; 1999.

15. Guccione AA, Felson DT, Anderson JJ, Anthony JM, Zhang Y, Wilson PW, et al. The effects of specific medical conditions on the functional limitations of elders in the Framingham Study. Am J Public Health. 1994;84(3):351-8.

16. Burstrom B, Fredlund P. Self rated health: Is it as good a predictor of subsequent mortality among adults in lower as well as in higher social classes? J Epidemiol Community Health. 2001;55:836-40.

17. Idler EL, Benyamini Y. Self-rated health and mortality: a review of twenty-seven community studies. J Health Soc Behav. 1997;38:21-37.

18. Townsend P, Davidson N. The Black Report. In: Townsend P, Davidson N, Whitehead M, editors. Inequalities in health. London: Penguin Books; 1988.

19. Mackenbach JP, van de Mheen HD, Stronks K. A prospective cohort study investigating the explanation of socio-economic inequalities in health in the Netherlands. Soc Sci Med. 1994;38(2):299-308.

20. Marmot M. Fair society, healthy lives. Strategic review of health inequalities in England post 2010. London: The Marmot Review; 2010.

21. Van Lenthe FJ, Schrijvers CT, Droomers M, Joung IM, Louwman MJ, Mackenbach JP. Investigating explanations of socio-economic inequities in health. Eur J Public Health. 2004;14:63-70.

22. West $P$. Rethinking the health selection explanation for health inequalities. Soc Sci Med. 1991;32(4):373-84.

23. Bosma H, Van Boxtel MP, Kempen GIJM, Van Eijk JTM, Jolles J. To what extent does IQ 'explain' socio-economic variations in function? BMC Public Health. 2007;7(179). 
24. Batty GD, Der G, Macintyre S, Deary IJ. Does IQ explain socioeconomic inequalities in health? evidence from a population based cohort study in the west of Scotland. Br Med J. 2006;332:580-4.

25. Mackenbach JP. Genetics and health inequalities: hypotheses and controversies. J Epidemiol Community Health. 2005;59:268-73.

26. Lynch JW, Kaplan GA, Salonen JT. Why do poor people behave poorly? Variation in adult health behaviours and psychosocial characteristics by stages of the socioeconomic lifecourse. Soc Sci Med. 1997;44(6):809-19.

27. Van Lenthe FJ, Gevers E, Joung IM, Bosma H, Mackenbach JP. Material and behavioral factors in the explanation of educational differences in incidence of acute myocardial infarction: the Globe study. Ann Epidemiol. 2002;12(8):535-42.

28. Huisman $M$, Kunst $A E$, Mackenbach JP. Inequalities in the prevalence of smoking in the European Union: comparing education and income. Prev Med. 2005;40(6):756-64.

29. Giskes K, Turrel G, van Lenthe FJ, Brug J, Mackenbach JP. A multilevel study of socio-economic inequalities in food choice behaviour and dietary intake among the Dutch population: the GLOBE study. Public Health Nutr. 2006;9(1):75-83.

30. Lindström M, Hanson BS, Östergren P. Socioeconomic differences in leisure-time physical activity: the role of social participation and social capital in shaping health related behaviour. Soc Sci Med. 2001;52(3):441-51.

31. Stafford M, Hemingway H, Stansfeld SA, Brunner E, Marmot M. Behavioural and biological correlates of physical functioning in middle aged office workers: the UK whitehall II study. J Epidemiol Community Health. 1998;52:353-8.

32. Van Gool CH, G.I.J.M. K, Bosma H, Van Boxtel MP, Jolles J, Van Eijk JTM. Associations between lifestyle and depressed mood: longitudinal results from the Maastricht Aging Study. Am J Public Health. 2007;97(5):887-94.

33. Marmot MG, Shipley MJ, Hemingway H, Head J, Brunner E. Biological and behavioural explanations of social inequalities in coronary heart disease: the Whitehall II study. Diabetologia. 2008;51(11):1980-8.

34. Crawford R. You are dangerous to your health--the ideology and politics of victim blaming. Int J Health Serv. 1977; 7:663-79.

35. Townsend P. Individual or social responsibility for premature death? Current controversies in the British debate about health. Int J Health Serv. 1990;20:373-92.

36. Tarasuk VS, Beaton GH. Household food insecurity and hunger among families using foodbanks. Can J Public Health. 1999;90(2):109-13.

37. Desain L, Van Gent MJ, Kroon P, Langendijk F, Van Waveren B. Eindrapport klantenanalyse voedselbanken. Amsterdam, the Netherlands: Regioplan beleidsonderzoek; Ministry of Social Affairs; 2006 March. Report No.: Regioplan:1398.

38. Mathematica Policy Research Inc. Hunger in America 2010. Chicago, Illinois: Feeding America; 2010.

39. European Federation of Food Banks. 2010 [cited 201012 April]; Available from: http://www.eurofoodbank.org/eng/1b1.htm

40. Lynch JW, Davey Smith G, Kaplan GA, House JS. Income inequality and mortality: importance to health of individual income, psychosocial environment, or material conditions. $\mathrm{Br} \mathrm{Med} J$. 2000;320:1200-4.

41. Boeing $\mathrm{H}$. Epidemiological research in stomach cancer: progress over the last ten years. J Cancer Res Clin Oncol. 1991;117(2):133-43.

42. Marmot M, Wilkinson RG. Social determinants of health. 2 ed. New York: Oxford University Press; 2006.

43. Stronks K, Van de Mheen HD, Looman CWN, Mackenbach JP. The importance of psychosocial stressors for socio-economic inequalities in perceived health. Soc Sci Med. 1998;46:611-23.

44. Wilkinson RG. Health, hierarchy and social anxiety. Ann N Y Acad Sci. 1999;896:48-63.

45. Buunk BP, Gibbons FX, Visser A. The relevance of social comparison processes for prevention and health care. Patient Educ Couns. 2002;47:1-3. 
46. Festinger L. A theory of social comparison processes. Hum Relat. 1954;7(2):117-40.

47. De Botton A. Status Anxiety. London: Hamish Hamilton; 2004.

48. Lundberg J, Kristenson M, Starrin B. Status incongruence revisited: associations with shame and mental wellbeing. Sociol Health IIIn. 2009;31(4):478-93.

49. Kristenson M, Eriksen HR, Sluiter JK, Starke D, Ursin H. Psychobiological mechanisms of socioeconomic differences in health. Soc Sci Med. 2004;58:1511-22.

50. Macleod J, Davey Smith G, Metcalfe C, Hart C. Is subjective social status a more important determinant of health than objective social status? Evidence from a prospective observational study of Scottish men. Soc Sci Med. 2005;61(9):1916-29.

51. Marmot $M$. The influence of income on health: views of an epidemiologist. Does money really matter? Or is it a marker for something else? Health Affairs. 2002;21(2):31-46.

52. Adler NE. When one's main effect is another's error: Material vs psychosocial explanations of health disparties. A commentary on Macleod et al. Soc Sci Med. 2006;63(4):846-50.

53. Macleod J, Davey Smith G. Psychosocial factors and public health: a suitable case for treatment? J Epidemiol Community Health. 2003;57:565-70.

54. Macleod J, Davey Smith G, Metcalfe C, Hart C. Subjective and objective status and health: a response to Adler. Soc Sci Med. 2006;63(4):851-7.

55. Klink A. Naar een weerbare samenleving. Beleidsplan aanpak gezondheidsverschillen op basis van sociaaleconomische achtergronden. Den Haag: Ministry of Public Health, Welfare and Sports; 2008.

56. Mackenbach JP, Bakker MJ. Tackling socioeconomic inequalities in health: analysis of European experiences. Lancet. 2003;362:1409-14.

57. Bambra C, Gibson M, Sowden A, Wrigth K, Whitehead M, Petticrew M. Tackling the wider social determinants of health and health inequalities: evidence from systematic reviews. J Epidemiol Community Health. 2010;64:284-91.

58. Van den Akker M, Spigt MG, de Raeve L, van Steenkiste B, Metsemakers JFM, van Voorst EJ, et al. The SMILE study: A Study of Medical Information and Lifestyles in Eindhoven. The rationale and contents of a large prospective dynamic cohort study. BMC Public Health. 2008;8(19).

59. Harris TB, Launer L, Eiriksdottir G, Kjartansson O, Johnsson PV, Sigurdsson G, et al. Age, Gene/Environment Susceptibility-Reykjavik study: Multidisciplinary applied phenomics. Am J Epidemiol. 2007;165(9):1076-87. 



\section{ABSTRACT}

\section{Background}

Even in generally wealthy Western countries material deprivation and poverty are not uncommon. There is, however, little data on the prevalence of material deprivation and its associations with health-related dysfunction in older people.

\section{Methods}

Cross-sectional data from the SMILE study were used to examine the prevalence of material deprivation and the associations between material deprivation and healthrelated dysfunction in persons aged 55 years and older $(n>4,000)$. Material deprivation was measured with a comprehensive questionnaire assessing 7 subdomains referring to current and anticipated financial problems and poverty in childhood. Health-related dysfunction was measured using the SF36-based physical and mental components. In addition, self-reported heart disease was examined as an indicator of health-related dysfunction as well.

\section{Results}

Almost $29 \%$ of subjects experienced at least one financial problem. Those reporting material deprivation had more than twice the risk of physical $(\mathrm{OR}=2.22 ; 95 \% \mathrm{Cl}$ : 1.72-2.86) and mental (OR=2.34; 95\% $\mathrm{Cl}: 1.84-2.97)$ dysfunction compared with non-deprived persons. A slightly weaker association was found when self-reported heart disease was used as an outcome variable (OR=1.74; $95 \% \mathrm{Cl}: 1.40-2.15$ ). Although odds ratios were generally higher for diseased older persons, no significant interaction effect between chronic disease and material deprivation subscales was found.

\section{Conclusion}

Material deprivation in the Netherlands is not uncommon and is strongly related to both mental and physical dysfunction, and therefore needs further attention in public health policy. Longitudinal research is necessary to clarify the causal nature of our results and to develop appropriate interventions. 


\section{INTRODUCTION}

Although the definition of poverty in a rich country differs qualitatively from that in a poor country, many developed countries have experienced a sharp rise in income inequality. ${ }^{1}$ In addition, there is evidence that income inequality is still increasing. ${ }^{2}$ This is also manifested in the fact that material deprivation is not uncommon even in generally wealthy Western countries. Moreover, the rise in the number of 'foodbanks' or food rescue organisations in these countries ${ }^{3}$ indicates that many people have trouble making ends meet.

In the Netherlands, it has recently been documented that persons between the ages of 55 and 64 live below the poverty line relatively often (10.4\% of this group can be defined as 'poor', compared with $9.1 \%$ in the general Dutch population). Moreover, income inequality in this group of 'young' older people is highest. ${ }^{4,5} \mathrm{Al}-$ though inconsistent results have been found, most research evidence suggest that differences in health (morbidity and mortality) across groups of different socioeconomic status are also present in early old age. ${ }^{6-9}$ However, evidence on the prevalence of material deprivation and its effects on health-related dysfunction, in particular in these older persons, is rather sparse ${ }^{7,10-13}$ and only a small number of deprivation indicators have been examined (mostly as proxies for socioeconomic status). ${ }^{14,15}$

Apart from the dearth of information, material deprivation and material factors have been conceptualised in different ways, from restricted standards of living (the lack of two or more of ten items or activities that are considered necessary by the majority of society), ${ }^{16,17}$ having financial problems (difficulties with paying bills for food, rent, or electricity), ${ }^{18}$ limited or lack of health insurance, no car ownership and no household tenure ${ }^{19}$ to restricted household item ownership (from basic needs to luxury goods). ${ }^{20}$ An in-depth examination of the prevalence of material deprivation - measured using a comprehensive questionnaire - and its effects on health is lacking, particularly in older people.

To obtain an in-depth insight into the potential relevance of material deprivation for public health (policy), this article describes the prevalence of material deprivation in a large community-based older population and explores the link between material deprivation and mental and physical dysfunction and heart disease.

\section{METHODS}

\section{Design}

Data were obtained from the longitudinal SMILE study (i.e. Study on Medical Information and Lifestyles Eindhoven). This dynamic cohort study started in November 
2002 in collaboration between Maastricht University and nine primary health care centres in Eindhoven, a city in the south-eastern part of the Netherlands. By means of postal questionnaires, data on health, lifestyle, and health care use have been collected. From May 2003, all people aged 55 and older who were registered with the participating primary health care centres (including persons living in homes for older people) received a questionnaire.

\section{Study population}

The present study uses data that were collected in May 2004, from 5,109 (response rate $=45.7 \%)$ men $(n=2,313 ; 45.3 \%)$ and women $(n=2,796 ; 54.7 \%)$ between the ages of 55 and 98 (mean age=68.2; SD=9.0). The respondents' age and sex distribution was similar to that of the target population of May $2004(n=11,172)$. Data on educational level was extracted from the May 2003 questionnaire. However, due to missing data ( $n=533$ for material deprivation, $n=67$ for educational level, and $n=738$ for mental and physical dysfunction - partly overlapping persons), analyses were conducted with a minimum number of 4,019 persons.

\section{Measures}

\section{Material factors}

Material deprivation was defined as a financial strain and/or the enforced lack of material resources. ${ }^{21,22}$ It was measured in May 2004 using a new, 20-item instrument developed by the Netherlands Institute for Social Research (SCP). ${ }^{22}$ The instrument comprises six subscales on problems with living expenses (one item), problems with managing the household income (one item), negative outlook on the upcoming year's financial situation (one item), problems with settling debts (one item), reports of economic strain (nine items), and lack of durables for financial reasons (seven items). Results of principal component analyses indicate that these six indicators all point to one factor: material deprivation (explained variance: $45 \%)^{22}$

The scales on living expenses, managing with household income, outlook on the upcoming year's financial situation, and settling debts were dichotomised, defining persons that report moderately heavy, heavy to very heavy problems as materially deprived (indicated in Table 1). ${ }^{22}$ Economic strain and the lack of durables were also dichotomised as defined in Table 1.

In addition, one item concerning poverty in childhood was appropriated from the Dutch GLOBE study. ${ }^{19}$ Originally, this item consisted of four potential answers ranging from "in the past we constantly lacked money to buy food or new clothes /shoes when necessary" to "we never lacked money in the past". This item was also dichotomised (see Table 1). 
After all subscales were dichotomised, a compound deprivation score (0-1) was also computed. Subjects were then considered deprived when reporting three or more material problems according to the seven subscales. With a Cronbach's $\alpha$ of 0.67 the internal consistency of the total seven-item material deprivation scale was found acceptable. When deleting the item relating to poverty in the past, Cronbach's $\alpha$ increased to 0.76 . Both the compound score and the individual subscale scores were used in the analyses.

\section{Health}

Three indicators of health-related function were used: self-reported mental and physical dysfunction and self-reported heart disease. Information about mental and physical dysfunction was derived from the Dutch version of the MOS SF36, measured in May 2004. ${ }^{23,24}$ The SF36 is a short-form health survey of 36 questions, clustered in eight subscales relating to functional health and well-being. The eight scales can be recoded in two distinct higher-ordered components: physical and mental function. Several factor analytic studies have confirmed that the physical and mental function components account for 80 to $85 \%$ of the reliable variance in the eight scales in general populations. ${ }^{24,25}$ For the purpose of this study, physical and mental dysfunction was defined as having a score below the 10th percentile (scores of 29 and 35 out of a range from 0 to 100, respectively). The prevalence of self-reported heart disease in May 2004 (13.8\%) was also used as an indicator of health-related function. Heart disease is often used as an outcome variable in relation to socioeconomic measures such as income, education, and occupation. ${ }^{26}$ However, the relationship between heart disease and measures of material deprivation in older people has been studied much less frequently. ${ }^{27}$

\section{Confounders}

Education was measured in May 2003, using a seven-point scale. Three categories were then created in such a way that each group contained a third of the sample: primary school only (low); lower vocational education and intermediate general education (middle); intermediate vocational education; higher general education; higher vocational education; and university (high).

Age and sex were also considered as confounding variables. Furthermore, because physical and mental dysfunction may be more common among persons with somatic disease, ${ }^{28}$ severe chronic diseases were also included as confounding variables in the analyses in which physical and mental dysfunction were the outcome variable. In addition, these analyses were performed separately for persons with (46\%) and without (54\%) at least one of the following selected chronic (selfreported) diseases: COPD/asthma (15.6\%), heart diseases (13.8\%), bowel diseases (9.6\%), liver diseases (1.9\%), kidney diseases (3.0\%), diabetes (10.4\%), cancer $(10.7 \%)$, epilepsy $(1.8 \%)$, or stroke $(4.6 \%)$. 


\section{Statistical analyses}

Chi-square tests were performed to evaluate whether there were sex, age, and educational differences in material deprivation. Moreover, multiple logistic regression models were fitted to examine how material deprivation scores were related to physical and mental dysfunction and self-reported heart disease. The 'not deprived' condition was always used as the reference category in these analyses (OR=1). In analyses in which physical and mental dysfunction were the outcome variables, the first model was adjusted for age and sex. The second model also included educational level, and the third the indicator for prevalent severe diseases. Further, analyses were performed separately for persons with and without severe diseases, and interactions between disease, sex and age and material deprivation subscales were tested as well.

In analyses in which self-reported heart disease was the outcome variable, the first model was adjusted for sex and age. The second model additionally included educational level.

All statistical analyses were performed using SPSS 12.0.1.

\section{RESULTS}

Table 1 presents the prevalence of material deprivation according to age, sex and level of education. The results show that $18.4 \%$ of our study population reported at least three of the selected material problems. Moreover, almost $29 \%$ experienced at least one of the financial problems. In particular, replacing old furniture $(20.9 \%)$, inviting family and friends for dinner (16.4\%), and going on a one-week holiday (15.3\%) were financially problematic items. However, it is also striking that four percent was not able to eat a meal with meat, chicken or fish every two days and that more than six percent was not able to heat their house adequately because of economic strain. Three percent of the study population had difficulties in the settling of debts.

The results further show that persons between 55 and 64 years of age were significantly more likely to be materially deprived: $20.3 \%$ of the youngest age category reported at least three problems, compared with $18.3 \%$ and $14.8 \%$ in the higher age categories. There were no substantial sex differences concerning material deprivation. However, women had a slightly better expectation of their financial situation for the upcoming 12 months compared with men (18.2\% vs. $21.9 \%$ expected her/his financial situation to deteriorate), though women experienced more current financial strain $(30.6 \%$ vs. $26.6 \%$ reported at least one immediate financial problem at present). With the exception of the upcoming year's financial outlook and the settling of debts, lower educational level was consistently and significantly related to the prevalence of material deprivation $(28.1 \%$ of the lowest educated 
group reported at least three material problems, compared with $11.6 \%$ of the highest educated group).

Table 2 shows a strong association between material deprivation and mental and physical dysfunction. Deprived persons had over twice the risk of physical (OR=2.63; 95\% Cl: 2.05-3.36) and mental dysfunction (OR=2.57; 95\% Cl: 2.04-3.25) compared with non-deprived persons (model 1 ). These associations remained when adjusted for age, sex, and educational level (model 2). When further adjusted for chronic severe diseases (model 3), the settling of debts (with its low prevalence; see also Table 1) was no longer significantly related to physical dysfunction. All other odds ratios for material deprivation remained significantly associated with physical and mental dysfunction $(\mathrm{OR}=2.22 ; 95 \% \mathrm{Cl}: 1.72-2.86$ and $\mathrm{OR}=2.34 ; 95 \% \mathrm{Cl}: 1.84-$ 2.97, respectively

Although it was hypothesised that persons with severe chronic disease may be more strongly affected by material deprivation, no significant interaction between disease and material deprivation subscales was found. However, results for both physical and mental function differed between persons that were and were not diseased. Odds ratios were, overall, slightly higher for the diseased older persons (see Table 3). 


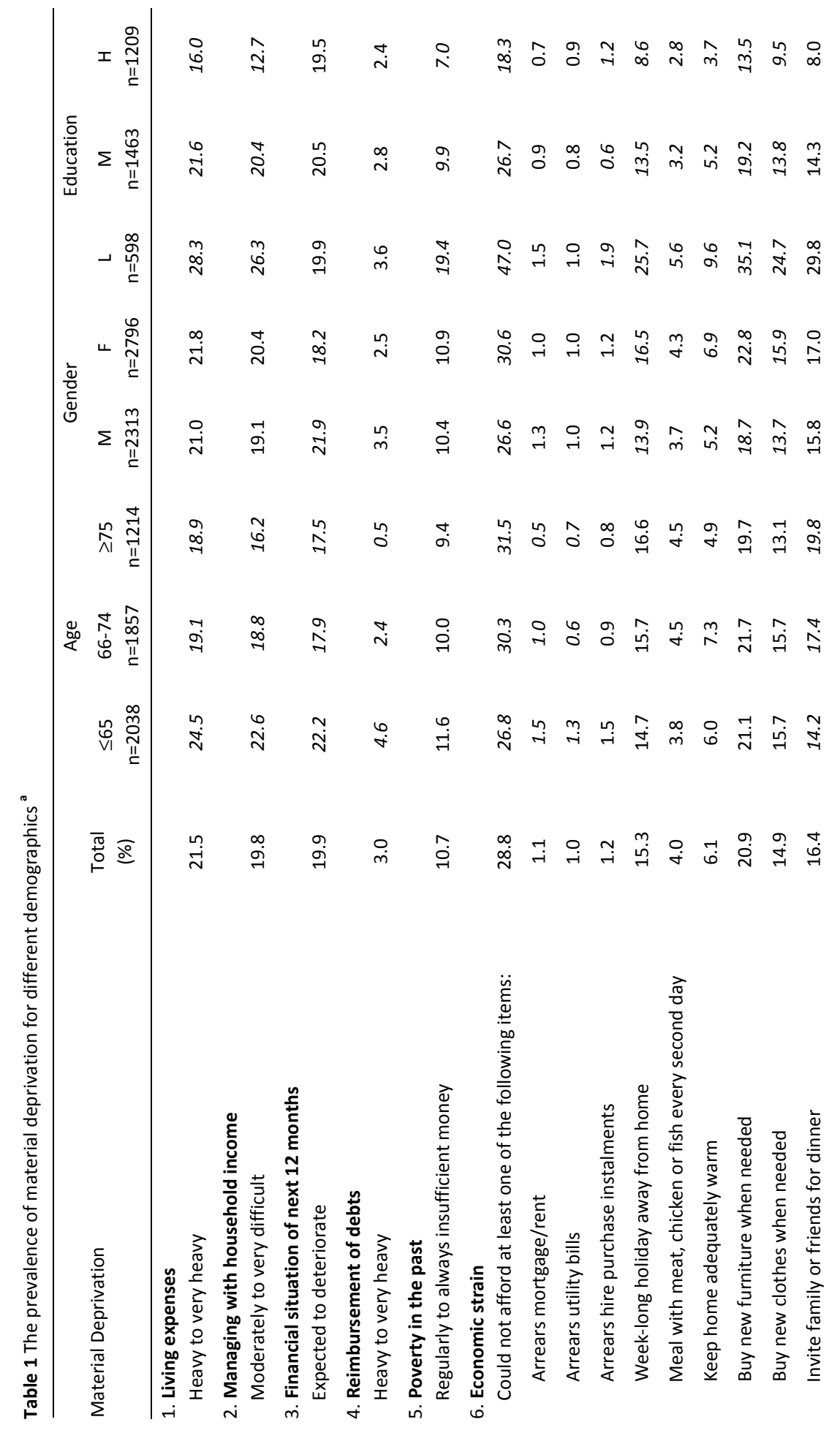




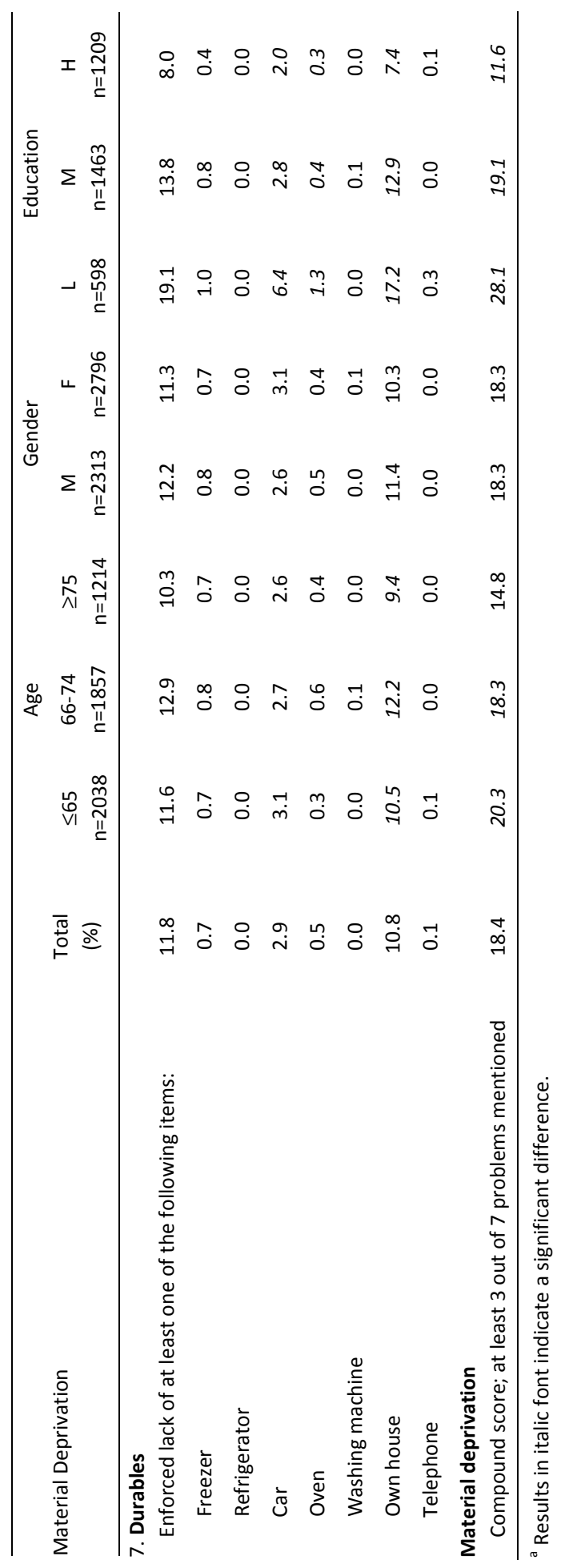




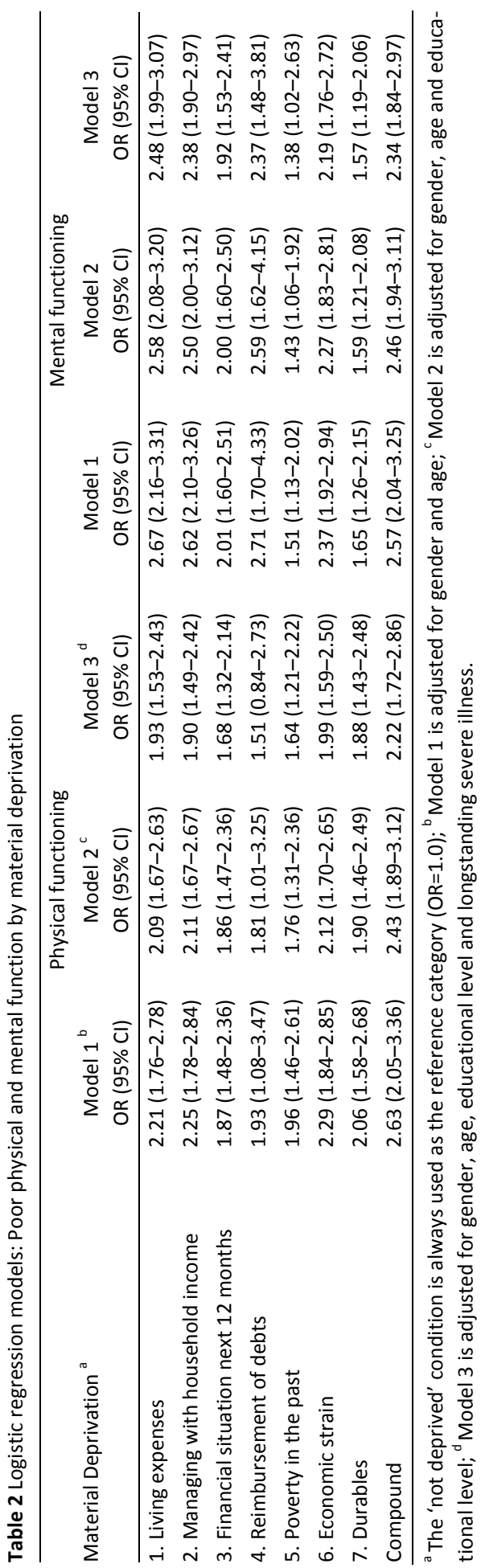

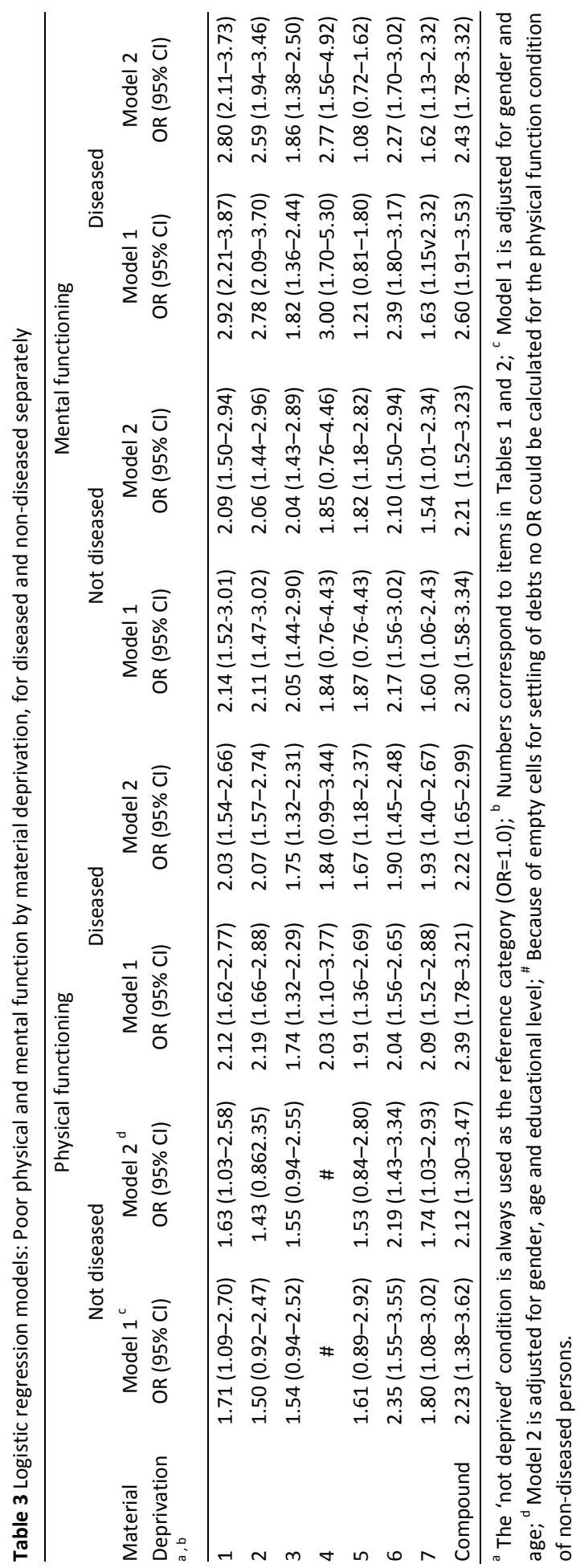




\section{Heart disease}

The odds ratios of heart disease for the deprivation indicators were slightly weaker, but still substantial and consistent across the deprivation measures even when controlled for educational level (Table 4) (OR=1.74; 95\% Cl: 1.40-2.15). A negative outlook on the financial situation and poverty in the past were not related to reports of heart disease. Adjusted odds ratios for other subscales ranged from 1.55 (95\% Cl: 1.27-1.88) for experiencing living expenses as (very) heavy to 2.85 (95\% Cl: 1.90-4.28) for the settling of debts.

Table 4 Logistic regression models: heart disease by material deprivation

\begin{tabular}{lcc}
\hline Material Deprivation $^{\mathrm{a}}$ & $\begin{array}{c}\text { Model } 1^{\mathrm{b}} \\
\text { OR }(95 \% \mathrm{Cl})\end{array}$ & $\begin{array}{c}\text { Model } 2^{\mathrm{c}} \\
\text { OR }(95 \% \mathrm{Cl})\end{array}$ \\
\hline $\begin{array}{l}1.65(1.36-2.00) \\
\text { 2. Living expenses }\end{array}$ & $1.70(1.40-2.08)$ & $1.58(1.27-1.88)$ \\
3. Financial situation next 12 months & $1.12(0.91-1.38)$ & $1.10(0.89-1.35)$ \\
4. Reimbursement of debts & $3.00(2.01-4.49)$ & $2.85(1.90-4.28)$ \\
5. Poverty in the past & $1.40(1.08-1.80)$ & $1.27(0.98-1.64)$ \\
6. Economic strain & $1.84(1.53-2.21)$ & $1.69(1.40-2.04)$ \\
7. Durables & $1.73(1.38-2.18)$ & $1.58(1.25-1.99)$ \\
Compound score & $1.90(1.54-2.34)$ & $1.74(1.40-2.15)$ \\
\hline
\end{tabular}

${ }^{a}$ The 'not deprived' condition is always used as the reference category (OR=1.0); ${ }^{\mathrm{b}}$ Model 1 is adjusted for sex and age; ${ }^{\mathrm{C}}$ Model 2 is adjusted for sex, age and educational level.

Effects were similar in men and women and for both the younger and older age groups. Interaction terms were not significant in our analyses. Further, when using linear regression analyses with mental and physical function as continuous variables, similar associations were found. In additional analyses, in which we corrected for individualised income instead of education (not tabulated), the odds ratios decreased but remained significant (OR=1.68; $\mathrm{Cl} 95 \%$ : 1.14-2.48 for physical dysfunction and $\mathrm{OR}=1.62 ; \mathrm{Cl} 95 \%$ : $1.10-2.38$ for mental dysfunction respectively). In the analyses presented here, we controlled for education, as correcting for income could have resulted in over-adjustment given that material deprivation and income are conceptually highly correlated. 


\section{DISCUSSION}

This study showed that material deprivation is highly prevalent among older adults in the Netherlands. One fifth of our subjects reported problems with managing the household income, one fifth expected future financial problems, and one fifth could not afford to buy new furniture. Material deprivation was more common in those younger than 65 and those with a lower educational level. Persons reporting material deprivation had more than twice the risk of physical and mental dysfunction compared with non-deprived persons. Although odds ratios were slightly higher for the diseased older persons, interaction tests revealed that deprivation had similar effects on physical and mental function in persons with and without a severe disease. Associations between material deprivation and heart disease were only slightly weaker compared with that of physical and mental dysfunction.

\section{Interpretation}

The meaning of poverty differs between rich and poor countries. In poor countries, material conditions influencing health include the mere absence of food, clean water, and sanitation. In rich countries, they include not being able to afford a meal with meat, chicken, or fish every second day or not being able to heat one's house properly. Both conditions might have direct biologically damaging effects on health and function. ${ }^{20,29}$ However, there may also be psychosocial pathways involved. ${ }^{30}$ The psychosocial factor hypothesis implies that inequalities are due to the effects of chronic stress ${ }^{16,31-33}$ stemming from existing on the lowest rung of the socioeconomic hierarchy. ${ }^{32,34}$ This relative disadvantage, along with social comparisons with others higher in hierarchy -rather than absolute material circumstances and their potentially direct biological consequences -, may also be relevant in explaining the poor health outcomes of socioeconomic adversity in Western countries. ${ }^{31,32}$ The additional importance of psychosocial mechanisms, even in cases of absolute poverty, was recently supported by the finding that Dutch food banks are increasingly being moved to the suburbs, where their customers report less shame and other psychosocial problems, given that their visits to these more secluded environments are less likely to be noticed. ${ }^{3}$

Our finding that the prevalence of material deprivation decreases with age (i.e., that persons between 55 and 64 years of age were more materially deprived compared with their older counterparts) is difficult to explain, especially when taking into account decreases in income due to retirement. However, this finding does correspond with previous research on poverty in the Netherlands., ${ }^{4,22}$ One explanation might be the 'wealthy survivor' effect: i.e., the most deprived persons have died prior to their $65^{\text {th }}$ birthday. It may also be that older people differ in their perception of material well-being because its definition has changed over time. ${ }^{21}$ For 
example, buying new clothes and taking a week-long holiday was much less obvious in the past than it is nowadays. Moreover, 'adaptive preferences' (as explained below) might also account for this finding.

\section{Limitations}

Several methodological limitations may affect the interpretation of these results. First, our analyses were based upon cross-sectional data. Therefore, it is not possible to draw any conclusions about the causal direction of our results. The causation perspective assumes that material deprivation affects health-related function. The selection perspective assumes that poor health affects material deprivation. ${ }^{35}$ In any case, we found substantial associations between material deprivation and health problems. The issue needs further examination in forthcoming longitudinal research: unravelling the causal mechanisms between material deprivation and health problems in older persons may help develop adequate interventions and programmes to promote healthy ageing.

Second, our study relied solely on self-reports, which might have led to bias in our dysfunction measures. ${ }^{36}$ Individuals with a general tendency towards negative perceptions of material well-being may also over-report symptoms of (heart) disease, ${ }^{37}$ which may have led to an overestimation of the presented association. Furthermore, individuals' expectations and negative perceptions of their material wellbeing tend to decrease with long-term poverty, the so-called 'adaptive preferences'. ${ }^{38,39}$ As a consequence, chronically poor people may have underreported their poverty. Out of shame, they may not want to admit not being able to afford certain items. Furthermore, the 'poverty in the past' item may have caused measurement errors due to the deteriorating memory in some of the older people. Whether and how these limitations have affected our findings, however, is unclear.

Third, important indicators of material circumstances such as physical housing, neighbourhood, and working conditions were not measured, and are therefore lacking in our study. The full impact of material factors on health-related dysfunction, then, is likely underestimated.

Finally, our research may be limited by possible selection biases. Older people living in convalescent homes were not included, which restricts the generalisability of our findings. The most disadvantaged older people may be underrepresented in our research, because of premature mortality (the 'healthy survivor' effect). Moreover, in the highest educated group (as reported in 2003), $24 \%$ were lost to follow up in 2004 , versus $37 \%$ in the lowest educated group. Further, $28 \%$ of persons reporting a good physical function in 2003 versus 34\% of persons reporting physical dysfunction were lost to follow up in 2004. Finally, analyses revealed that persons with missing values on mental and/or physical function scales were generally more likely to be lower educated and more materially deprived. Similarly, persons with 
missing values on material deprivation items were more likely to report poor mental and physical function. This selective response and attrition may have led to an underestimation of the prevalence of material deprivation and the relationship between material deprivation and physical and mental dysfunction.

\section{CONCLUSION}

Material deprivation is not uncommon in older people in the Netherlands, between the ages of 55 and 65 in particular, and is strongly related to both mental and physical dysfunction. This issue, therefore, clearly requires further attention in public health policy. Taking into account the increasingly ageing population and associated healthcare costs, heightening public awareness of material deprivation and its adverse health effects is of great importance. Further, more longitudinal research is necessary to develop efficient, targeted interventions.

\section{Acknowledgements}

The longitudinal SMILE study is carried out by the Department of General Practice of Maastricht University, in collaboration with the Eindhoven Corporation of Primary Care Centres. The researchers are indebted to the participants for their willingness to participate in the study. 


\section{REFERENCES}

1. Subramanian SV, Kawachi I. Income inequality and health: what have we learned so far? Epidemiol Rev. 2004;26:78-91.

2. WorldBank. World development report 2006: Equity and development. New York; 2006.

3. Desain L, Van Gent MJ, Kroon P, Langendijk F, Van Waveren B. Eindrapport klantenanalyse voedselbanken. Amsterdam, the Netherlands: Ministry of social affairs; 2006.

4. De Boer AH. Rapportage ouderen 2006; veranderingen in de leefsituatie en levensloop. The Hague: Netherlands Institute for Social Research (SCP); 2006. Report No.: SCP-publicatie2006/12.

5. Otten F, Bos W, Vrooman C, Hoff S. Armoede bericht 2006. Voorburg/Heerlen: Statistics Netherlands (CBS); 2006.

6. Van Rossum CTM, Van de Mheen HD, Mackenbach JP, Grobbee DE. Socioeconomic status and mortality in Dutch elderly people; The Rotterdam Study. Eur J Public Health. 2000;10(4):255-61.

7. Breeze E, Fletcher AE, Leon DA, Marmot MG, Clarke RJ, Shipley MJ. Do socioeconomic disadvantages persist into old age? Self-reported morbidity in a 29-year follow-up of the Whitehall study. Am J Public Health. 2001;91(2):277-83.

8. Chandola T, Ferrie JE, Sacker A, Marmot M. Social inequalities in self reported health in early old age: follow-up of prospective cohort study. Br Med J. 2007;334(7601):990-.

9. Minkler M, Fuller-Thomson E, Guralnik JM. Gradient of disability across the socioeconomic spectrum in the United States. N Engl J Med. 2006;355(7):695-703.

10. Breeze $E$, Jones DA, Wilkinson P, Latif AM, Bulpitt CJ, Fletcher AE. Association of quality of life in old age in Britain with socioeconomic position: baseline data from a randomised controlled trial. J Epidemiol Community Health. 2003;58:667-73.

11. Bobak M, Pikhart H, Rose R, Hertzman C, Marmot M. Socioeconomic factors, material inequalities, and perceived control in self-rated health: cross-sectional data from seven post-communist countries. Soc Sci Med. 2000;51:1343-50.

12. Von dem Kneseback O, Luschen G, Cockerham WC, Siegrist J. Socioeconomic status and health among the aged in the United States and Germany: A comparative cross-sectional study. Soc Sci Med. 2003;57:1643-52.

13. Adamson JA, Ebrahim S, Hunt K. The psychosocial versus material hypothesis to explain observed inequality in disability among older adults: data from the West of Scotland Twenty-07 Study. J Epidemiol Community Health. 2006;60:974-80.

14. Matthews RJ, Smith LK, Hancock RM, Jagger C, Spiers NA. Socioeconomic factors associated with the onset of disability in older age: a longitudinal study of people aged 75 years and over. Soc Sci Med. 2005;61:1567-75.

15. Matthews RJ, Jagger C, Hancock RM. Does socio-economic advantage lead to a longer, healthier old age? Soc Sci Med. 2006;62:2489-99.

16. Vetter S, Endrass J, Schweizer I, Teng HM, Rossler W, Gallo WT. The effects of economic deprivation on psychological well-being among the working populatin of Switzerland. BMC Public Health. 2006;6(1):223.

17. Stronks K, van de Mheen HD, Mackenbach JP. A higher prevalence of health problems in low income groups: does it reflect relative deprivation? J Epidemiol Community Health. 1998;52:548-57.

18. Schrijvers CT, Stronks K, Van de Mheen HD, Mackenbach JP. Explaining educational differences in mortality: The role of behavioral and material factors. Am J Public Health. 1999;89(4):535-40.

19. Van Lenthe FJ, Gevers E, Joung IM, Bosma H, Mackenbach JP. Material and behavioral factors in the explanation of educational differences in incidence of acute myocardial infarction: the Globe study. Ann epidemiol. 2002;12(8):535-42.

20. Pikhart H, Bobak M, Rose R, Marmot M. Household item ownership and self-rated health: material and psychosocial explanations. BMC Public Health. 2003;3(38).

21. Vrooman C, Dirven H, Soede A, Trimp R. Armoede monitor 2005. The Hague: Netherlands Institute for Social Research (SCP) and Statistics Netherlands (CBS), 2005. 
22. Jehoel-Gijsbers G. Sociale uitsluiting in Nederland. The Hague: Netherlands Institute for Social Research (SCP); 2003. Report No.: scp-publicatie 2004/17.

23. Ware JE, Sherbourne CD. The Rand-36 Short-form Health Status Survey 1: Conceptual framework and item selection. Med Care. 1992;30(6):473-81.

24. Van der Zee KI, Sanderman R, Heyink J. De psychometrische kwaliteiten van de MOS 36 item Short Form Health Survey in een nederlandse populatie. Tijdschr Soc Gezondheidsz. 1993;4:183-91.

25. Ware JE, Kosinski M. Interpreting SF-36 summary health measures: a response. Qual Life Res. 2001;10:415-20.

26. Kaplan GA, Keil JE. Socioeconomic factors and cardiovascular disease: a review of the literature. Circulation. 1993;88:1973-88.

27. Ferrie JE, Martikainen P, Shipley MJ, Marmot MG. Self-reported economic difficulties and coronary events in men: evidence from the Whitehall II study. Int J Epidemiol. 2005;34(3):640-8.

28. Bosma H, Diederiks JP, van Santen HMS, van Eijk JTM. Meer sociale uitsluiting van chronisch zieken bij een lager inkomen. Ned Tijdschr Geneeskd. 2005;149:1898-902.

29. Lynch JW, Davey Smith G, Kaplan GA, House JS. Income inequality and mortality: importance to health of individual income, psychosocial environment, or material conditions. $\mathrm{Br}$ Med J. 2000;320:1200-4.

30. Marmot M. Harveian Oration: Health in an unequal world. Lancet. 2006;368:2081-94.

31. Wilkinson RG. Health, hierarchy and social anxiety. Ann N Y Acad Sci. 1999;896:48-63.

32. Marmot MG, Wilkinson RG. Psychosocial and material pathways in the relation between income and health: a response to Lynch et al. Br Med J. 2001;322:1233-6.

33. Bosma H. Socio-economic differences in health: are control beliefs fundamental mediators? In: Siegrist J, Marmot M, editors. Social inequalities in health; new evidence and policiy implications. Oxford: Oxford University Press; 2006. p. 153-66.

34. Marmot MG. Status syndrome: a challenge to medicine. JAMA. 2006;295(11):1304-7.

35. Adler NE, Ostrove JM. Socioeconomic status and health: what we know and what we don't. Ann N Y Acad Sci. 1999;896:3-15.

36. Kempen GI, Steverink N, Ormel J, Deeg DJ. The assessment of ADL among frail elderly in an interview survey:self-report versus performance-based tests and determinants of discrepancies. J Gerontol B Psychol Sci Soc Sci. 1996;51:254-60.

37. Macleod J, Davey Smith G, Heslop P, Metcalfe C, Carroll D, Hart C. Psychological stress and cardiovascular disease: empirical demonstration of bias in a prospective observational study of Scottish men. Br Med J. 2002;324:1247-53.

38. Von Weizsacker CC. The welfare economics of adaptive preferences. Bonn: Max Planck Institute for Research on Collective Goods; 2005.

39. Teschl M, Comim F. Adaptive preferences and capabilities: some preliminary conceptual explorations. Rev Soc Econ. 2005;63(2):229-47. 



\section{ABSTRACT}

\section{Background}

More so than the traditional socioeconomic indicators, such as education and income, wealth reflects the accumulation of resources and makes socioeconomic ranking manifest and explicitly visible to the outside world. While the lack of basic goods, such as a refrigerator, may affect health directly, via biological pathways, the lack of luxury goods, such as an LCD television, may affect health indirectly through psychosocial mechanisms. We set out to examine, firstly, the relevance of both basic and luxury goods in explaining health-related dysfunction in older persons, and, secondly, the extent to which these associations are independent of traditional socioeconomic indicators.

\section{Methods}

Cross-sectional and longitudinal data from 2,067 men and women aged 55 years and older who participated in the Study on Medical Information and Lifestyles Eindhoven (SMILE) were gathered. Logistic regression analyses were used to study the relation between a lack of basic and luxury goods and health-related function, assessed with two sub-domains of the SF-36.

\section{Results}

The lack of basic goods was closely related to incident physical $(O R=2.32)$ and mental $(O R=2.12)$ dysfunction, even when the traditional measures of socioeconomic status, i.e. education or income, were taken into account. Cross-sectional analyses, in which basic and luxury goods were compared, showed that the lack of basic goods was strongly associated with mental dysfunction. Lack of luxury goods was, however, not related to dysfunction.

\section{Conclusion}

Even in a relatively wealthy country like the Netherlands, the lack of certain basic goods is not uncommon. More importantly, lack of basic goods, as an indicator of wealth, was strongly related to health-related dysfunction also when traditional measures of socioeconomic status were taken into account. In contrast, no effects of luxury goods on physical or mental dysfunction were found. Future longitudinal research is necessary to clarify the precise mechanisms underlying these effects. 


\section{BACKGROUND}

Adverse socioeconomic circumstances affect probabilities of good health and risks of disease. ${ }^{1,2}$ Less clear is whether this also holds for older populations of whom many are retired and not in the paid labour force anymore. ${ }^{3,4}$ In such populations, wealth may be a more valid indicator of socioeconomic ranking than the traditional indicators of socioeconomic status, such as education and income. Wealth refers to the individual's or household's total financial resources amassed over the course of life. ${ }^{5}$ Hence, the cumulative character of wealth might be important, particularly among older persons because of such life course effects. Furthermore, through being wealthy or not, socioeconomic ranking becomes explicitly visible to the outside world, more than through variations in educational and income level. For example, possession of goods, such as a car and a house, may be an explicit projection of how wealthy a household is.

Although differently measured across studies, ${ }^{5-8}$ wealth can be measured by the possession or lack of basic (e.g. refrigerator) and luxury goods (e.g. LCD television). ${ }^{7}$ Lack of basic goods may have direct biological effects on health. ${ }^{7,9}$ For example, the lack of a refrigerator has been shown to increase the risk of stomach cancer. ${ }^{10}$ The lack of such basic goods may, further, be related to the lack of sufficient or qualitatively good food and poor housing conditions (e.g. cold and draught), factors that more generally have their sources in the material world. ${ }^{9}$ According to some scholars, this neo-material hypothesis is the most important explanation of health differences. $^{9,11}$

For the lack of luxury goods in a household, however, it is much more difficult to imagine direct biological effects. The visibility of socioeconomic ranking might be particularly important for the luxury items. The ownership of a large LCD television (preferably visible through the windows) or two cars (preferably both in front of the house) may be an expression of conspicuous consumption and be considered as an outward-directed symbol of status and prestige. The resulting psychosocial comparisons with others (having less or more of such goods) emphasise the potential relevance of psychosocial explanations of socioeconomic differences in health, rather than material explanations alone.,12-14

While wealth might be particularly important for an older population because of its cumulative character, the effects of specific measures of wealth on healthrelated functioning, independent of education and income, have not been widely studied among older persons. ${ }^{5,15}$ Using cross-sectional and longitudinal data from the SMILE study, we set out to examine, firstly, the links between the possession of both basic and luxury goods and both mental and physical dysfunction in older Dutch men and women, and, secondly, the extent to which these links are independent of more traditional socioeconomic indicators, such as education and income. 


\section{METHODS}

\section{Design}

Data came from the longitudinal SMILE study (i.e. Study on Medical Information and Lifestyles Eindhoven), which started in November 2002 as a joint project of Maastricht University and the Eindhoven Corporation of Primary Health Care Centres. Eindhoven is a moderate city of approximately 200,000 inhabitants in the Southern part of The Netherlands. General practitioner's registers and annual postal questionnaires were used to collect data on health, lifestyles, and health care use. SMILE is a dynamic cohort, meaning that new participants will enter the population sample when they either reach the age of inclusion or when they are enrolled as a new patient in one of the participating centres and give informed consent. Responders may leave the population either through leaving the participating centres or due to death or drop-out. ${ }^{16}$ Persons aged 55 years and older are considered as a separate population within SMILE. ${ }^{17}$

\section{Study population}

The present study uses data that were collected in May 2004 and May 2007. In May $2004,11,180$ persons of 55 years or older were sent a self-administered questionnaire, of whom 5,109 (46\%) responded. Forty-two percent $(n=2,131)$ were followed up until May 2007. Data on educational level was extracted from the May 2003 questionnaire. After exclusion of persons that have missing scores on variables of interest, the main analyses consisted of 2,067 persons (989 men and 1,078 women; mean age $=67.6, \mathrm{SD}=7.5$ ).

\section{Ethical review}

Written informed consent was asked when a patient registered in one of the participating health care centres. Privacy regulations are in agreement with the Dutch legislation. The medical ethical committee of the Maastricht Academic Hospital has approved of the study protocol of the SMILE study. Furthermore, the study was registered at the Dutch Data Protection Authority. ${ }^{16}$

\section{Measures}

\section{Health-related function}

Information about mental and physical dysfunction was derived from the Dutch version of the MOS SF36, ${ }^{80,81}$ assessed in May 2004 and May 2007. The SF36 is a short-form health survey with 36 questions, clustered in eight subscales related to 
functional health and well-being. The eight scales can be recoded in two distinct higher-order components, i.e. physical and mental function. ${ }^{19,20}$ For the purpose of this study, physical and mental dysfunction was defined as having a score below the 10th percentile (scores of $\leq 30$ and $\leq 36$ out of a range from 10 to 75 , respectively). Furthermore, persons that have more than $50 \%$ missing scores on physical or mental function were excluded from the analyses. ${ }^{19}$

\section{Basic and luxury goods}

Basic goods, measured in May 2004, included a freezer, oven, washing machine, refrigerator, telephone, car and own house.,17,21 Intentionally, three categories were created in such a way that each group contained approximately a third of the sample at baseline: the possession of 0 to 4 basic goods, possession of 5 or 6 basic goods, and possession of all 7 basic goods. Luxury goods have been measured in May 2007 and included a dishwasher, (tumble) dryer, solarium, microwave oven, DVD-player, DVD-recorder, video camera, PC (desktop), laptop, mp3-player, internet connection, plasma/LCD television, cell-phone, caravan/trailer, second house, musical instrument, second car, navigation system in car, digital television, game console, and a digital photo camera. ${ }^{7}$ Again, three categories were created: the possession of 0 to 5 luxury goods; possession of 6 to 10 luxury goods, and possession of 11 to 21 luxury goods.

\section{Covariates}

Covariates were age, sex, educational level, and prevalent severe and less severe disease. Education was measured in May 2003, using a seven-point scale. Three categories were then created in such a way that each group contained approximately a third of the sample: primary school only (lowest); lower vocational education and intermediate general education (middle); intermediate vocational education, higher general education, higher vocational education, and university (highest). Income and financial problems were also separately controlled for, instead of educational level, but as findings were very similar, despite income having more missing scores, only findings for the educational control are presented. Respondents were further asked whether or not they had any of the severe (COPD, heart disease, bowel disease, liver disease, kidney disease, diabetes, cancer, epilepsy, and stroke) and less severe (migraine, joints, rheumatoid arthritis, arthrosis, back, injury, and other) diseases. ${ }^{22}$ Presence of diseases was measured in May 2004 and May 2007.

\section{Statistical analyses}

Chi-square tests, based on cross-tabulations, were computed to examine whether there were sex, age, disease status, and physical and mental function differences in the possession of basic or luxury goods. The associations of educational level with 
the possession of basic and luxury goods and with dysfunction were analysed as well. Multiple logistic regression models were fitted to examine whether lack of basic or luxury goods were associated with physical and mental dysfunction (measured in 2007). Possession of all of the selected basic goods or the highest category of luxury goods was the reference category. The first model was adjusted for age and sex. The second model comprised age and sex and was simultaneously adjusted for both the possession of luxury and basic goods. In the third model, odds ratios were further adjusted for educational level. The final model additionally controlled for the presence of severe (0-9) and less severe (0-7) diseases (measured in 2007). For the basic goods, longitudinal analyses were also done to study the relation with incident dysfunction between 2004 and $2007(n=124)$. Prevalent dysfunction at the 2004 baseline was excluded $(n=150)$. A similar sequence of models as described above was used, adjusting for severe and less severe diseases at baseline (measured in 2004). Finally, exploratory analyses were performed for different subgroups, i.e. younger (55-65) and older (>65) persons, male and female, persons with and without chronic diseases and persons with high or low education. All statistical analyses were performed using SPSS 14.0.1.

\section{RESULTS}

Older persons and women more often reported a relative lack of basic and luxury goods (not tabulated). For example, persons aged 75 or older were more likely to report owning four or less of the basic goods (20\%) than persons between 55 and 64 years of age $(5 \%)$. Furthermore, women were significantly more likely to report owning four or less of the basic goods (11\%) than men (7\%). Similar associations were found for the lack of luxury goods. Seventy percent of persons aged 75 years and older reported owning five or less of the luxury goods, while only $20 \%$ of persons between 55 and 65 years of age did so. Furthermore, only $4 \%$ of the oldest age group reported owning 11 to 21 of the luxury goods, while this was reported by $32 \%$ of the youngest age group. Moreover, men were more likely to report owning 11 to 21 of the luxury goods ( $22 \%$ versus $15 \%$ ), and were less likely to report having five or less of the luxury goods ( $30 \%$ versus $45 \%$ ) compared with women.

Table 1 presents the associations between the lack of basic and luxury goods and the prevalence of less severe and more severe diseases and physical and mental dysfunction. Persons owning four or less of the basic goods were more likely to suffer from severe diseases (31\% versus $24 \%$ ) and physical and mental dysfunction (19\% versus $6 \%)$ than persons owning all of the selected basic goods. The lack of luxury goods was also related to the prevalence of severe diseases and physical and mental dysfunction, although associations were somewhat weaker. 
Table 1 Percentages of participants with diseases and with relative poor physical or mental function ${ }^{\mathrm{a}, \mathrm{b}, \mathrm{c}}$

\begin{tabular}{lccccc}
\hline & Total & $\begin{array}{c}\geq 1 \text { less severe } \\
\text { disease } \\
n=2858^{\mathrm{d}}\end{array}$ & $\begin{array}{c}\geq 1 \text { severe } \\
\text { disease } \\
n=769\end{array}$ & $\begin{array}{c}\text { Physical } \\
\text { dysfunction } \\
n=262\end{array}$ & $\begin{array}{c}\text { Mental } \\
\text { dysfunction }\end{array}$ \\
$\begin{array}{l}\text { Basic goods } \\
\leq 4\end{array}$ & $\mathrm{n}=252$ & 42.1 & 31.3 & 19.4 & 18.9 \\
$5-6$ & $\mathrm{n}=1566$ & 40.4 & 28.4 & 12.1 & 10.6 \\
7 & $\mathrm{n}=1023$ & 39.3 & 24.2 & 6.3 & 5.9 \\
$\begin{array}{l}\text { Luxury goods } \\
\leq 5\end{array}$ & $\mathrm{n}=1081$ & 39.3 & 31.2 & 16.2 & 12.2 \\
$6-10$ & $\mathrm{n}=1232$ & 40.7 & 25.2 & 7.1 & 8.2 \\
$11-21$ & $\mathrm{n}=514$ & 41.4 & 23.5 & 7.2 & 7.0 \\
\hline
\end{tabular}

${ }^{a}$ Row percentages, for basic and luxury goods separately; ${ }^{b}$ Results in italic font indicate a significant difference $\left(X^{2} ; p<0.05\right) ;{ }^{c}$ Diseases were self-reported; ${ }^{d}$ Basic and luxury goods have different number of missing values.

Examination of the individual basic items (not tabulated) showed that not owning one's own house $(52 \%)$, car $(17 \%)$, or freezer $(16 \%)$ were most often reported. Moreover, the lack of a car and own house were most strongly related to dysfunction. For example, $20 \%$ of persons not owning a car suffered from physical dysfunction compared with $7 \%$ of the car owners. Persons not owning a washing machine were more likely to report mental dysfunction (19\% versus $9 \%$ ) than those who possessed such a machine. Examination of the individual luxury items showed that it was particularly the lack of a personal computer, internet connection, and a mobile phone which were associated with dysfunction. For example, almost $15 \%$ of persons lacking an internet connection at home reported physical dysfunction, compared with only $7 \%$ of persons who had an internet connection available.

There was a significant positive association between the number of basic goods and the number of luxury goods (Spearman's $R=0.50, p<0.001$ using the continuous measures). Cross tabulations (not presented) showed that $84 \%$ of persons owning only four or less of the basic goods reported owning only five or less of the luxury goods, compared with only $18 \%$ of persons owning all of the basic goods.

Table 2 shows how education was associated with the possession of basic and luxury goods and health-related dysfunction. Twenty percent of persons with a low educational level reported owning only four or less of the basic goods, while only $4 \%$ of persons with a high educational level did so. Furthermore, $16 \%$ of persons with a low educational level reported poor physical and mental functioning, while only $7 \%$ in the group with a high educational level did so. 
Table 2 The association of educational level with basic and luxury goods and health-related function ${ }^{a, b, c}$

\begin{tabular}{lcccccccccc}
\hline Education & \multicolumn{3}{c}{ Basic goods } & \multicolumn{3}{c}{ Luxury goods } & \multicolumn{3}{c}{ Physical function } & Mental function \\
& \multicolumn{1}{c}{$\begin{array}{c}\leq 4 \\
\mathrm{n}=195\end{array}$} & $\begin{array}{c}5-6 \\
\mathrm{n}=1280\end{array}$ & $\begin{array}{c}7 \\
\mathrm{n}=839\end{array}$ & $\begin{array}{c}\leq 5 \\
\mathrm{n}=868\end{array}$ & $\begin{array}{c}6-10 \\
\mathrm{n}=1015\end{array}$ & $\begin{array}{c}11-21 \\
\mathrm{n}=417\end{array}$ & $\begin{array}{c}\text { Healthy } \\
\mathrm{n}=1871\end{array}$ & $\begin{array}{c}\text { Poor } \\
\mathrm{n}=208\end{array}$ & $\begin{array}{c}\text { Healthy } \\
\mathrm{n}=1893\end{array}$ & $\begin{array}{c}\text { Poor } \\
\mathrm{n}=185\end{array}$ \\
& 19.8 & 67.4 & 12.8 & 65.2 & 28.7 & 6.0 & 84.2 & 15.8 & 84.2 & 15.8 \\
Low & 8.5 & 60.8 & 30.8 & 41.0 & 42.9 & 16.1 & 89.1 & 10.9 & 91.4 & 8.6 \\
Middle & 3.9 & 45.7 & 50.5 & 24.0 & 51.3 & 24.7 & 92.7 & 7.3 & 93.1 & 6.9 \\
\hline
\end{tabular}

${ }^{a}$ Row percentages; ${ }^{b}$ Results in bold indicate a significant difference $\left(X^{2} ; p<0.05\right) ;{ }^{c}$ Basic and luxury goods have different number of missing values.

Table 3 shows that there was a substantial association between the lack of basic goods and mental dysfunction. Persons with four or less basic goods had more than twice the risk of mental dysfunction $(O R=2.56)$ of persons owning all of the selected basic goods. The significance of these associations even held after additional adjustment for luxury goods, educational level and severe and less severe diseases $(O R=2.13)$. The lack of basic goods was also related to physical dysfunction $(O R=1.91)$. However, the odds ratios became non-significant, when controlled for educational level and diseases. In contrast, the lack of luxury goods was not related to either mental or physical dysfunction. The unadjusted significant association between the relative lack of luxury goods and dysfunction, as shown in Table 1, disappeared when controlled for age and sex. Those without luxury goods being older, in particular, explained $85 \%$ of the corresponding unadjusted odds ratio of 2.59 (95\% Cl: 1.66-4.04).

Longitudinal analyses showed that the lack of basic goods was related to both incident mental and physical dysfunction, even after additional adjustment for sex, age, luxury goods, educational level, and severe and less severe disease (OR=2.32 for physical functioning and $\mathrm{OR}=2.12$ for mental functioning) (Table 4).

Effects were similar in men and women, for the younger $(\leq 65)$ and older $(>65)$ age groups, for diseased and non-diseased persons, and for both the lower and higher educated persons, as the respective interaction terms were not significant in our analyses. Furthermore, when using linear regression analyses with mental and physical function as continuous variables, similar associations were found. 
Table 3 Adjusted Odds Ratios (OR) of physical and mental dysfunction by basic and luxury goods

\begin{tabular}{|c|c|c|c|c|}
\hline & $\begin{array}{c}\text { Model } 1^{\mathrm{a}} \\
\text { OR }(95 \% \mathrm{Cl})\end{array}$ & $\begin{array}{c}\text { Model } 2^{b} \\
\text { OR }(95 \% \mathrm{Cl})\end{array}$ & $\begin{array}{c}\text { Model } 3^{c} \\
\text { OR }(95 \% \mathrm{Cl})\end{array}$ & $\begin{array}{c}\text { Model } 4^{d} \\
\text { OR }(95 \% \mathrm{Cl})\end{array}$ \\
\hline \multicolumn{5}{|c|}{ Physical dysfunction ( $n=2067)$} \\
\hline \multicolumn{5}{|c|}{ Basic goods } \\
\hline$\leq 4$ & $1.91(1.10-3.33)$ & $1.65(0.93-2.93)$ & $1.49(0.83-2.68)$ & $1.28(0.68-2.42)$ \\
\hline $5-6$ & $1.62(1.15-2.29)$ & $1.51(1.06-2.15)$ & $1.42(0.99-2.04)$ & $1.41(0.96-2.08)$ \\
\hline 7 & 1.00 & 1.00 & 1.00 & 1.00 \\
\hline \multicolumn{5}{|c|}{ Luxury goods } \\
\hline$\leq 5$ & $1.54(0.94-2.52)$ & $1.32(0.79-2.19)$ & $1.25(0.75-2.09)$ & $1.11(0.64-1.92)$ \\
\hline $6-10$ & $0.88(0.55-1.42)$ & $0.82(0.51-1.32)$ & $0.81(0.50-1.31)$ & $0.77(0.46-1.28)$ \\
\hline $11-21$ & 1.00 & 1.00 & 1.00 & 1.00 \\
\hline \multicolumn{5}{|c|}{ Mental dysfunction ( $n=2067)$} \\
\hline \multicolumn{5}{|c|}{ Basic goods } \\
\hline$\leq 4$ & $2.56(1.48-4.34)$ & $2.47(1.39-4.41)$ & $2.18(1.21-3.93)$ & $2.13(1.17-3.84)$ \\
\hline $5-6$ & $1.53(1.08-2.18)$ & $1.51(1.05-2.17)$ & $1.39(0.96-2.02)$ & $1.37(0.95-1.99)$ \\
\hline 7 & 1.00 & 1.00 & 1.00 & 1.00 \\
\hline \multicolumn{5}{|c|}{ Luxury goods } \\
\hline$\leq 5$ & $1.33(0.82-2.16)$ & $1.04(0.62-1.74)$ & $0.97(0.58-1.62)$ & $0.91(0.54-1.53)$ \\
\hline $6-10$ & $1.02(0.65-1.60)$ & $0.91(0.58-1.44)$ & $0.90(0.57-1.43)$ & $0.88(0.56-1.40)$ \\
\hline $11-21$ & 1.00 & 1.00 & 1.00 & 1.00 \\
\hline
\end{tabular}

${ }^{a}$ Model 1 is adjusted for age and sexr; ${ }^{b}$ Model 2 is adjusted for age, sex and simultaneously for luxury goods or basic goods; ${ }^{c}$ Model 3 is additionally adjusted for education; ${ }^{d}$ Model 4 is additionally adjusted for severe and less severe diseases.

Table 4 Odds ratios (OR) of the incidence of physical and mental dysfunction by basic goods ${ }^{a}$

\begin{tabular}{|c|c|c|c|c|}
\hline & $\begin{array}{c}\text { Model } 1^{b} \\
\text { OR }(95 \% \mathrm{Cl})\end{array}$ & $\begin{array}{c}\text { Model } 2^{\mathrm{C}} \\
\text { OR }(95 \% \mathrm{Cl})\end{array}$ & $\begin{array}{c}\text { Model } 3^{d} \\
\text { OR }(95 \% \mathrm{Cl})\end{array}$ & $\begin{array}{c}\text { Model } 4^{\mathrm{e}} \\
\text { OR }(95 \% \mathrm{Cl})\end{array}$ \\
\hline \multicolumn{5}{|c|}{ Physical functioning ( $n=1769$ ) } \\
\hline \multicolumn{5}{|c|}{ Basic goods } \\
\hline$\leq 4$ & $2.56(1.17-5.60)$ & $2.52(1.11-5.70)$ & $2.63(1.14-6.07)$ & $2.32(1.00-5.38)$ \\
\hline $5-6$ & $1.73(1.04-2.89)$ & $1.71(1.01-2.90)$ & $1.76(1.03-3.00)$ & $1.70(0.99-2.90)$ \\
\hline 7 & 1.00 & 1.00 & 1.00 & 1.00 \\
\hline \multicolumn{5}{|c|}{ Mental functioning ( $n=1761$ ) } \\
\hline \multicolumn{5}{|c|}{ Basic goods } \\
\hline$\leq 4$ & $2.50(1.26-4.94)$ & $2.52(1.23-5.16)$ & $2.30(1.11-4.79)$ & $2.12(1.01-4.73)$ \\
\hline $5-6$ & $1.35(0.87-2.11)$ & $1.36(0.86-2.15)$ & $1.29(0.81-2.05)$ & $1.26(0.79-2.01)$ \\
\hline 7 & 1.00 & 1.00 & 1.00 & 1.00 \\
\hline
\end{tabular}

${ }^{a}$ Prevalent dysfunction cases in 2004 are excluded from the analyses; ${ }^{b}$ Model 1 is adjusted for age and sex; ${ }^{c}$ Model 2 is additionally adjusted for luxury goods; ${ }^{\mathrm{d}}$ Model 3 is additionally adjusted for education; ${ }^{\mathrm{e}}$ Model 4 is additionally adjusted for severe and less severe diseases. 


\section{DISCUSSION}

In this group of older Dutch men and women, a lack of basic goods was not uncommon. Moreover, this lack of basic goods, as indicator of wealth, turned out to be a good predictor of both incident physical and mental dysfunction, even when traditional measures of socioeconomic status, i.e. education and income, were taken into account. No significant associations were found between the lack of luxury goods and dysfunction. All association were independent of the prevalence of severe and less severe diseases.

Given that basic goods are indicators of wealth, ${ }^{5-8}$ our results suggest that for an older population wealth might be an additional or even more appropriate predictor of health-related dysfunction than the traditional measures of SES, i.e. education and income. This may be due to its cumulative character, indicating economic advantage and disadvantage amassed over the course of life. Wealth may, further, buffer the effects of lost or temporarily low income., 5

The lack of basic goods having more impact on health-related dysfunction than the lack of luxury goods is consistent with the view that material factors are important determinants of health. Living in poor material conditions or with a lack of resources may have a direct, biological, effect on health. ${ }^{9}$ Furthermore, the lack of a car makes shopping for (healthy) food and access to health care services much more difficult and the ownership of a house may, on average, be associated with better housing conditions. ${ }^{23}$

However, psychological or psychosocial pathways cannot be excluded either. The lack of a car, refrigerator, or oven is visible for neighbours, friends, and acquaintances. The negative social comparison resulting from this apparent visibility might have adverse effects on self-esteem and subjective prestige, pride, and status through which eventually both mental and physical dysfunction might become compromised as well. ${ }^{12,14,24}$ The possibility that psychological pathways might contribute is also substantiated by recent experiences with Dutch food banks. These are increasingly being moved to the suburbs, where their customers report less shame and other psychosocial problems, given that their visits to these more secluded environments are less likely to be noticed. ${ }^{25}$ Perhaps shame may even be more prominent when lacking sufficient food or a refrigerator than a second house or a DVD recorder.

Why then are there no effects of a lack of luxury goods, where visibility and corresponding psychosocial pathways were hypothesised to have particular relevance? Our data suggest that the possession of a large LCD television or a second car does not make older persons healthier and happier compared with their neighbours who do not have such items. Pikhart and colleagues (2003), however, found that luxury items remained strongly associated with self-rated health even in fully adjusted models. It should, however, be noticed that this finding only held for 
a, on average younger (18+) Hungarian population. Similar to our study, luxury goods were only studied using cross-sectional data. Future longitudinal research is necessary to clarify the relations. As mentioned above, visible status, social comparisons and related psychosocial mechanisms ${ }^{26}$ might also, and perhaps particularly, hold for explaining the adverse health outcomes of lacking basic goods.

\section{Methodological considerations}

Several methodological limitations may affect the interpretation of the results of our study. Firstly, the selection of items is cultural ${ }^{27}$ and time-dependent. The individual basic and luxury good items were chosen on the basis of recent reports. ${ }^{7,21}$ Furthermore, as we state in our results section, certain items have more predictive power than others. However, before reducing the scales to the items that are predictive for dysfunction, more research is needed, also with other health outcomes. Further development and validation of measurement instruments to assess the possession of both basic and luxury goods is recommended. Moreover, more attention should be paid to additional measures of poor material circumstances, such as poor physical housing and working conditions (e.g. dampness, mould, and cold in the house and lifting heavy loads at work). ${ }^{28,29}$

Secondly, our study relied solely on self-reports which might have introduced measurement error for the dysfunction measures. ${ }^{30}$ Individuals with a general tendency towards negative perceptions of material well-being may also over-report symptoms of health-related dysfunction (i.e. negative affectivity). ${ }^{31}$ This may have led to an overestimation of the presented association. However, by excluding prevalent dysfunction cases from the longitudinal analyses, persons with negative affectivity $^{32,33}$ have also been excluded. Overlap between the physical and mental functioning component of the SF-36 outcome measure might also have distorted our results. ${ }^{34}$ However, these measures were only weakly correlated (Pearson's $\mathrm{R}=$ $0.168, p<0.001$ ) within our study population. Furthermore, poor people may have underreported their poverty. Out of shame, people may not want to admit not being able to afford certain (basic) items. This bias may have led to an underestimation of the presented associations.

Thirdly, the question remains why the longitudinal association between basic goods and physical dysfunction is stronger than the corresponding cross-sectional association. Except that longitudinal analyses are generally considered superior because of the exclusion of reverse causation, we could not come to an answer to this question. More research is recommended to disentangle possible underlying mechanisms.

Finally, our research may be limited by potential selection biases. Older persons living in nursing homes were not included which restricts the generalisability of our findings. The most disadvantaged older persons may be underrepresented in our 
research, because of premature mortality (the 'wealthy survivor' effect). Response analyses showed that men and persons from the youngest $(<65)$ age groups were more likely to respond. Furthermore, attrition (between 2004 and 2007, 33\% were lost to follow-up) was higher for persons that were lower educated and had worse scores on physical and mental function scores at the 2004 baseline $(p<0.001)$. Missing values analyses revealed that persons with missing values on mental and/or physical function scales were significantly more likely to be lower educated, have fewer basic and luxury goods and have worse physical and mental function scores at the 2004 baseline. Similarly, persons with missing values on basic or luxury good items were more likely to report poor mental and physical function. This pattern of selective response and attrition may have led to an underestimation of the reported associations, although attrition's effect may be more disturbing for descriptive results than for measures of (longitudinal) association. ${ }^{35}$

\section{CONCLUSION}

Even in a relatively wealthy country like the Netherlands, the lack of certain basic goods is not uncommon. More importantly, lack of basic goods, as indicator of wealth, was strongly related to health-related dysfunction, also when taking into account traditional measures of socioeconomic status. In contrast, no effects of luxury goods on physical or mental dysfunction were found. Future longitudinal research is necessary to clarify the precise mechanisms underlying the effects and -particularly in older persons- to explore strategies to intervene upon the adverse effects of material deprivation.

\section{Acknowledgements}

The longitudinal SMILE study is carried out by the department of General Practice of Maastricht University, in collaboration with the Public Health Services of the city of Eindhoven. Currently, nine general practices and their 40,000 patients are participating. The investigators are indebted to the participants for their willingness to participate in the study. 


\section{REFERENCES}

1. Wilkinson RG, Marmot M. Social determinants of health: the solid facts. 2 nd ed. Copenhagen: WHO; 2003.

2. Ferrie JE, Shipley MJ, Davey Smith G, Stansfeld S, Marmot M. Change in health inequalities among British civil servants: the Whitehall II study. J Epidemiol Community Health. 2002;56:922-6.

3. Breeze E, Fletcher AE, Leon DA, Marmot MG, Clarke RJ, Shipley MJ. Do socioeconomic disadvantages persist into old age? Self-reported morbidity in a 29-year follow-up of the Whitehall study. Am J Public Health. 2001;91(2):277-83.

4. Artazcoz L, Rueda S. Social inequalities in health among the elderly: a challenge for public health research. J Epidemiol Community Health. 2007;61:466-7.

5. Pollack CE, Chideya S, Cubbin C, Williams B, Dekker M, Braveman PA. Should health studies measure wealth? A systematic review. Am J Prev Med. 2007;33(3):250-64.

6. Macintyre S, McKay L, Der G, Hiscock R. Socio-economic position and health: what you observe depends on how you measure it. J Public Health Med. 2003;25(4):288-94.

7. Pikhart $H$, Bobak M, Rose R, Marmot M. Household item ownership and self-rated health: material and psychosocial explanations. BMC Public Health. 2003;3(38).

8. Duncan GJ, Daly MC, McDonough P, Williams DR. Optimal indicators of socioeconomic status for health research. Am J Public Health. 2002;92(7):1151-7.

9. Lynch JW, Davey Smith G, Kaplan GA, House JS. Income inequality and mortality: importance to health of individual income, psychosocial environment, or material conditions. $\mathrm{Br}$ Med J. 2000;320:1200-4.

10. Boeing $\mathrm{H}$. Epidemiological research in stomach cancer: progress over the last ten years. J Cancer Res Clin Oncol. 1991;117(2):133-43.

11. Macleod J, Davey Smith G, Metcalfe C, Hart C. Is subjective social status a more important determinant of health than objective social status? Evidence from a prospective observational study of Scottish men. Soc Sci Med. 2005;61(9):1916-29.

12. Marmot MG, Wilkinson RG. Psychosocial and material pathways in the relation between income and health: a response to Lynch et al. Br Med J. 2001;322:1233-6.

13. Marmot MG. Understanding social inequalities in health. Perspect Biol Med. 2003;46:S9-S23.

14. Fliessbach $K$, Weber B, Trautner $P$, Dohmen $T$, Sunde U, Elger CE, et al. Social comparison affects reward-related brain activity in the human ventral striatum. Science. 2007;318:1305-8.

15. von dem Knesebeck O, Luschen G, Cockerham WC, Siegrist J. Socioeconomic status and health among the aged in the United States and Germany: A comparative cross-sectional study. Soc Sci Med. 2003;57:1643-52.

16. Van den Akker M, Spigt MG, de Raeve L, van Steenkiste B, Metsemakers JFM, van Voorst EJ, et al. The SMILE study: A Study of Medical Information and Lifestyles in Eindhoven. The rationale and contents of a large prospective dynamic cohort study. BMC Public Health. 2008;8(19).

17. Groffen DAl, Bosma $H$, van den Akker M, Kempen GIJM, van Eijk JTM. Material deprivation and health-related dysfunction in older Dutch people; Findings from the SMILE study. Eur J Public Health. 2008;18(3):258-63.

18. Ware JE, Sherbourne CD. The Rand-36 Short-form Health Status Survey 1: Conceptual framework and item selection. Medical Care. 1992;30(6):473-81.

19. Van der Zee KI, Sanderman R, Heyink J. De psychometrische kwaliteiten van de MOS 36 item Short Form Health Survey in een Nederlandse populatie. Tijdschr Soc Gezondheidsz. 1993;4:183-91.

20. Ware JE, Kosinski M. Interpreting SF-36 summary health measures: a response. Qual Life Res. 2001;10:415-20.

21. Jehoel-Gijsbers G. Sociale uitsluiting in Nederland. The Hague: Netherlands Institute for Social Research (SCP); 2003. 
22. Koster A, Bosma H, Kempen GI, Van Lenthe FJ, Van Eijk JT, Mackenbach JP. Socioeconomic inequalities in mobility decline in chronic disease groups (asthma/COPD, heart disease, diabetes mellitus, low back pain): only a minor role for disease severity and comorbidity. J Epidemiol Community Health. 2004;58:862-9.

23. Grundy $\mathrm{H}$, Holt $\mathrm{G}$. The socioeconomic status of older adults: how should we measure it in studies of health inequalities? J Epidemiol Community Health. 2001;55:895-904.

24. Vetter S, Endrass J, Schweizer I, Teng HM, Rossler W, Gallo WT. The effects of economic deprivation on psychological well-being among the working population of Switzerland. BMC Public Health. 2006;6(1):223.

25. Desain L, Van Gent MJ, Kroon P, Langendijk F, Van Waveren B. Eindrapport klantenanalyse voedselbanken. Amsterdam, the Netherlands: Regioplan beleidsonderzoek; Ministry of Social Affairs; 2006 March. Report No.: Regioplan:1398.

26. Wilkinson RG, Pickett KE. The problems of relative deprivation: Why some societies do better than others. Soc Sci Med. 2007;65(9):1965-78.

27. Dressler WW. Culture and the risk of disease. Br Med Bull. 2004;69:21-31.

28. Evans J, Hyndman S, Stewart Brown S, Smith D, Petersen S. An epidemiological study of the relative importance of damp housing in relation to adult health. J Epidemiol Community Health. 2000;54(9):677-86.

29. Packer CN, Stewart Brown S, Fowle SE. Damp housing and adult health - results from a life-style study in Worcester, England. J Epidemiol Community Health. 1994;48:555-9.

30. Kempen GI, Steverink N, Ormel J, Deeg DJ. The assessment of ADL among frail elderly in an interview survey:self-report versus performance-based tests and determinants of discrepancies. J Gerontol B Psychol Sci Soc Sci. 1996;51:254-60.

31. Macleod J, Davey Smith G, Heslop P, Metcalfe C, Carroll D, Hart C. Psychological stress and cardiovascular disease: empirical demonstration of bias in a prospective observational study of Scottish men. Br Med J. 2002;324:1247-53.

32. Kressin NR, Spiro A, Skinner KM. Negative affectivity and health related quality of life. Med Care. 2000;38(8):858-67.

33. Watson D, Pennebakker JW. Health complaints, stress, and distress: exploring the central role of negative affectivity. Psychol Rev. 1989;96(2):234-54.

34. Simon GE, Revicki DA, Grothaus L, Vonkorff M. SF-36 summary scores; Are physical and mental health truly distinct? Med Care. 1998;36(4):567-72.

35. Kempen GIJM, Van Sonderen E. Psychological attributes and changes in disability among lowfunctioning, older persons: does attrition affect the outcomes? J Clin Epidemiol. 2002;55:224-9. 



\section{ABSTRACT}

\section{Background}

We examined the independent effects of classic socioeconomic status (SES) measures (e.g. education and occupation) and of other aspects of SES (e.g. material factors, including the possession of basic goods, housing age and quality) on selfreported mobility limitations, walking speed and depressed mood.

\section{Methods}

We used data obtained in midlife to assess the effects of early life circumstances and midlife material factors on physical dysfunction and depressed mood three decades later. Data were from 4,809 men and women, aged 33-65 years who participated in the Reykjavik Study (1967-1992) and who were re-examined in old age in the Age, Gene/Environment Susceptibility (AGES)-Reykjavik Study (2002-2006; mean follow-up=29 years).

Results

Independent of the classic measures of SES, not owning a house or car, and living in older or poorer quality housing were important determinants of self-reported mobility limitation, depressed mood (GDS), and low walking speed three decades later. Similarly, recalled shortages of food in childhood were related to health outcomes.

\section{Conclusion}

These findings support the hypothesis that even accounting for the classic SES measures, other (material) life circumstances continue to affect health status in old age. 


\section{INTRODUCTION}

Classical indicators of socioeconomic status (SES), such as education and occupation are already well-established predictors of disease and dysfunction. ${ }^{1,2}$ However, why these measures have such a powerful effect on health is not well-understood, nor is it clear whether there are other aspects of SES that might additionally contribute to health outcomes. ${ }^{3}$ In particular, indicators of a cumulative character that capture the relative burden of SES at different points in time across the lifespan may be important. ${ }^{4}$ It is postulated that the highest rates of morbidity and dysfunction are exhibited by those who have experienced the greatest cumulative exposures to financial and material adversity over the life course. ${ }^{5,6}$ Material factors, including the possession of basic goods, such as a car, but also housing age and quality may play a role in health differences, and may affect health either via direct or indirect pathways. $^{7-9}$ For example, the lack of a car may affect access to adequate health care and makes shopping for healthy foods much more difficult. ${ }^{7,10}$ Living under poor housing conditions, which might include no central heating or piped hot water, may increase risk of exposures to damp or cold. ${ }^{11}$

Most studies of older persons include measures of current socioeconomic status. Few include data on earlier life circumstances. These data are difficult to ascertain through recall because those with poorer health status may have differential recall of exposures. ${ }^{12}$ One way to address this would be to look at studies in which material factors were assessed at an earlier life time in the course of a general health study for which long-term health outcome data is now available. Such data were available in the Age, Gene/Environment Susceptibility (AGES)-Reykjavik Study. In this study, material factors were ascertained in midlife as part of an examination of cardiovascular risk factors and functional status in several domains was ascertained three decades later. We explored two hypotheses: first, that classical measures of SES, as measured in midlife, would be related to physical dysfunction and depressed mood in old age; and second, that independent of these classic SES measures, material factors would also be related to physical dysfunction and depressed mood in old age.

\section{METHODS}

\section{Design and study population}

The Age, Gene/Environment Susceptibility-Reykjavik (AGES-Reykjavik) Study is drawn from the Reykjavik Study, a population-based cohort established in 1967 by investigators at the Icelandic Heart Association (IHA). ${ }^{13,14}$ This cohort originally comprised a random sample of 30,795 men and women born between 1907 and 1935 . 
As part of the Reykjavik Study (termed midlife), participants completed questionnaires and participated in a standardised medical examination. Baseline measurements took place over a period of more than 20 years, from 1967 until 1992. The initial follow-up examination for AGES-Reykjavik started in 2002 and concluded in 2006. ${ }^{15}$ As part of the AGES-Reykjavik Study, participants completed interviews about functional health status and disability, health conditions, health behaviours, and family history and had a series of standardised health examinations.

The present study sample consisted of 5,764 survivors from the Reykjavik Study who participated in the AGES-Reykjavik Study. The interval between the Reykjavik Study and the AGES-Reykjavik Study ranged from 13 to 38 years (mean=28.8, $\mathrm{SD}=5.6$ ). Persons that had left midlife (persons older than 65 years) at baseline $(n=109)$ or that had missing values on occupation $(n=107)$ or on one or more of the measures of health-related function ( $n=414$ for walking speed, $n=431$ for mobility limitations and $n=377$ for depressed mood - partly overlapping persons) were excluded from the analyses, leaving 4,809 participants for the current analyses (43\% male, mean age in midlife $=47.5, \mathrm{SD}=7.1$ ). Excluded persons with missing values on physical dysfunction or depressed mood at follow up were significantly more likely to be older $(p<0.001)$, lower educated and to do heavy manual jobs $(p<0.001)$ at baseline. Similarly, persons with missing values on material factors or SES at baseline were more likely to report mobility limitation at follow up $(p<0.001)$.

AGES-Reykjavik was approved by the National Bioethics Committee in Iceland that acts as the institutional review board for the IHA (approval number VSN-00063) and the National Institute on Aging Intramural Institutional Review Board. Release of data for analysis is governed by rules created by these bodies to protect the privacy of Icelandic participants. ${ }^{15}$

\section{Measures}

\section{Health-related function}

Health-related function was measured using both self-reported and objective performance measures, assessed in the AGES-Reykjavik Study between 2002 and 2006. First, self-reported mobility limitation was assessed. Mobility limitation was defined as a report of any difficulty walking 500 meters or climbing 10 steps. This definition has been used as an outcome in other studies of aging and is related to morbidity and mortality. ${ }^{16}$ We also examined performance measures of function. Two six meter walking tests were performed to measure normal walking speed. Average walking time was then calculated and divided by the distance $(6 \mathrm{~m})$ to obtain the normal walking speed in meters per second $(\mathrm{m} / \mathrm{s}) .{ }^{17}$ We also examined self-reported depressed mood. This was measured using the 15 -item version of the Geriatric Depression Scale (GDS) translated into Icelandic. ${ }^{18,19}$ A score of five or higher was used to indicate depressive symptoms. ${ }^{20}$ 


\section{Socioeconomic status}

Two traditional measures of SES were included in the Reykjavik Study questionnaire. Educational level was defined as the highest level of completed education among which primary school or less, secondary education, college education, and university education. Because of small numbers in the third and fourth categories, college and university levels were combined so that three categories remained for the analyses.

Current occupation at the time of midlife examination was categorised into four groups. The first group was designated as 'homemaker/miscellaneous'. For male participants, this group included persons identified as having jobs that did not fall into any other category, such as students. For female participants, this first group included homemakers only. The second group, 'manual', included mostly participants engaged in heavy manual work, for example dockworkers, fishermen, cement workers, and farm workers. Group three, 'service workers', consisted of participants engaged in light skilled crafts, clerical work and services, for example salesmen, postal clerks, typists, and nurses. Group four, 'professional', were participants engaged in non-physical work, such as directors, managers, teachers, doctors, and priests.

\section{Material factors}

We reviewed both the original Reykjavik Study questionnaire administered in midlife and the AGES-Reykjavik Study questionnaire from old age and identified all questions related to socioeconomic and material conditions during both the participants' early life and midlife.

The Reykjavik Study questionnaire included extensive information about the participant's housing. Housing quality was assessed in several ways: ownership of a house (tenant or owner), house type, apartment size, and house age. House type included living in an apartment, duplex (attached house), or freestanding house. Living space was calculated by dividing the apartment size, reported in square meters, by the number of inhabitants reported to live in it. Three categories were then created in such a way that each group contained approximately a third of the sample at baseline (i. e. $\leq 23,8 \mathrm{~m}^{2}, 23,9-35,0 \mathrm{~m}^{2}$, and $>35 \mathrm{~m}^{2}$ per inhabitant). House age also included three categories: house of 9 years or younger; house of between 10 and 19 years of age, or living in a house of 20 years or older.

Participants also were asked to indicate whether their home included: central heating, a water closet, a bathtub, a shower, piped cold water, and piped hot water. Three categories were then created: possession of all of these features, lack of 1 feature, or lack of 2 or more features. For the logistic and linear regression analyses, however, group two and three were combined due to small numbers in the last category. We defined a separate variable for car ownership based on a midlife question. 
Several questions were included in the Reykjavik Study questionnaire about working life, including normal working hours per week and extra hours of work. The total number of work-hours per week was calculated by summing these two responses. The sum score was divided into three categories: 15-40 hours per week, 41-55 hours per week, and 56-80 hours per week. ${ }^{21}$ Respondents also were asked to indicate how they spend most of their working time, which included three categories: sitting, standing or on the move.

Finally, from the questionnaire at the follow-up examinations we created two measures of the circumstances of young adulthood. First, respondents were asked if they had enough to eat when growing up (categorised as 'sometimes or often not enough to eat' versus 'mostly to often enough to eat'). Second, they were asked the type of place they lived as a teenager, i.e. farm, fishing village, small village, or city. Dummy variables were created for missing values on material factors.

\section{Covariates}

Covariates were derived from the baseline questionnaire and included sex, age at baseline (33-65 years), year of first examination at the IHA (1967-1996, to control for secular trends affecting SES and material factors in Iceland), marital status (currently single/currently together with a partner), and the number of prevalent chronic diseases (currently under doctor's care or diagnosed with one or more of the following diseases: diabetes, angina pectoris, disease of the heart valves, coronary thrombosis, another heart disease, disease of the lungs, disease of the kidneys, disease of the thyroid, disease of the stomach/intestines, arthritis, glaucoma, cancer, asthma or COPD, and tuberculosis).

\section{Statistical analyses}

All analyses were performed using SPSS version 15.0. and were stratified by gender (because of gender differences in the occupational coding). First, differences in main characteristics between men and women were determined using chi-square tests for categorical variables and t-test statistics for continuous variables. Second, logistic regression analyses were performed to study whether measures of SES and material factors, i.e. housing quality and features, working circumstances and circumstances during earlier stages of life, were independently related to mobility limitation and depressed mood almost three decades later. The first model was adjusted for age at baseline, year of first examination, marital status and the number of chronic diseases as an indicator of predisposition to later disability. The second model was additionally adjusted for all material factors or for education and occupation for the analyses that examined relations between classic SES measures and health-related function and between material factors and health-related function, respectively. 
Third, linear regression analyses were performed to study the relations between measures of SES and material factors and normal walking speed. Similar models as described above were used. For all analyses, the most favorable socio-economic position was used as a reference category. Finally, interactions between all relevant variables were tested and analyses were performed for different subgroups and cut off points to guarantee robustness of findings.

\section{RESULTS}

The characteristics of the analysis sample are presented in Table 1. Level of education was significantly higher in men compared with women $(p<0.001)$. Seventy-four percent of women reported themselves as homemakers at the time of first examination and $38 \%$ of men were engaged in heavy manual jobs. Women were more likely than men to live in an apartment, to live in houses older than 20 years of age and to report that they did not own a car $(p<0.001)$. Women were more likely to estimate their workweeks between 60 and 80 hours $(p<0.001)$. Particularly the women who reported their primary occupation as homemakers, reported extra work (66\%, data not shown). Finally, women were also more likely to report any mobility limitation and to have lower walking speeds $(p<0.001)$.

Table 2 presents the adjusted odds ratios (OR) of mobility limitation by indicators of the classic SES measures as well as for material factors. Men and women with primary or secondary education had greater risk of mobility limitation in old age compared with these with college and university education. This effect remained significant even when adjusted for all material factors. Occupation was a significant predictor of mobility limitation in men; men engaged in heavy manual work had the highest risks of mobility limitation, even when adjusted for all material factors (OR=1.53; 95\% Confidence Interval ( $\mathrm{Cl})$ : 1.17-2.00).

Several material factors were also independently related to mobility limitation in old age. Lack of ownership of a car or house were significant predictors of mobility limitation for men, even when adjusted for education and occupation. Growing up in a fishing village was protective for mobility limitation in old age, even after adjustment for education and occupation (OR=0.71; 95\% $\mathrm{Cl}$ : 0.53-0.96). For women, the lack of one or more of the housing features, and not having enough to eat when growing up were significant predictors of mobility limitation in old age. These relations remained significant when additionally adjusted for education and occupation in model 2. 
Table 1 Characteristics of the analysis sample, Reykjavik Study (1967-1992) and Age, Gene/Environment Susceptibility Study (2002-2006), Reykjavik, Iceland

\begin{tabular}{|c|c|c|c|}
\hline & $\begin{array}{c}\text { Men } \\
(n=2068)\end{array}$ & $\begin{array}{l}\text { Women } \\
(n=2741)\end{array}$ & P-value $^{a}$ \\
\hline Age, Mean (SD) & $46.7(6.8)$ & $48.1(7.2)$ & $<0.001$ \\
\hline Follow-up, Mean (SD) & $29.8(5.0)$ & $28.1(5.9)$ & $<0.001^{b}$ \\
\hline$\geq 1$ chronic diseases $^{\mathrm{c}}(\%)$ & 29.7 & 25.1 & $<0.001$ \\
\hline Married/living together (\%) & 89.9 & 83.8 & $<0.001$ \\
\hline \multicolumn{4}{|c|}{ Classic SES measures (Reykjavik Study) } \\
\hline \multicolumn{4}{|l|}{ Education (\%) } \\
\hline Primary & 22.1 & 41.8 & $<0.001$ \\
\hline Secondary & 51.0 & 46.6 & \\
\hline College/University & 26.9 & 11.6 & \\
\hline \multicolumn{4}{|l|}{ Occupation (\%) } \\
\hline Homemaker/miscellaneous & 4.2 & 74.1 & $<0.001$ \\
\hline Manual & 38.2 & 3.7 & \\
\hline Service & 30.6 & 17.3 & \\
\hline Professional & 27.1 & 4.9 & \\
\hline \multicolumn{4}{|c|}{ Housing measures (Reykjavik Study) } \\
\hline Did not own house (\%) & 10.8 & 11.1 & 0.807 \\
\hline \multicolumn{4}{|l|}{ House type (\%) } \\
\hline Apartment & 39.7 & 44.7 & 0.001 \\
\hline Attached house & 21.9 & 18.8 & \\
\hline Stand alone house & 34.5 & 31.9 & \\
\hline \multicolumn{4}{|l|}{ Housing space/inhabitants (\%) } \\
\hline $0-23.8 \mathrm{~m}^{2}$ & 39.3 & 31.8 & $<0.001$ \\
\hline $23.9-35.0 \mathrm{~m}^{2}$ & 30.1 & 27.5 & \\
\hline$>35.0 \mathrm{~m}^{2}$ & 26.6 & 34.7 & \\
\hline \multicolumn{4}{|l|}{ House age (\%) } \\
\hline$\geq 20$ years & 27.9 & 38.3 & $<0.001$ \\
\hline $10-19$ years & 33.8 & 33.7 & \\
\hline $0-9$ years & 36.9 & 26.0 & \\
\hline \multicolumn{4}{|l|}{ Assets (Reykjavik Study) } \\
\hline \multicolumn{4}{|l|}{ Housing features $^{d}(\%)$} \\
\hline Lack of 2-6 features & 3.7 & 2.9 & 0.265 \\
\hline Lack of 1 feature & 44.3 & 45.7 & \\
\hline Possesses all features & 52.0 & 51.4 & \\
\hline Did not personally own car (\%) & 13.1 & 30.2 & $<0.001$ \\
\hline
\end{tabular}




\begin{tabular}{|c|c|c|c|}
\hline & $\begin{array}{c}\text { Men } \\
(n=2068)\end{array}$ & $\begin{array}{l}\text { Women } \\
(n=2741)\end{array}$ & P-value ${ }^{a}$ \\
\hline \multicolumn{4}{|c|}{ Working conditions (Reykjavik Study) } \\
\hline \multicolumn{4}{|l|}{ Workweek $^{\mathrm{e}}$} \\
\hline $56-80 \mathrm{hrs} / \mathrm{wk}$ & 19.3 & 49.4 & $<0.001$ \\
\hline $41-55 \mathrm{hrs} / \mathrm{wk}$ & 71.6 & 39.5 & \\
\hline $15-40 \mathrm{hrs} / \mathrm{wk}$ & 7.6 & 6.8 & \\
\hline \multicolumn{4}{|l|}{ Spends work (\%) } \\
\hline On the move & 41.6 & 78.0 & $<0.001$ \\
\hline Standing & 14.4 & 3.6 & \\
\hline Sitting & 40.9 & 13.9 & \\
\hline \multicolumn{4}{|c|}{ Early life circumstances (from AGES-Reykjavik) } \\
\hline Not enough to eat (\%) & 5.2 & 2.8 & $<0.001$ \\
\hline \multicolumn{4}{|l|}{ Where live as a teenager (\%) } \\
\hline Farm & 29.5 & 28.7 & 0.516 \\
\hline Fishing village & 17.4 & 17.2 & \\
\hline Village & 14.4 & 13.1 & \\
\hline City & 38.3 & 40.6 & \\
\hline \multicolumn{4}{|l|}{ Outcomes (from AGES-Reykjavik) } \\
\hline Mobility limitation ${ }^{f}(\%)$ & 26.8 & 39.5 & $<0.001$ \\
\hline Indication of depressed mood (\%) & 11.0 & 12.8 & 0.058 \\
\hline Walking speed (m/s), Mean (SD) & $0.97(0.2)$ & $0.91(0.2)$ & $<0.001$ \\
\hline
\end{tabular}

${ }^{a}$ Based on Chi-square tests for categorical variables and t-tests for continuous variables; ${ }^{b}$ This difference reflects the fact that women were recruited later; ${ }^{c}$ Number of the following diseases at baseline: Diabetes, angina pectoris, disease of the heart valves, coronary thrombosis, another heart disease, disease of the lungs, disease of the kidneys, disease of the thyroid, disease of the stomach/intestines, arthritis, glaucoma, cancer, asthma or COPD, and tuberculosis; ${ }^{d}$ Housing features included: central heating, water closet, bathtub, shower, piped cold water, and piped hot water; ${ }^{~}$ Working hours were determined by summing up normal working hours and extra working hours per week; ${ }^{f}$ Mobility limitation was considered to be present when a person reported any difficulty walking 500 meters or climbing 10 steps.

\section{Legend to Table 2}

adjusted for age at baseline, year of first examination, marital status, and number of chronic diseases;

${ }^{\mathrm{b}}$ Additionally adjusted for material factors (as under housing quality, assets, working circumstances, and early life circumstances), or education and occupation, depending on variable of interest (education and occupation are adjusted for material factors, all other variables are adjusted for education and occupation). 
Table 2 Adjusted Odds Ratios (OR) of mobility limitation by indicators of SES and material factors

\begin{tabular}{|c|c|c|c|c|c|c|c|c|}
\hline & \multicolumn{4}{|c|}{$\operatorname{Men}(n=2068)$} & \multicolumn{4}{|c|}{ Women $(n=2741)$} \\
\hline & \multicolumn{2}{|c|}{ Model $1^{\mathrm{a}}$} & \multicolumn{2}{|c|}{ Model $2^{b}$} & \multicolumn{2}{|c|}{ Model 1} & \multicolumn{2}{|r|}{ Model 2} \\
\hline & OR & $95 \% \mathrm{Cl}$ & OR & $95 \% \mathrm{Cl}$ & OR & $95 \% \mathrm{Cl}$ & OR & $95 \% \mathrm{Cl}$ \\
\hline \multicolumn{9}{|l|}{ Classic SES measures } \\
\hline \multicolumn{9}{|l|}{ Education } \\
\hline Primary & 1.68 & $1.26,2.25$ & 1.55 & $1.15,2.10$ & 1.51 & $1.15,1.97$ & 1.41 & $1.08,1.86$ \\
\hline Secondary & 1.58 & $1.23,2.03$ & 1.57 & $1.22,2.02$ & 1.31 & $1.01,1.71$ & 1.29 & $0.99,1.68$ \\
\hline College/University & Ref. & & Ref. & & Ref. & & Ref. & \\
\hline \multicolumn{9}{|l|}{ Occupation } \\
\hline Homemaker/Misc. & 1.36 & $0.81,2.28$ & 1.34 & $0.79,2.27$ & 1.07 & $0.74,1.59$ & 1.03 & $0.71,1.49$ \\
\hline Manual & 1.63 & $1.26,2.11$ & 1.53 & $1.17,2.00$ & 1.66 & $0.97,2.82$ & 1.51 & $0.88,2.60$ \\
\hline Services & 1.48 & $1.13,1.95$ & 1.43 & $1.09,1.89$ & 1.03 & $0.69,1.55$ & 0.97 & $0.65,1.46$ \\
\hline Professional & Ref. & & Ref. & & Ref. & & Ref. & \\
\hline \multicolumn{9}{|l|}{ Housing measures } \\
\hline Did not own house & 1.46 & $1.07,1.99$ & 1.42 & $1.04,1.93$ & 1.14 & $0.89,1.47$ & 1.10 & $0.85,1.42$ \\
\hline \multicolumn{9}{|l|}{ House type } \\
\hline Apartment & 1.24 & $0.99,1.56$ & 1.20 & $0.95,1.51$ & 1.00 & $0.83,1.20$ & 0.97 & $0.81,1.17$ \\
\hline Attached & 0.97 & $0.74,1.28$ & 0.98 & $0.74,1.29$ & 0.80 & $0.63,1.00$ & 0.80 & $0.64,1.01$ \\
\hline Stand alone & Ref. & & Ref. & & Ref. & & Ref. & \\
\hline \multicolumn{9}{|l|}{ Housing space } \\
\hline $0-23.8 \mathrm{~m}^{2}$ & 1.01 & $0.76,1.33$ & 0.90 & $0.67,1.19$ & 1.05 & $0.84,1.31$ & 1.00 & $0.80,1.26$ \\
\hline $23.9-35.0 \mathrm{~m}^{2}$ & 1.08 & $0.82,1.42$ & 1.03 & $0.79,1.36$ & 0.96 & $0.78,1.19$ & 0.95 & $0.77,1.17$ \\
\hline$>35.0 \mathrm{~m}^{2}$ & Ref. & & Ref. & & Ref. & & Ref. & \\
\hline \multicolumn{9}{|l|}{ House age } \\
\hline$\geq 20$ years & 1.13 & $0.87,1.46$ & 1.10 & $0.84,1.42$ & 1.09 & $0.87,1.35$ & 1.08 & $0.87,1.35$ \\
\hline $10-19$ years & 0.73 & $0.57,0.93$ & 0.72 & $0.57,0.93$ & 0.90 & $0.73,1.11$ & 0.91 & $0.73,1.12$ \\
\hline $0-9$ years & Ref. & & Ref. & & Ref. & & Ref. & \\
\hline \multicolumn{9}{|l|}{ Assets } \\
\hline Lack of $\geq 1$ features & 1.23 & $1.01,1.51$ & 1.14 & $0.93,1.40$ & 1.27 & $1.08,1.49$ & 1.22 & $1.04,1.44$ \\
\hline Did not own car & 1.58 & $1.20,2.09$ & 1.48 & $1.12,1.97$ & 1.20 & $1.01,1.43$ & 1.17 & $0.98,1.39$ \\
\hline \multicolumn{9}{|l|}{ Working conditions } \\
\hline \multicolumn{9}{|l|}{ Workweek } \\
\hline $56-80 \mathrm{hrs} / \mathrm{wk}$ & 0.83 & $0.55,1.27$ & 0.76 & $0.49,1.16$ & 0.79 & $0.58,1.09$ & 0.79 & $0.57,1.09$ \\
\hline $41-55 \mathrm{hrs} / \mathrm{wk}$ & 0.90 & $0.62,1.30$ & 0.79 & $0.54,1.15$ & 0.87 & $0.63,1.21$ & 0.86 & $0.62,1.20$ \\
\hline $15-40 \mathrm{hrs} / \mathrm{wk}$ & Ref. & & Ref. & & Ref. & & Ref. & \\
\hline \multicolumn{9}{|l|}{ Spends work } \\
\hline On the move & 1.19 & $0.95,1.48$ & 1.00 & $0.79,1.27$ & 1.17 & $0.93,1.48$ & 1.17 & $0.90,1.52$ \\
\hline Standing & 1.14 & $0.84,1.55$ & 1.02 & $0.74,1.39$ & 1.10 & $0.69,1.74$ & 1.08 & $0.68,1.73$ \\
\hline Sitting & Ref. & & Ref. & & Ref. & & Ref. & \\
\hline \multicolumn{9}{|c|}{ Early life circumstances } \\
\hline Not enough to eat & 1.11 & $0.72,1.70$ & 1.03 & $0.66,1.58$ & 1.95 & $1.22,3.12$ & 1.86 & $1.16,2.98$ \\
\hline \multicolumn{9}{|l|}{ Lived as a teenager } \\
\hline Farm & 0.99 & $0.78,1.26$ & 0.93 & $0.73,1.19$ & 0.91 & $0.75,1.10$ & 0.87 & $0.72,1.06$ \\
\hline Fishing village & 0.74 & $0.55,0.99$ & 0.71 & $0.53,0.96$ & 1.05 & $0.84,1.32$ & 1.01 & $0.80,1.27$ \\
\hline Village & 0.96 & $0.71,1.30$ & 0.95 & $0.70,1.30$ & 1.14 & $0.89,1.47$ & 1.12 & $0.87,1.43$ \\
\hline City & Ref. & & Ref. & & Ref. & & Ref. & \\
\hline
\end{tabular}


Table 3 presents the relations between indicators of SES and material factors and normal walking speed. Again, the classic SES measures were related to walking speed in old age. Having followed only primary education and performing heavy manual jobs was significantly related to walking speed in both men and women, even when adjusted for all material factors. Living in a house of 20 years or older and lacking ownership of a car were significant predictors of lower walking speed in old age for both men and women. For women, not owning a house, living in an apartment, and lacking one or more of the housing features were also significant predictors of lower walking speed in old age when adjusted for education and occupation. Growing up in a farm or fishing village were significant predictors of higher walking speed in women.

Table 4 presents the relations between indicators of SES and material factors and depressed mood. Educational level was a significant predictor of depressed mood, for both men and women, even when adjusted for all material factors. In men, doing heavy manual labor or having a job classified as "miscellaneous" was a significant predictor of depressed mood compared with men who reported being professionals. Of the material factors, the apartment size and house age were found to be significant predictors of depressed mood in men. For women, the lack of home or car ownership were significantly related to depressed mood, also when adjusted for education and occupation.

Additional adjustment for behavioural factors (i.e. BMI, physical activity and smoking status), did not significantly change the results (data not shown). While the odds ratios for younger men (according to date of birth, independent of year of first examination) were slightly higher compared with those of older men, no interaction terms were significant.

\section{Legend to Table 3}

${ }^{*} \mathrm{p}<0.05$; ** $\mathrm{p}<0.010 ;{ }^{* *} \mathrm{p}<0.001$; $^{\text {a }}$ Adjusted for age at baseline, year of first examination, marital status, and number of chronic diseases; ${ }^{b}$ Additionally adjusted for material factors (as under housing quality, assets, working circumstances, and early life circumstances), or education and occupation, depending on variable of interest (education and occupation are adjusted for material factors, all other variables are adjusted for education and occupation).

\section{Legend to Table 4}

${ }^{a}$ Adjusted for age at baseline, year of first examination, marital status, and number of chronic diseases; ${ }^{b}$ Additionally adjusted for material factors (as under housing quality, assets, working circumstances, and early life circumstances) or education and occupation, depending on variable of interest (education and occupation are adjusted for material factors, all other variables are adjusted for education and occupation). 
Table 3 Regression coefficients (with SE) of normal walking speed $(\mathrm{m} / \mathrm{s}$ ) by indicators of SES and material factors

\begin{tabular}{|c|c|c|c|c|}
\hline & \multicolumn{2}{|c|}{ Men $(n=2068)$} & \multicolumn{2}{|c|}{ Women $(n=2741)$} \\
\hline & Model $1^{a}$ Beta (SE) & Model $2^{\mathrm{b}}$ Beta (SE) & Model 1 Beta (SE) & Model 2 Beta (SE) \\
\hline \multicolumn{5}{|l|}{ Classic SES measures } \\
\hline \multicolumn{5}{|l|}{ Education } \\
\hline Primary & $-0.105(0.012)^{* * *}$ & $-0.092(0.012)^{* * *}$ & $-0.115(0.012)^{* * *}$ & $-0.095(0.012)^{* *}$ \\
\hline Secondary & $-0.081(0.010)^{* *}$ & $-0.074(0.010)^{* *}$ & $-0.052(0.012)$ & $-0.047(0.012)$ \\
\hline College/University & Ref. & Ref. & Ref. & Ref. \\
\hline \multicolumn{5}{|l|}{ Occupation } \\
\hline Homemaker/Misc. & $-0.046(0.022)^{*}$ & $-0.042(0.022)$ & $-0.032(0.017)$ & $-0.022(0.017)$ \\
\hline Manual & $-0.117(0.011)^{* * *}$ & $-0.103(0.011)^{* * *}$ & $-0.065(0.024)^{* *}$ & $-0.051(0.025)^{*}$ \\
\hline Services & $-0.059(0.011)^{*}$ & $-0.049(0.011)$ & $-0.014(0.018)$ & $0.005(0.018)$ \\
\hline Professional & Ref. & Ref. & Ref. & Ref. \\
\hline \multicolumn{5}{|l|}{ Housing measures } \\
\hline Did not own house & $-0.014(0.014)$ & $-0.008(0.014)$ & $-0.051(0.011)^{* *}$ & $-0.045(0.012)^{*}$ \\
\hline \multicolumn{5}{|l|}{ House type } \\
\hline Apartment & $-0.030(0.010)$ & $-0.021(0.010)$ & $-0.063(0.008)^{* *}$ & $-0.056(0.008)^{* *}$ \\
\hline Attached & $-0.027(0.011)$ & $-0.029(0.011)$ & $-0.005(0.010)$ & $-0.007(0.010)$ \\
\hline Stand alone & Ref. & Ref. & Ref. & Ref. \\
\hline \multicolumn{5}{|l|}{ Housing space } \\
\hline $0-23.8 \mathrm{~m}^{2}$ & $-0.009(0.012)$ & $0.021(0.012)$ & $-0.030(0.010)$ & $-0.014(0.010)$ \\
\hline $23.9-35.0 \mathrm{~m}^{2}$ & $-0.018(0.012)$ & $-0.007(0.012)$ & $-0.010(0.010)$ & $-0.004(0.010)$ \\
\hline$>35.0 \mathrm{~m}^{2}$ & Ref. & Ref. & Ref. & Ref. \\
\hline \multicolumn{5}{|l|}{ House age } \\
\hline$\geq 20$ years & $-0.084(0.011)^{* *}$ & $-0.077(0.011)^{* *}$ & $-0.085\left(0.010^{* * *}\right.$ & $-0.085(0.010)^{* * *}$ \\
\hline $10-19$ years & $-0.007(0.010)$ & $-0.006(0.010)$ & $-0.001(0.010)$ & $-0.005(0.009)$ \\
\hline $0-9$ years & Ref. & Ref. & Ref. & Ref. \\
\hline \multicolumn{5}{|l|}{ Assets } \\
\hline Lack of $\geq 1$ features & $-0.061(0.008)^{* *}$ & $-0.039(0.009)$ & $-0.069(0.007)^{* * *}$ & $-0.057(0.007)^{* *}$ \\
\hline Did not own car & $-0.060(0.013)^{* *}$ & $-0.048(0.013)^{*}$ & $-0.064(0.008)^{* * *}$ & $-0.056(0.008)^{* *}$ \\
\hline \multicolumn{5}{|l|}{ Working conditions } \\
\hline \multicolumn{5}{|l|}{ Workweek } \\
\hline $56-80 \mathrm{hrs} / \mathrm{wk}$ & $0.050(0.018)$ & $0.070(0.018)$ & $-0.004(0.015)$ & $-0.002(0.015)$ \\
\hline $41-55 \mathrm{hrs} / \mathrm{wk}$ & $-0.007(0.016)$ & $0.022(0.016)$ & $-0.034(0.015)$ & $-0.029(0.015)$ \\
\hline $15-40 \mathrm{hrs} / \mathrm{wk}$ & Ref. & Ref. & Ref. & Ref. \\
\hline \multicolumn{5}{|l|}{ Spends work } \\
\hline On the move & $-0.034(0.009)$ & $0.013(0.010)$ & $-0.029(0.010)$ & $-0.017(0.012)$ \\
\hline Standing & $-0.035(0.013)$ & $-0.012(0.013)$ & $-0.024(0.021)$ & $-0.020(0.021)$ \\
\hline Sitting & Ref. & Ref. & Ref. & Ref. \\
\hline \multicolumn{5}{|c|}{ Early life circumstances } \\
\hline Not enough to eat & $-0.004(0.019)$ & $0.004(0.019)$ & $-0.020(0.022)$ & $-0.014(0.022)$ \\
\hline \multicolumn{5}{|l|}{ Lived as a teenager } \\
\hline Farm & $-0.011(0.010)$ & $0.007(0.010)$ & $0.026(0.009)$ & $0.039(0.009)^{*}$ \\
\hline Fishing village & $0.034(0.012)$ & $0.043(0.012)$ & $0.031(0.010)$ & $0.041(0.010)^{*}$ \\
\hline Village & $-0.003(0.013)$ & $-0.002(0.013)$ & $0.007(0.011)$ & $0.012(0.011)$ \\
\hline City & Ref. & Ref. & Ref. & Ref. \\
\hline
\end{tabular}


Table 4 Adjusted Odds Ratios (OR) of depressed mood by indicators of SES and material factors

\begin{tabular}{|c|c|c|c|c|c|c|c|c|}
\hline & \multicolumn{4}{|c|}{ Men $(n=2068)$} & \multicolumn{4}{|c|}{ Women $(n=2741)$} \\
\hline & \multicolumn{2}{|c|}{ Model $1^{\mathrm{a}}$} & \multicolumn{2}{|c|}{ Model $2^{b}$} & \multicolumn{2}{|c|}{ Model 1} & \multicolumn{2}{|c|}{ Model 2} \\
\hline & OR & $95 \% \mathrm{Cl}$ & OR & $95 \% \mathrm{Cl}$ & OR & $95 \% \mathrm{Cl}$ & OR & $95 \% \mathrm{Cl}$ \\
\hline \multicolumn{9}{|l|}{ Classic SES measures } \\
\hline \multicolumn{9}{|l|}{ Education } \\
\hline Primary & 2.15 & $1.42,3.26$ & 2.06 & $1.34,3.15$ & 2.11 & $1.34,3.34$ & 2.02 & $1.27,3.21$ \\
\hline Secondary & 1.68 & $1.15,2.45$ & 1.64 & $1.12,2.40$ & 1.83 & $1.16,2.89$ & 1.82 & $1.15,2.89$ \\
\hline College/University & Ref. & & Ref. & & Ref. & & Ref. & \\
\hline \multicolumn{9}{|l|}{ Occupation } \\
\hline Homemaker/Misc. & 2.33 & $1.24,4.37$ & 2.37 & $1.23,4.54$ & 1.41 & $0.78,2.54$ & 1.38 & $0.76,2.49$ \\
\hline Manual & 1.94 & $1.34,2.80$ & 1.83 & $1.25,2.69$ & 1.90 & $0.87,4.13$ & 1.60 & $0.73,3.53$ \\
\hline Services & 1.13 & $0.75,1.71$ & 1.09 & $0.72,1.66$ & 1.52 & $0.81,2.86$ & 1.39 & $0.73,2.63$ \\
\hline Professional & Ref. & & Ref. & & Ref. & & Ref. & \\
\hline \multicolumn{9}{|l|}{ Housing measures } \\
\hline Did not own house & 0.93 & $0.58,1.50$ & 0.88 & $0.54,1.42$ & 1.47 & $1.06,2.05$ & 1.40 & $1.00,1.96$ \\
\hline \multicolumn{9}{|l|}{ House type } \\
\hline Apartment & 1.09 & $0.79,1.50$ & 1.02 & $0.74,1.40$ & 1.10 & $0.85,1.42$ & 1.06 & $0.82,1.38$ \\
\hline Attached & 0.81 & $0.55,1.21$ & 0.82 & $0.55,1.22$ & 0.78 & $0.55,1.10$ & 0.79 & $0.55,1.12$ \\
\hline Stand alone & Ref. & & Ref. & & Ref. & & Ref. & \\
\hline \multicolumn{9}{|l|}{ Housing space } \\
\hline $0-23.8 \mathrm{~m}^{2}$ & 1.51 & $1.00,2.27$ & 1.26 & $0.83,1.91$ & 0.82 & $0.59,1.13$ & 0.75 & $0.54,1.05$ \\
\hline $23.9-35.0 \mathrm{~m}^{2}$ & 1.65 & $1.12,2.45$ & 1.54 & $1.04,2.29$ & 0.98 & $0.73,1.32$ & 0.95 & $0.71,1.28$ \\
\hline$>35.0 \mathrm{~m}^{2}$ & Ref. & & Ref. & & Ref. & & Ref. & \\
\hline \multicolumn{9}{|l|}{ House age } \\
\hline$\geq 20$ years & 1.78 & $1.24,2.15$ & 1.70 & $1.19,2.44$ & 1.00 & $0.73,1.76$ & 0.99 & $0.73,1.36$ \\
\hline $10-19$ years & 1.01 & $0.71,1.45$ & 1.01 & $0.70,1.45$ & 0.85 & $0.62,1.16$ & 0.87 & $0.81,1.18$ \\
\hline $0-9$ years & Ref. & & Ref. & & Ref. & & Ref. & \\
\hline \multicolumn{9}{|l|}{ Assets } \\
\hline Lack of $\geq 1$ features & 1.15 & $0.87,1.52$ & 0.99 & $0.74,1.32$ & 1.20 & $0.95,1.52$ & 1.13 & $0.89,1.42$ \\
\hline Did not own car & 1.53 & $1.05,2.23$ & 1.37 & $0.93,2.00$ & 1.43 & $1.13,1.82$ & 1.37 & $1.07,1.74$ \\
\hline \multicolumn{9}{|l|}{ Working conditions } \\
\hline \multicolumn{9}{|l|}{ Workweek } \\
\hline $56-80 \mathrm{hrs} / \mathrm{wk}$ & 0.71 & $0.39,1.32$ & 0.61 & $0.33,1.14$ & 0.91 & $0.60,1.41$ & 0.90 & $0.59,1.39$ \\
\hline $41-55 \mathrm{hrs} / \mathrm{wk}$ & 1.02 & $0.61,1.69$ & 0.83 & $0.49,1.40$ & 0.73 & $0.47,1.15$ & 0.71 & $0.45,1.12$ \\
\hline $15-40 \mathrm{hrs} / \mathrm{wk}$ & Ref. & & Ref. & & Ref. & & Ref. & \\
\hline \multicolumn{9}{|l|}{ Spends work } \\
\hline On the move & 1.29 & $0.94,1.76$ & 0.98 & $0.70,1.37$ & 0.93 & $0.67,1.28$ & 0.84 & $0.58,1.21$ \\
\hline Standing & 1.45 & $0.96,2.19$ & 1.19 & $0.78,1.82$ & 1.02 & $0.54,1.93$ & 0.96 & $0.50,1.83$ \\
\hline Sitting & Ref. & & Ref. & & Ref. & & Ref. & \\
\hline \multicolumn{9}{|c|}{ Early life circumstances } \\
\hline Not enough to eat & 1.77 & $1.06,2.95$ & 1.60 & $0.95,2.68$ & 1.74 & $0.99,3.08$ & 1.62 & $0.91,2.86$ \\
\hline \multicolumn{9}{|l|}{ Lived as a teenager } \\
\hline Farm & 1.44 & $1.02,2.02$ & 1.29 & $0.91,1.83$ & 0.98 & $0.74,1.31$ & 0.93 & $0.70,1.23$ \\
\hline Fishing village & 1.45 & $0.98,2.15$ & 1.36 & $0.91,2.03$ & 1.18 & $0.86,1.62$ & 1.11 & $0.80,1.53$ \\
\hline Village & 0.99 & $0.62,1.58$ & 0.99 & $0.62,1.58$ & 1.27 & $0.89,1.79$ & 1.23 & $0.87,1.74$ \\
\hline City & Ref. & & Ref. & & Ref. & & Ref. & \\
\hline
\end{tabular}




\section{DISCUSSION}

We were able to examine data from a cohort of 4,809 men and women with an average of 29 years of follow-up. Men and women from low educational and occupational levels had the highest risk of mobility limitation, low walking speed and depressed mood almost three decades later. Although not all material factors were consistently related to all outcome measures in both sexes, some measures, such as home or car ownership, age of housing, home features, and report of not having enough to eat when growing up, turned out to be important determinants related to dysfunction in old age, independent of the classic measures of SES.

Our results suggest that for an older population material factors might be an additional predictor of health-related dysfunction. Instead of looking at material factors as a mediator between SES and health, they might be considered as a toxic component of a person's social status itself. This may be due to their cumulative character, indicating economic advantage and disadvantage amassed over the course of a lifetime. ${ }^{4}$ Living in poor material conditions or with a lack of resources may have a direct, biological effect on physical health. ${ }^{22}$ However, psychological pathways cannot be excluded either. Taking into account the emotional distress and increased stress levels accompanying the hard physical circumstances in which people lived, both mental and physical dysfunction might become compromised as well. $^{23-25}$ The life course perspective on health argues that not only exposures during adulthood, but in early life as well, are important for health in old age. ${ }^{26,27}$ In our study, recall of not having enough food in childhood emerged as a predictor of mobility limitations in old age. This issue also speaks to the historical, social context of the study. Iceland nowadays is a progressive Nordic country and in 2007, the country was ranked as the most developed country in the world. ${ }^{28}$ Iceland currently has a relatively equal distribution of income and assets, as assessed by the Gini Coefficient. ${ }^{28,29}$ Moreover, Iceland's health and life expectancy is considered to be one of the best in the world. ${ }^{30,31}$ However, during the youth of the participants in this study - a time where physical labor in accomplishing chores of daily life such as cleaning, washing clothes, or getting to and from school and work was common - , part of the population in Iceland, as much of Europe and Scandinavia, experienced inadequate material standards of living, but were on the verge of accelerated economic progress. $^{32}$

Not all material factors in our study were consistent predictors of health-related dysfunction among both men and women. For example, variables on working circumstances do not carry any predictive power in neither men nor women. Other variables, such as living in an apartment, housing features and early life circumstances, only predict dysfunction in women but not in men. Inferences about sex differences in socioeconomic inequality in health-related functioning are, however, difficult to make. Neither is it possible to choose a sex-specific measure that cap- 
tures material circumstances over the life course. From a public health perspective, more research on this issue is needed to help develop adequate environmental interventions to tackle health problems in older men and women.

\section{Strengths and limitations}

The strengths of this study include a long follow-up period and the possibility to study the influence of both early life and midlife material circumstances. Combining these data with the old age functional data allowed for extensive longitudinal analyses to better characterize social gradients in health across the major part of the persons' life course.

However, several methodological limitations may affect the interpretation of the results of this study. First, because of a lack of measures on physical dysfunction and depressed mood at the baseline measurements, we were not able to exclude persons with prevalent physical dysfunction and depressed mood at the start of the follow up period. This may have distorted the measurement of dysfunction cases. All analyses were, however, instead adjusted for the prevalence of chronic diseases at baseline. In addition, material factors and covariates were also assessed only at baseline. These indicators could have easily changed during the time of follow-up. It is, however, unclear how these changes might have affected the results of our study.

Second, our study relied, for a large part, on self-reports which might have introduced measurement error for the physical dysfunction and depressed mood measures. $^{33}$ Individuals with a general tendency towards negative perceptions of well-being may also over-report symptoms of health-related dysfunction (i.e. negative affectivity). ${ }^{34,35}$ This may have led to an overestimation of the presented associations, although control for self-reported disease might have attenuated this potential bias.

Third, results with regard to women's social class have to be interpreted with caution. Seventy-four percent of women identified themselves as being a homemaker. However, it is very likely that these women also had part-time jobs in, for example, the fisheries, cleaning, laundry, or childcare. No measures of their husband's social class were available and the study did not specifically enroll spouse pairs. Moreover, for women, a variable like car ownership might not have any meaning in the context of this study. Additional research on women's social class and health-related function is thus recommended.

Fourth, the baseline measurement of our study took place over a period of more than 20 years time (between 1967 and 1996), with the oldest and youngest person born in 1910 and 1936, respectively. Because over this period the social significance of the same educational or occupational level and material factors may have changed markedly, interactions with all predictor variables and year of first 
examination were tested. Corresponding interaction terms were not significant. However, to counteract possible bias because of the temporal trends occurring during the study period, the year of first examination and the age at first examination was adjusted for in our logistic and linear regression analyses. ${ }^{13}$

Furthermore, our research may be limited by potential selection biases. The most disadvantaged persons may be underrepresented in our research, because of premature mortality (the 'healthy survivor' effect). Follow up analyses showed that persons from low SES were more likely to die prematurely. ${ }^{13}$ This pattern of selective response and attrition may have led to an underestimation of the reported relations.

\section{CONCLUSION}

In this older cohort, traditional measures of SES as well as early life and midlife material factors are independently related to self-reported mobility limitation, depressed mood, and objectively assessed walking speed over a period of, on average, 29 years of follow-up in both men and women. These findings support the hypotheses that - in the context of socioeconomic health differences in middle-aged and older persons - varying material factors from both midlife and early life may provide independent predictive power. From a public health perspective, information on the importance of material factors across the life course might provide starting points for future intervention research in order to reduce existing socioeconomic differences in health in both men and women.

\section{Acknowledgements}

The Age, Gene/Environment Susceptibility Reykjavik Study is funded by NIH contract N01-AG-12100, the NIA Intramural Research Program, Hjartavernd (the Icelandic Heart Association), and the Althingi (the Icelandic Parliament).

The researchers are indebted to the participants for their willingness to participate in the study. 


\section{REFERENCES}

1. Wilkinson RG, Marmot M. Social determinants of health: the solid facts. 2nd ed. Copenhagen: WHO; 2003.

2. Ferrie JE, Shipley MJ, Davey Smith G, Stansfeld S, Marmot M. Change in health inequalities among British civil servants: the Whitehall II study. J Epidemiol Community Health. 2002;56:922-6.

3. Galobardes B, Shaw M, Lawlor DA, Lynch JW, Davey Smith G. Indicators of socioeconomic position (part 1). J Epidemiol Community Health. 2006;60:7-12.

4. Pollack CE, Chideya S, Cubbin C, Williams B, Dekker M, Braveman PA. Should health studies measure wealth? A systematic review. Am J Prev Med. 2007;33(3):250-64.

5. Turrel G, Lynch JW, Leite C, Raghunathan T, Kaplan GA. Socioeconomic disadvantage in childhood and across the life course and all-cause mortality and physical function in adulthood: evidence from the Alameda County Study. J Epidemiol Community Health. 2007;61:723-30.

6. Lynch JW, Kaplan GA, Shema SJ. Cumulative impact of sustained economic hardship on physical, cognitive, psychological, and social functioning. N Engl J Med. 1997;1137:1889-95.

7. Groffen DAI, Bosma H, Akker van den M, Kempen GIJM, Eijk van JTM. Lack of basic and luxury goods and health-related dysfunction in older persons; Findings from the SMILE study. BMC Public Health. 2008;8:242.

8. Macintyre S, Ellaway A, Der G, Ford g, Hunt K. Do housing tenure and car access predict health because they are simply markers of income or self esteem? A Scottish study. J Epidemiol Community Health. 1998;52:657-64.

9. Pikhart H, Bobak M, Rose R, Marmot M. Household item ownership and self-rated health: material and psychosocial explanations. BMC Public Health. 2003;3(38).

10. Grundy $\mathrm{H}$, Holt $\mathrm{G}$. The socioeconomic status of older adults: how should we measure it in studies of health inequalities? J Epidemiol Community Health. 2001;55:895-904.

11. Rauh VA, Landrigan PJ, Claudio L. Housing and health: Intersection of poverty and environmental exposures. Ann N Y Acad Sci. 2008;1136(1):276-88.

12. Coughlin SS. Recall bias in epidemiologic studies. Journal of Clinical Epidemiology. 1990;43:87-91.

13. Hardarson T, Gardarsdottir M, Gudmundsson KT, Thorgeirsson G, Sigvaldason H, Sigfusson N. The relationship between educational level and mortality. The Reykjavik Study. J Int Med. 2001;249:495502.

14. Sigurdsson E, Thorgeirsson G, Sigvaldason H, Sigfusson N. Unrecognized myocardial infarction: epidemiology, clinical characteristics, and the prognostic role of angina pectoris. The Reykjavik Study. Ann Int Med. 1995;122:96-102.

15. Harris TB, Launer U, Eiriksdottir G, Kjartansson O, Johnsson PV, Sigurdsson G, et al. Age, Gene/Environment Susceptibility-Reykjavik study: Multidisciplinary applied phenomics. Am J Epidemiol. 2007;165(9):1076-87.

16. Koster A, Penninx BW, Bosma H, Kempen GIJM, Harris TB, Newman AB, et al. Is there a biomedical explanation for socioeconomic differences in incident mobility limitation? J Gerontol A Biol Sci Med Sci. 2005;60:1022-7.

17. Guralnik JM, Simonsick EM, Ferruci L, Glynn RJ, Berkman LF, Blazer DG, et al. A short physical performance battery assessing lower extremity function: association with self-reported disability and prediction of mortality and nursing home admission. J Gerontol. 1994;49(2):M85-94.

18. Sheikh JA, Yesavage JA. Geriatric Depression Scale (GDS): Recent findings and development of a shorter version. In: Brink TL, editor. Clinical Gerontology: A Guide to Assessment and Intervention. New York: Howarth Press; 1986.

19. Valdimarsdóttir M, Jónsson JE, Einarsdóttir S, Tómasson K. Validation of an Icelandic version of the Geriatric Depression Scale (GDS). Laeknabladid. 2000;86(5):344-8.

20. Almeida OP, Almeida SA. Short versions of the geriatric depression scale: a study of their validity for the diagnosis of a major depressive episode according to ICD-10 and DSM-IV. Int J Geriatr Psychiatry. 1999;14(10):858-65. 
21. Virtanen $M$, Singh-Manoux A, Ferrie JE, Gimeno D, Marmot MG, Elovainio $M$, et al. Long working hours and cognitive function; The Whitehall II Study. Am J Epidemiol. 2009;169(5):596-605.

22. Lynch JW, Davey Smith G, Kaplan GA, House JS. Income inequality and mortality: importance to health of individual income, psychosocial environment, or material conditions. $\mathrm{Br}$ Med J. 2000;320:1200-4.

23. Marmot MG, Wilkinson RG. Psychosocial and material pathways in the relation between income and health: a response to Lynch et al. Br Med J. 2001;322:1233-6.

24. Vetter S, Endrass J, Schweizer I, Teng HM, Rossler W, Gallo WT. The effects of economic deprivation on psychological well-being among the working population of Switzerland. BMC Public Health. 2006;6(1):223.

25. Kristenson M, Eriksen HR, Sluiter JK, Starke D, Ursin H. Psychobiological mechanisms of socioeconomic differences in health. Soc Sci Med. 2004;58:1511-22.

26. Kuh D, Ben-Shlomo Y, Lynch JW, Hallqvist J, Power C. Life course epidemiology. J Epidemiol Community Health. 2003;57:778-83.

27. Van de Mheen HD, Stronks K, Mackenbach JP. A lifecourse perspective on socio-economic inequalities in health: the influence of childhood socio-economic conditions and selection processes. Sociol Health Illn. 1998;20 (5):754-77.

28. Nations U. Human Development Index; Human Development Reports. New York: United Nations Development Programme; 2007.

29. Subramanian SV, Kawachi I. Income inequality and health: what have we learned so far? Epidemiol Rev. 2004;26:78-91.

30. Mackenbach JP, Stirbu I, Roskam AR, Schaap MM, Menvielle G, Leinsalu M, et al. Socioeconomic inequalities in health in 22 European countries. N Engl J Med. 2008;358(23):2468-81.

31. Halldorsson M, Cavelaars AEJM, Kunst AE, Mackenbach JP. Socioeconomic differences in health and well-being of children and adolescents in Iceland. Scand J Public Health. 1999;27(1):43-7.

32. Jonsson PV. Letter from Reykjavik. Ann Int Med. 1998;128(11):941-5.

33. Kempen GI, Steverink N, Ormel J, Deeg DJ. The assessment of ADL among frail elderly in an interview survey: self-report versus performance-based tests and determinants of discrepancies. J Gerontol B Psychol Sci Soc Sci. 1996;51:254-60.

34. Kressin NR, Spiro A, Skinner KM. Negative affectivity and health related quality of life. Med Care. 2000;38(8):858-67.

35. Watson D, Pennebakker JW. Health complaints, stress, and distress: exploring the central role of negative affectivity. Psychol Rev. 1989;96(2):234-54. 


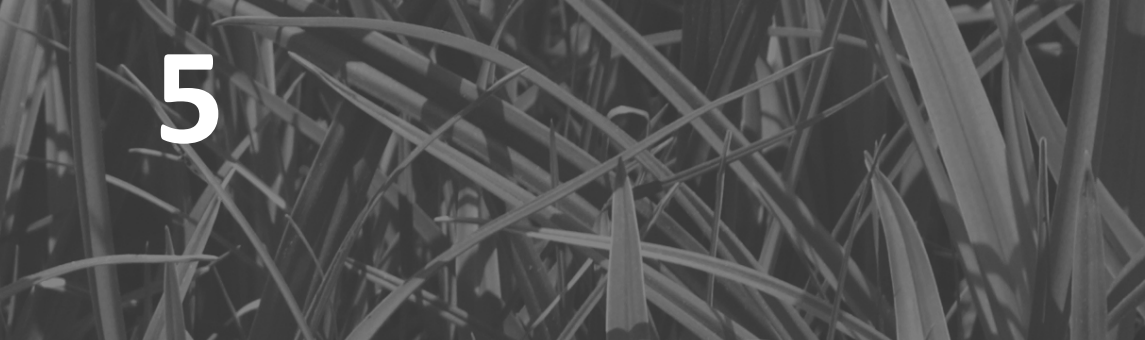

\section{Personality and health as}

\section{predictors of income decrease in}

\section{old age}

Findings from the longitudinal

\section{SMILE study}

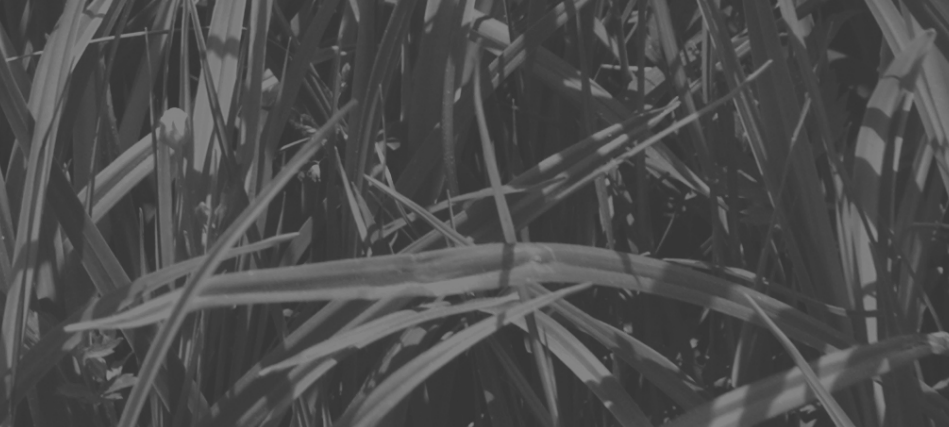

Published as:

Groffen DAI, Bosma H, van den Akker M, Kempen GIJM, van Eijk JThM. Personality and health as predictors of income decrease in old age: Findings from the longitudinal SMILE study. Eur J Public Health. 2009;19(4):418-23. 


\section{ABSTRACT}

\section{Background}

There is much evidence for the influence of low socioeconomic status on poor health. It is, however, also important to study the ways in which people attain and retain their socioeconomic status and the factors that predict changes in socioeconomic status, such as a decrease in income. Such mobility also occurs in older populations, in which financial and health-related changes are very common, especially after retirement.

\section{Methods}

Three years of follow-up data from 1,443 Dutch men and women aged 55 years and older who participated in the Study on Medical Information and Lifestyles Eindhoven (SMILE) were gathered. Logistic regression analyses were used to study the independent effects of physical and mental dysfunction and severity of chronic diseases and adverse personality factors on decrease in income.

\section{Results}

Social anxiety $(\mathrm{OR}=1.62,95 \% \mathrm{Cl}: 1.09-2.40)$, physical dysfunction $(\mathrm{OR}=1.71,95 \% \mathrm{Cl}$ : 1.07-2.74), and severe diseases $(\mathrm{OR}=1.37,95 \% \mathrm{Cl}: 1.05-1.78)$ were significant predictors of decrease in income. These contributions were independent of each other, and remained robust after controlling for other confounding factors, such as sex, age and educational level and change in employment status. Mental dysfunction and other personality characteristics, such as hostility and mastery, did not contribute to decrease in income.

\section{Conclusion}

Social anxiety and poor physical health are relevant factors associated with decrease in income in old age. The findings suggest that these factors are important in retaining one's socioeconomic status. Future longitudinal research is necessary to further disentangle the additional mechanisms and pathways along the whole lifecourse. 


\section{INTRODUCTION}

Adverse socioeconomic circumstances are related to disease and health-related dysfunction. For example, income inequalities are important determinants of population health. ${ }^{1,2}$ Furthermore, lower socioeconomic status (SES) is also related to adverse personality characteristics. Lachman and Weaver (1998), for example, showed that persons with lower income had lower perceived mastery and control. ${ }^{3}$

For scientific purposes and purposes related to setting up more effective interventions aimed at reducing socioeconomic health differences, it is, however, also important to examine the possibility of reverse associations and to study the ways in which people attain and retain their SES and the factors that predict changes in SES, such as a decrease in income. Such mobility also occurs in older populations, in which financial and health-related changes are very common, especially after retirement.

First, it has been proposed that people with initially poorer health and healthrelated dysfunction are more likely to attain lower educational and occupational positions ${ }^{4}$ and to move downward in income. ${ }^{5}$ For example, in the Dutch GLOBE study, it was shown that childhood poor health partly contributes to the explanation of socioeconomic inequalities in adult health by determining both downward socioeconomic mobility and adult poor health. ${ }^{6}$

Second, adverse personality characteristics, such as mastery and control beliefs may also be related to socioeconomic attainment and socioeconomic mobility. ${ }^{7}$ For example, Osborne (2000) found that women with low control beliefs have lower incomes than women with high control beliefs. ${ }^{8}$ Furthermore, Wang and colleagues (1999) found that high control beliefs had stronger positive effects on later educational and occupational attainment than both the educational level of the parents and the level of intelligence. ${ }^{9}$ Other personality factors, such as social anxiety and neuroticism may also be associated with career success, for example when applying for jobs or social benefits.

To our knowledge, the role of health and personality as predictors of income change in old age have not been studied before. Using three years of follow-up data from the longitudinal SMILE study among Dutch men and women 55 years or older, we set out to examine whether, in older persons, adverse personality characteristics and poor initial health-related functioning and disease are independent predictors of decrease in income after three years of follow-up. A simplified model of the relationships under study is shown in Figure 1 . The potential reciprocal relation between personality and health further complicates the model. This issue will explicitly be addressed by both controlling for, and discussing its confounding influence. 


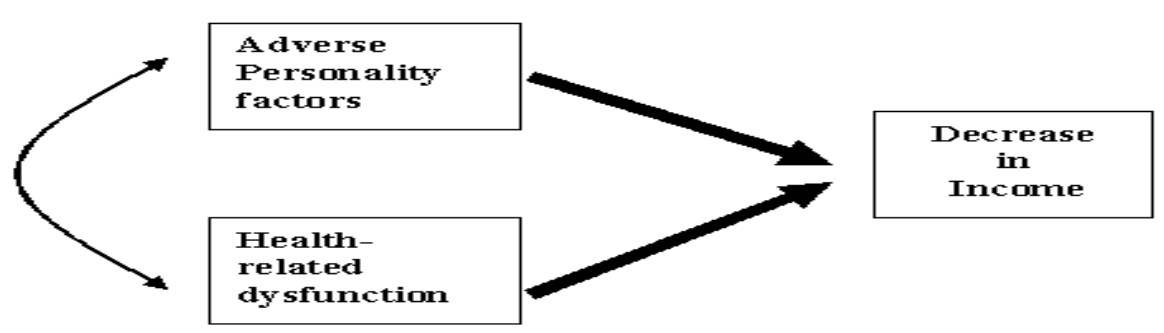

Figure 1 Hypothetical model, personality and health-related function as predictors of income decrease.

\section{METHODS}

\section{Design}

Data came from the longitudinal SMILE study (i.e. Study on Medical Information and Lifestyles Eindhoven). ${ }^{10}$ SMILE is a dynamic cohort, meaning that new participants will enter the population sample when they either reach the age of inclusion or when they are enrolled as a new patient in one of the participating centres ( 9 health care centres with 32 general practitioners) and give informed consent. Respondents may leave the population either through leaving the participating centres or due to death or drop-out. ${ }^{10}$ Persons aged 55 years and older are considered as a separate population within SMILE. ${ }^{11}$ The present study uses data that were collected between May 2003 and May 2006.

\section{Study population}

In May 2003, 9,557 persons of 55 years or older were sent self-administered questionnaires, of whom 4,745 (50\%) responded. Fifty-seven percent $(n=2,705)$ were followed up until May 2006. After exclusion of persons that had missing scores on variables of interest, the main analyses consisted of 1,443 persons (53\%) (753 men and 690 women; mean age $68.9, \mathrm{SD}=8.5$ ). Largest numbers of missing values were found for income (33\%) and health-related function (15\%). Persons from low socioeconomic status groups and with health-related dysfunction participated somewhat less in this study. Potential biases from non-response and attrition will be addressed in the Discussion. 


\section{Measures}

\section{Income change}

Income was measured in May 2003 and May 2006, using 11 ordinal categories ranging from $<750$ Euro to $>3000$ Euro Net. The midpoint of each category was chosen to create a pseudo-interval variable. To adjust for the number of persons who had to live from the household income, we divided both household income variables by an equivalence factor. To calculate this equivalence factor, we used the following formula: 1 (the first adult) $+0.5 *$ the number of extra adults that had to live from the household income $+0.3^{*}$ the number of children below the age of 18 that had to live from the household income. ${ }^{12}$ Next, income at the 2003 baseline was adjusted for inflation (+5.1\%), allowing a comparison with income levels in 2006. For the logistic regression analyses, the difference between income in 2006 and income in 2003 was calculated and the outcome was dichotomised (i.e. decrease versus no decrease). Alternative outcomes, using wider or more stringent cut-off scores, were calculated as well.

\section{Personality}

Personality was measured using different scales in May 2003 and May 2004.

Social anxiety was measured by the social inadequacy subscale of the "Dutch Personality Questionnaire" (DPQ) (15 items; range: 0-30; Cronbach's $\alpha=0.87$ ). One of the items is: "I feel uncomfortable talking to strangers". ${ }^{13}$ Social dominance (17 items; range: $0-34$; Cronbach's $\alpha=0.77$ ) was also assessed by a subscale of the DPQ. One of the items is: "I dislike people who can't make decisions". Both social anxiety and social dominance were measured in May 2004. Neuroticism (12 items; range 012; Cronbach's $\alpha=0.85$ ) was measured in May 2003 using the Dutch version of the Eysenck Personality Questionnaire. ${ }^{14,15}$ One of the items is: "Do you consider yourself a worrier?". Hostility (eight items; range: $8-40$; Cronbach's $\alpha=0.77$ ) was measured in May 2004 using a subscale of the Dutch version of the aggression questionnaire. ${ }^{16-18}$ One of the items is: "I sometimes feel that people are laughing at me behind my back". The Dutch version of Pearlin and Schooler's Mastery scale (seven items; range 7-35; Cronbach's $\alpha=0.83$ ) was used to measure the extent to which people believe that their behaviour matters for the events that occur in their environment in May 2003. ${ }^{19,20}$ One of the items is: "Sometimes I feel that I am being pushed around in life". For the purpose of this study, personality measures were dichotomised, defining the $10 \%$ worst scorers as having adverse personality characteristics (i.e. high levels of social anxiety, social dominance, neuroticism, and hostility respectively, and low levels of mastery). 


\section{Health-related function and disease}

Data about mental and physical function was derived from the Dutch version of the MOS SF36, ${ }^{21,22}$ assessed in May 2003. Physical and mental dysfunction was defined as having a score below the 10th percentile (scores of $\leq 29$ and $\leq 36$ out of a range from 10 to 70, respectively). Respondents were further asked whether or not they had any of the severe (chronic obstructive pulmonary disease, heart disease, bowel disease, liver disease, kidney disease, diabetes, cancer, epilepsy, and stroke) and less severe (migraine, joints, rheumatoid arthritis, arthrosis, back, injury, and other) chronic diseases. ${ }^{23}$ Presence of diseases was also measured in May 2003.

\section{Potential confounders}

Covariates were age, sex, educational level, and change in employment status. Education, as an indicator of prior (and current) socioeconomic influences, was measured in May 2003, using a seven-point scale. Three categories were then created in such a way that each group contained approximately a third of the sample: primary school only (lowest); lower vocational education and intermediate general education (middle); intermediate vocational education, higher general education, higher vocational education, and university (highest). Change in employment status was defined as a change in employment status between 2003 and 2006, for example due to retirement or discharge.

\section{Statistical analyses}

Firstly, chi-square tests, based on cross-tabulations, were computed to examine whether there were sex, age, and educational differences in decrease in income, prevalence of adverse personality, and health-related dysfunction and disease. Secondly, multiple logistic regression models were fitted to examine whether personality factors were related to a decrease in income between 2003 and 2006.The first model was adjusted for age, sex, education, change in employment status, and inflation corrected income at the 2003 baseline measurement. The second model was additionally adjusted for significant measures of health-related dysfunction and disease. Similarly, logistic regression models were also fitted to examine whether health-related function and the prevalence of diseases were related to a decrease in income. Analyses were adjusted for age, sex, education and income at baseline (model 1) and additionally for significant adverse personality factors. To test the robustness of the findings, all analyses with the dichotomised scoring (of the outcome and personality measures) were repeated with continuous scoring, using linear regression analyses. Moreover, analyses were performed for different subgroups, i.e. younger (55-65) and older (>65) persons, male and female, persons with and without chronic diseases, and persons with high or low education. All statistical analyses were performed using SPSS 15.0.1. 


\section{RESULTS}

Table 1 presents the associations of income change, negative change in employment status, adverse personality and disease and dysfunction with age, sex, and educational level. Persons above the age of 75 were significantly more likely to report a decrease in income between 2003 and 2006 (52\% versus 37\% in the youngest age category). These older persons were also more likely to report social anxiety and low mastery. Furthermore, women were more likely to report an income change. Moreover, they were significantly more likely to report low mastery $(8 \%$ versus $4 \%$ in men), high neuroticism ( $10 \%$ versus $6 \%$ in men), and to report mental dysfunction ( $10 \%$ versus $6 \%$ in men) and less severe diseases ( $47 \%$ versus $41 \%$ in men). However, men were more likely to report a negative change in employment status and high social dominance levels ( $20 \%$ versus $7 \%$ in women). Finally, persons with a lower educational level did not have higher probabilities of reporting a decrease in income, and were even significantly less likely to report a change in employment status. However, these persons were significantly more likely to report high levels of adverse personality characteristics. For example, $18 \%$ of the lower educated persons reported high levels of social anxiety, compared with $7 \%$ of the highest educated persons. Moreover, it is shown that lower educated persons are more likely to suffer from physical ( $9 \%$ versus $5 \%$ in higher educated persons) and mental dysfunction (13\% versus $6 \%$ in higher educated persons.

Table 2 shows how adverse personality and disease and dysfunction are related to decrease in income between 2003 and 2006. Persons who reported to have high levels of social anxiety had a 1.69 (95\% Cl: 1.15-2.50) times higher odds of a decrease in income compared with persons who did not report high social anxiety. The significance of this association even held after additional adjustment for physical and mental dysfunction and diseases (OR $=1.62 ; 95 \% \mathrm{Cl}: 1.09-2.40)$. Other adverse personality characteristics, although consistently having negative cross-sectional associations with income, were not significantly related to a decrease in income. Similar to social anxiety, physical dysfunction was strongly related to income decrease $(\mathrm{OR}=1.67 ; 95 \% \mathrm{Cl}$ : 1.06-2.61). When adjusting for adverse personality factors, the association remained statistically significant (OR=1.71 95\% Cl: 1.07-2.74). In addition, the prevalence of one or more severe diseases at baseline was also significantly related to decrease in income, even when adjusted for social anxiety (OR=1.37; 95\% Cl: 1.05-1.78). Although consistently in the predicted direction, mental dysfunction and less severe diseases were not significantly related to a decrease in income. 
Table 1 Percentages of people with a decrease in income after three years of follow up, negative psychosocial characteristics and health-related dysfunction by age, sex, and educational level at baseline and change in employment status between 2003 and $2006^{a}$

\begin{tabular}{|c|c|c|c|c|c|c|c|c|c|c|}
\hline & \multirow{2}{*}{$\begin{array}{c}\text { Included } \\
\text { Total } \\
n=1443\end{array}$} & \multicolumn{3}{|c|}{ Age } & \multicolumn{2}{|c|}{ Sex } & \multicolumn{3}{|c|}{ Educational level } & \multirow{2}{*}{$\begin{array}{c}\text { Excluded } \\
\text { Lost to f.u. } \\
n=2040\end{array}$} \\
\hline & & $\begin{array}{l}55-64 \\
n=610\end{array}$ & $\begin{array}{c}65-74 \\
n=586\end{array}$ & $\begin{array}{c}\geq 75 \\
\mathrm{n}=247\end{array}$ & $\begin{array}{c}M \\
n=753\end{array}$ & $\begin{array}{c}F \\
n=690\end{array}$ & $\begin{array}{c}\mathrm{L} \\
\mathrm{n}=187\end{array}$ & $\begin{array}{c}M \\
n=551\end{array}$ & $\begin{array}{c}\mathrm{H} \\
\mathrm{n}=705\end{array}$ & \\
\hline \multicolumn{11}{|l|}{ Income change } \\
\hline Decrease & 35.6 & 36.6 & 27.6 & 51.8 & 34.3 & 37.0 & 35.8 & 33.4 & 37.2 & - \\
\hline \multicolumn{11}{|l|}{ Employment status } \\
\hline Changed 2003-2006 & 7.2 & 14.9 & 2.2 & 0 & 8.0 & 6.4 & 4.3 & 5.6 & 9.2 & - \\
\hline \multicolumn{11}{|l|}{ Adverse personality } \\
\hline Social anxiety & 8.6 & 7.7 & 8.2 & 11.7 & 8.0 & 9.3 & 17.6 & 7.8 & 6.8 & 11.8 \\
\hline Low mastery & 6.3 & 6.1 & 6.6 & 7.7 & 4.4 & 8.4 & 8.6 & 8.0 & 4.4 & 15.6 \\
\hline Hostility & 9.5 & 10.3 & 8.7 & 9.3 & 10.1 & 8.8 & 13.9 & 12.2 & 6.2 & 14.8 \\
\hline Social dominance & 13.6 & 13.3 & 13.8 & 13.8 & 19.7 & 7.0 & 4.8 & 10.0 & 18.7 & 11.9 \\
\hline Neuroticism & 7.7 & 8.4 & 7.8 & 5.7 & 5.7 & 9.9 & 9.6 & 10.9 & 4.7 & 12.9 \\
\hline \multicolumn{11}{|l|}{ Disease and dysfunction } \\
\hline Physical dysfunction & 6.4 & 5.2 & 6.5 & 8.9 & 5.4 & 7.4 & 9.1 & 7.8 & 4.5 & 14.2 \\
\hline Mental dysfunction & 7.5 & 7.9 & 7.0 & 7.7 & 5.6 & 9.6 & 13.4 & 7.6 & 5.8 & 13.3 \\
\hline$\geq 1$ Disease (any) & 55.6 & 53.9 & 56.7 & 57.5 & 54.1 & 57.4 & 56.1 & 57.5 & 54.0 & 52.0 \\
\hline$\geq 1$ Severe disease & 23.4 & 20.2 & 23.7 & 30.8 & 21.6 & 22.2 & 26.7 & 24.5 & 21.7 & 27.6 \\
\hline$\geq 1$ Less severe disease & 44.1 & 42.6 & 46.1 & 43.3 & 41.4 & 47.1 & 45.5 & 45.6 & 42.7 & 39.9 \\
\hline
\end{tabular}

${ }^{a}$ Results in italic font indicate a significant $(p<0.05)$ difference.

Table 2 Adjusted Odds Ratios (OR) of decrease in income (2003-2006) by adverse personality and disease and health-related dysfunction $(n=1,443)$

\begin{tabular}{lcc}
\hline & $\begin{array}{c}\text { Model } 1^{\mathrm{a}} \\
\text { OR }(95 \% \mathrm{Cl})\end{array}$ & $\begin{array}{c}\text { Model }^{\mathrm{b}} \\
\text { OR }(95 \% \mathrm{Cl})\end{array}$ \\
\hline $\begin{array}{l}\text { Adverse personality } \\
\text { Social anxiety }\end{array}$ & $1.69(1.15-2.50)$ & $1.62(1.09-2.40)$ \\
Mastery & $1.14(0.72-1.81)$ & $0.88(0.52-1.48)$ \\
Hostility & $1.09(0.74-1.61)$ & $1.00(0.67-1.49)$ \\
Social dominance & $1.05(0.76-1.46)$ & $1.05(0.75-1.46)$ \\
Neuroticism & $1.21(0.79-1.84)$ & $1.07(0.67-1.69)$ \\
Disease and dysfunction & & \\
$\quad$ Physical dysfunction & $1.67(1.06-2.61)$ & $1.71(1.07-2.74)$ \\
Mental dysfunction & $1.25(0.81-1.90)$ & $1.20(0.74-1.94)$ \\
$\geq 1$ Disease (any) & $1.10(0.88-1.38)$ & $1.08(0.86-1.36)$ \\
$\geq 1$ Severe disease & $1.41(1.08-1.83)$ & $1.37(1.05-1.78)$ \\
$\geq 1$ Less severe disease & $1.09(0.87-1.36)$ & $1.06(0.85-1.34)$ \\
\hline
\end{tabular}

a Model 1 is adjusted for sex, age, educational level, inflation corrected income 2003, and change in employment status; ${ }^{b}$ For the analyses that examine the role of adverse personality, model 2 is additionally adjusted for physical and mental dysfunction and diseases. For the analyses that examine the role of disease and dysfunction, model 2 is additionally adjusted for adverse personality factors. 
Effects were similar in men and women, diseased and non-diseased, and in the younger $(\leq 65)$ and older $(>65)$ age groups: the respective interaction terms were not significant in our analyses (not tabulated). Social anxiety was also similarly related to decrease in income in low and high educated persons and in persons with high and low income levels at baseline: the respective interaction term was not significant $(p=0.68)$.

Similarly, additional analyses were performed, using wider cut-off points for income decrease (e.g. based upon reliable change analyses where an income drop is defined by drops larger than $0.5 * 1$ SD of the income decrease or based upon alternative more stringent cut-offs, such as a greater than $5 \%$ decrease or a greater than $€ 50$ decreases) and also using the continuous income levels in 2006, adjusted for income in 2003 (with linear regression/ANCOVA). The pattern of results was comparable in all these analyses, showing similar regression coefficients and significance levels. Moreover, findings were similar with and without correction for inflation.

\section{DISCUSSION}

This prospective study intended to clarify the role of adverse personality characteristics and disease and health-related dysfunction in the explanation of decrease in income among older persons. The results showed that prior physical dysfunction and severe disease, as well as social anxiety were independent predictors of decrease in income in three years of follow-up.

How should these findings be interpreted? With regard to social anxiety, it is likely that the persons reporting higher social anxiety levels were the ones less likely and less able to take up opportunities to retain similar income levels, for example by applying for additional social security benefits. The absence of an interaction with educational level indicates that social anxiety apparently hinders both high and low educated persons in the prevention of a decrease in income in old age. Social anxiety or social inadequacy, ${ }^{24}$ as well as related concepts, such as shyness, introversion, and neuroticism ${ }^{15}$ might reflect beliefs of low control in social circumstances. Consequently, persons with these adverse personality characteristics are less likely to engage in activities which expand their pool of material, social and cultural resources; this may limit their educational and occupational achievements ${ }^{25}$ and - as we show in the present study - probably also heightens their risk of decrease in income.

From a sociological perspective, the effects of health on socioeconomic attainment might involve stigma and social discrimination against the ill and disabled. Due to this discrimination, it is argued that ill and disabled individuals are deprived of the same job opportunities and the accompanying material and psychosocial benefits. ${ }^{26}$ For example, van de Mheen and colleagues (1999) have reported higher risks 
of health-related mobility out of employment (i.e. disability pension or early retirement) with a corresponding decrease in income of ill persons. ${ }^{27}$

As the prior health condition and personality might not only be related to decrease in income, but also to later health outcomes, ${ }^{28}$ our findings also relate to the 'selection' or 'reversed causation' hypothesis regarding socioeconomic health inequalities. $^{5,7,26,29,30}$ The 'direct selection hypothesis' proposes that a person's health and health-related function are related to where people end up in socioeconomic terms. The 'indirect selection hypothesis' postulates that some other quality of the individual, for example personality, affects where one ends up in terms of both socioeconomic status and health. ${ }^{7,26,29,30}$ Although social anxiety was related to income decrease in our study, there was only little association between social anxiety and health in 2003, as the odds ratio of income decrease for social anxiety hardly decreased when the health indicators were controlled for (see Table 2). Preliminary longitudinal findings, however, indicated that social anxiety in 2003 was related to changes in the health indicators thereafter (not tabulated), suggesting a role of anxiety in indirect selection processes. This corroborates recent work of others. ${ }^{30}$ For example, the GAZEL study found that a substantial part of the socioeconomic differences in mortality were based on adverse personality characteristics. ${ }^{30}$ SES and personality were, however, not measured at the same measurement phase, making it difficult to ascertain the causal nature of the association between personality and SES. ${ }^{30}$

Although in our study all adverse personality characteristics were related to a subsequent decrease in income, only social anxiety was a statistically significant predictor. Social anxiety has been discussed as an important psychological pathway through which income inequality affects health. ${ }^{31}$ In our study, however, the opposite causal ordering from anxiety to income is supported by the adjustment not only for baseline income level, but also for educational level. The trait component of personality has been shown to be remarkably stable over the adult life span. ${ }^{32}$ The stability of social anxiety is further supported by the supposedly trait-like measurement of social anxiety by the Dutch Personality Questionnaire. ${ }^{13}$ Moreover, evidence exists that social anxiety-related personality characteristics are, to at least some extent, hereditary, as is the case with several other personality characteristics. $^{33,34}$

If social anxiety and other aspects of personality are fundamental determinants of socioeconomic attainment and future health and health behaviour, the task of reducing health inequalities may, however, be further complicated, depending on the amenability to change the relevant aspects of personality. To even more fully determine the contribution of personality factors and health in the life-course of older persons, advanced modelling of lagged repeated measures of health, socioeconomic status, and personality over longer periods of time is needed. ${ }^{35}$ 


\section{Methodological considerations}

Several methodological limitations may affect the interpretation of the results of our study. Firstly, our study relied solely on self-reports which might have introduced measurement error. ${ }^{36}$ In the form of negative affectivity (tendency to complain), ${ }^{37}$ this may have led to an overestimation of associations. Because of the prospective design of this study and the repeated measurement of income, we consider this problem minimal. Undoubtedly, the crude categorical measurement of income (chosen to increase response on the income question) and the open end highest category introduced at least some measurement error. Furthermore, changes that remain within the highest category (>3000 Euro) were not picked up by our method. Moreover, persons on the lower end of the income ladder might show less income decrease because of additional social benefits. Another problem related to the measurement of income might be 'regression to the mean. ${ }^{38}$ Regression to the mean is highest when outcome measures are poorly correlated. ${ }^{38}$ Our analyses show that income level in 2003 and in $\mathbf{2 0 0 6}$ are moderately correlated (Spearman's rho: $0.67, p<0.01$ ), indicating that regression to the mean is not likely to be a substantial problem. Furthermore, it is reassuring that interactions with income level at baseline and, for example, social anxiety, are not significant, indicating similar prediction at the high and low end of the income measure. Similarly, additional analyses, using wider cut-off points for income decrease and also using the continuous income levels in 2006, adjusted for income in 2003 (with linear regression/ ANCOVA), showed comparable results.

Second, response analyses showed that men and persons from the youngest $(<65)$ age groups were more likely to respond. Moreover, attrition (between May 2003 and May 2006, 43\% were lost to follow-up) was higher for persons who were lower educated or had lower income levels at baseline. Table 1 shows that persons who were lost to follow up were also more likely to report adverse personality characteristics and reported worse physical and mental function scores at baseline.

Missing values analyses (not tabulated) revealed that persons with missing scores on the baseline income measurement were significantly more likely to be lower educated ( $26 \%$ is lower educated, compared with $15 \%$ in responders). Moreover, persons that were excluded due to missing values on any of the variables of interest were more likely to report adverse personality characteristics (e.g. more than $10 \%$ of persons with missing values on items regarding disease and dysfunction or regarding income variables reported high levels of social anxiety, versus $8.6 \%$ in persons without missing values) and more often report poor physical function (e.g. more than $8 \%$ of persons with missing values on personality factors or on the income variables reported physical dysfunction, compared with $6.4 \%$ in persons without missing values). This pattern of selective response and attrition may have led to an underestimation of the reported associations. 


\section{CONCLUSION}

Social anxiety and poor physical health are relevant factors associated with decrease in income in old age. The findings suggest that these factors are important for socioeconomic attainment and mobility in elderly persons. Future longitudinal research is necessary to further disentangle the additional mechanisms and pathways related to socioeconomic health inequalities along the whole life-course.

\section{Acknowledgements}

The longitudinal SMILE study is carried out by the Department of General Practice of Maastricht University, in collaboration with the Eindhoven Corporation of Primary Care Centres. The researchers are indebted to the participants for their willingness to participate in the study. 


\section{REFERENCES}

1. Wilkinson RG, Marmot M. Social determinants of health: the solid facts. 2 nd ed. Copenhagen: WHO; 2003.

2. Ferrie JE, Shipley MJ, Davey Smith G, Stansfeld S, Marmot M. Change in health inequalities among British civil servants: the Whitehall II study. J Epidemiol Community Health. 2002;56:922-6.

3. Lachman ME, Weaver SL. The sense of control as a moderator of social class differences in health and well-being. J Pers Soc Psychol. 1998;74:763-73.

4. Koivusilta L, Arja R, Adnres V. Health behaviours and health in adolescence as predictors of educational level in adulthood: a follow-up study from Finland. Soc Sci Med. 2003;57:577-93.

5. Chandola T, Bartley M, Sacker A, Jenkinson C, Marmot M. Health selection in the Whitehall II study, UK. Soc Sci Med. 2003;56:2059-72.

6. Van de Mheen HD, Stronks K, Looman CWN, Mackenbach JP. Role of childhood health in the explanation of socioeconomic inequalities in early adult health. J Epidemiol Community Health. 1998;52:15-9.

7. Mackenbach JP. Genetics and health inequalities: hypotheses and controversies. J Epidemiol Community Health. 2005;59:268-73.

8. Osborne M. the power of personality; labor market rewards and the transmission of earnings. Massachusetts: University of Massachusetts; 2000.

9. Wang LY, Kick E, Fraser J, Burns TJ. Status attainment in America: the roles of locus of control and self-esteem in educational and occupational outcomes. Sociol Spectr. 1999;19:281-9.

10. Van den Akker M, Spigt MG, de Raeve L, van Steenkiste B, Metsemakers JFM, van Voorst EJ, et al. The SMILE study: A Study of Medical Information and Lifestyles in Eindhoven. The rationale and contents of a large prospective dynamic cohort study. BMC Public Health. 2008;8(19).

11. Groffen DAI, Bosma H, van den Akker M, Kempen GIJM, van Eijk JTM. Material deprivation and health-related dysfunction in older Dutch people; Findings from the SMILE study. Eur J Public Health. 2008;18(3):258-63.

12. Vrooman C, Dirven H, Soede A, Trimp R. Armoede monitor 2005/Poverty monitor 2005. The Hague: Netherlands Institute for Social Research (SCP) and Statistics Netherlands (CBS); 2005.

13. Luteijn F, Starren J, van Dijk H. Manual for the Dutch Personality Questionnaire: revised edition. Lisse: Swets en Zeitlinger; 2000.

14. Sanderman R, Arrindell WA, Ranchor AV, Eysenck HJ, Eysenck SBG. Eysenck personality questionnaire (EPQ). Groningen, The Netherlands: Noordelijk Centrum voor Gezondheidsvraagstukken; 1991.

15. Eysenck HJ, Eysenck SGB. Personality structure and measurement. Londen: Routledge; 1969.

16. Buss AH, Perry M. The aggression questionnaire. J Pers Soc Psychol. 1992;63:452-9.

17. Schrijvers $\mathrm{CT}$, Bosma $\mathrm{H}$, Mackenbach JP. Hostility and the educational gradient in health; the mediating role of health-related behaviours. Eur J Public Health. 2002;12:110-6.

18. Meesters C, Murris P, Bosma H, Schouten E, Beuving S. Psychometric evaluation of the Dutch version of the Aggression Questionnaire. Behav Res Ther. 1996;34(10):839-43.

19. Bosma H, van Jaarsveld CH, Tuinstra J, Sanderman R, Ranchor AV, van Eijk JT, et al. Low control beliefs, classical coronary risk factors, and socio-economic differences in heart disease in older persons. Soc Sci Med. 2005;60:737-45.

20. Pearlin II, Schooler C. The structure of coping. J Health Soc Behav. 1978;19:2-21.

21. Ware JE, Sherbourne CD. The Rand-36 Short-form Health Status Survey 1: Conceptual framework and item selection. Med Care. 1992;30(6):473-81.

22. Ware JE, Kosinski M. Interpreting SF-36 summary health measures: a response. Qual Life Res. 2001;10:415-20.

23. Koster A, Bosma H, Kempen GI, Van Lenthe FJ, Van Eijk JT, Mackenbach JP. Socioeconomic inequalities in mobility decline in chronic disease groups (asthma/COPD, heart disease, diabetes mellitus, low back pain): only a minor role for disease severity and comorbidity. J Epidemiol Community Health. 2004;58:862-9. 
24. Leitenberg H. Handbook of Social and Evaluation Anxiety. New York: Plenum Press; 1990.

25. Pulkki L, Kivimaki M, Keltikangas-Jarvinen L, Elovainio M, Leino M, Viikari J. Contribution of adolescent and early adults personality to the inverse association between education and cardiovascular risk behaviours: prospective population-based cohort study. Int J Epidemiol. 2003;32:968-75.

26. West P. Rethinking the health selection explanation for health inequalities. Soc Sci Med. 1991;32(4):373-84.

27. Van de Mheen HD, Stronks K, Schrijvers CT, Mackenbach JP. The influence of adult ill health on occupational class mobility and mobility out of and into employment in The Netherlands. Soc Sci Med. 1999;49:509-18.

28. Steptoe A, Marmot M. The role of psychobiological pathways in socio-economic inequalities in cardiovascular disease risk. Eur Heart J. 2002;23:13-25.

29. Bosma H. Socio-economic differences in health: are control beliefs fundamental mediators? In: Siegrist J, Marmot M, editors. Social inequalities in health; new evidence and policy implications. Oxford: Oxford University Press; 2006. p. 153-66.

30. Nabi H, Kivimaki M, Marmot MG, Ferrie JE, Zins M, Ducimetiere $P$, et al. Does personality explain social inequalities in mortality? The French GAZEL cohort study. Int J Epidemiol. 2008;37(3):591-602.

31. Wilkinson RG. Health, hierarchy and social anxiety. Ann N Y Acad Sci. 1999;896:48-63.

32. Caspi A, Bem DJ. Personality continuity and change across the life course. In: Pervin LA, editor. Handbook of personality: Theory and research. New York: Guilford Press; 1990. p. 549 - 75.

33. Jang KL, Livesley WJ. Heritability of the big five personality dimensions and their facets: A twin study. J Pers. 1996;64(3):577-91.

34. Stein MB, Jang KL, Livesley WJ. Heritability of social anxiety-related concerns and personality characteristics: A twin study. J Nerv Ment Dis. 2002;190:219-24.

35. Kuh D, Ben-Shlomo Y, Lynch JW, Hallqvist J, Power C. Life course epidemiology. J Epidemiol Community Health. 2003;57:778-83.

36. Kempen GI, Steverink N, Ormel J, Deeg DJ. The assessment of ADL among frail elderly in an interview survey:self-report versus performance-based tests and determinants of discrepancies. J Gerontol B Psychol Sci Soc Sci. 1996;51:254-60.

37. Kressin NR, Spiro A, Skinner KM. Negative affectivity and health related quality of life. Med Care. 2000;38(8):858-67.

38. Barnett AG, Van der Pols JC, Dobson AJ. Regression to the mean: what it is and how to deal with it. Int J Epidemiol. 2005;34:215-20. 


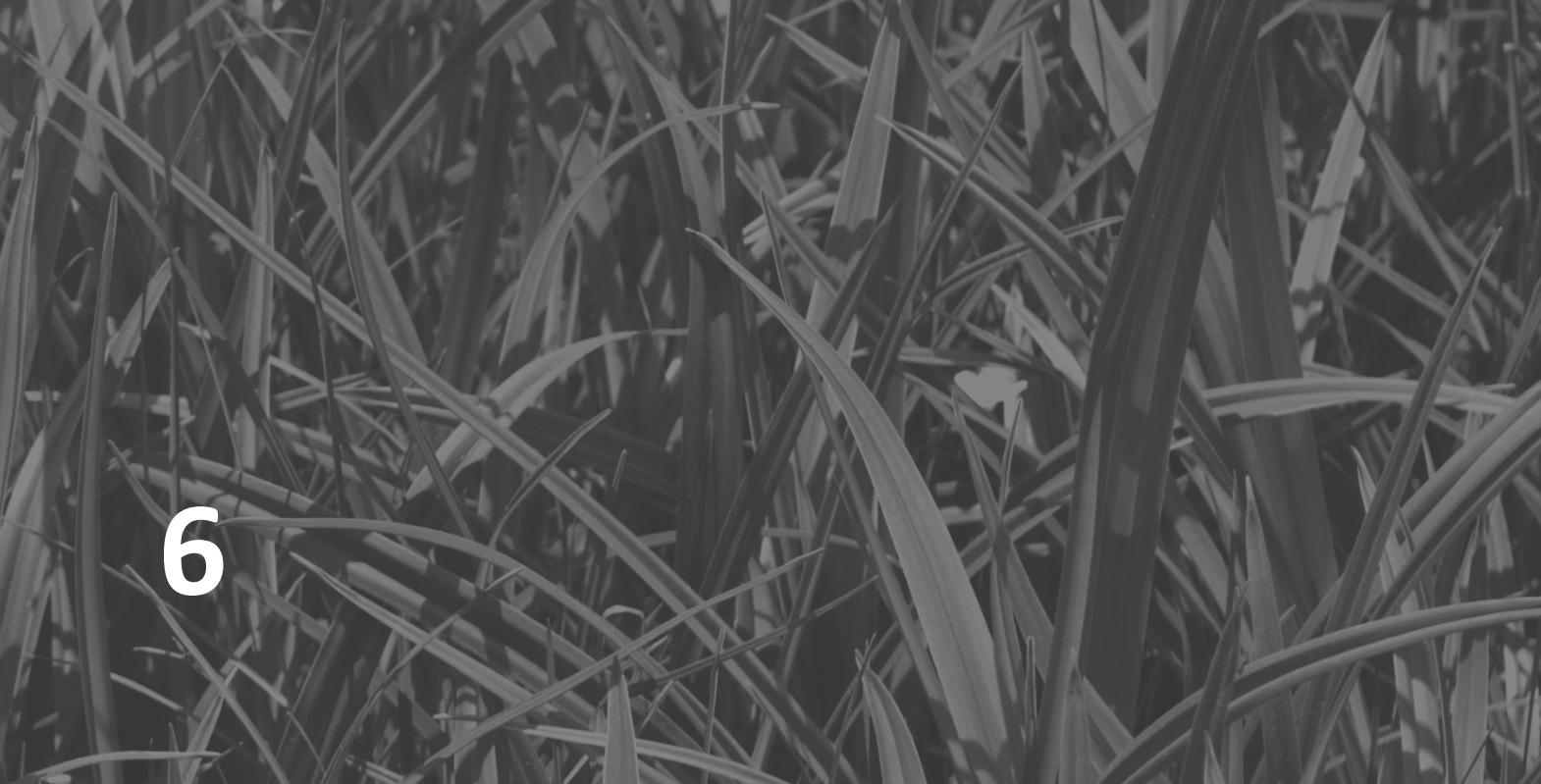

\section{Socioeconomic adversity and} depressive symptoms in older persons: mediating effects of an unhealthy lifestyle Findings from the Health $A B C$

\section{study}

\section{Submitted as:}

Groffen DAI, Koster A, Bosma H, van den Akker M, Kempen GIJM, van Eijk JThM, van Gool CH, Penninx BWJH, Harris. TB, Rubin SM, Pahor M, Schulz R, Simonsick EM, Perry SE, Ayonayon HN, Kritchevsky SB, for the Health ABC study. Socioeconomic adversity and incident depressive symptoms in older persons: mediating effects of an unhealthy lifestyle; Findings from the Health ABC Study. 


\section{ABSTRACT}

\section{Background}

Depressive symptoms show a socioeconomic gradient and are common in older persons. Although studies have found associations between low socioeconomic status (SES) and unhealthy lifestyle factors and between unhealthy lifestyle factors and depressive symptoms, not much is known about potential mediating effects of an unhealthy lifestyle on the socioeconomic gradient in depressive symptoms in older persons.

\section{Methods}

To study the independent pathways between SES (education, income, perceived income, and financial assets), lifestyle factors (smoking, alcohol use, body mass index, and physical activity), and incident depressive symptoms (CES-D 10 and reported use of antidepressant medication), we used 9 years of follow-up data (19972007) from 2,757 older American black and white, men and women participating in the Health, Aging, and Body Composition (Health $A B C$ ) study.

\section{Results}

Adjusted hazard ratios for incident depressive symptoms were higher in participants from lower SES groups compared with the highest SES group. The strongest relationships were found for black men. Although unhealthy lifestyle factors were consistently associated with low SES, they were weakly related to incident depressive symptoms. Lifestyle factors did not significantly reduce hazard ratios for depressive symptoms by SES.

\section{Conclusion}

In generally healthy persons aged 70-79 years lifestyle factors do not mediate the relationship between SES and depressive symptoms. 


\section{INTRODUCTION}

Socioeconomic gradients in health status are consistent across numerous physical health outcomes, settings and age and sex strata. ${ }^{1-10}$ Socioeconomic gradients have also been found for mental health outcomes, such as depressive symptoms. ${ }^{11-12}$ Explanations for these gradients include psychosocial factors, material resources, work characteristics, and adverse exposures in childhood. ${ }^{13-15}$ Lifestyle factors, such as smoking, excessive alcohol consumption, overweight and obesity, and low physical activity pattern, may also contribute to socioeconomic differences in depressive symptoms. ${ }^{13-14}$ Several studies have identified a relationship between low socioeconomic status (SES) and unhealthy lifestyle factors ${ }^{16-19}$ and there exists good evidence that unhealthy lifestyles elicit or exacerbate symptoms of depression. ${ }^{20-22}$ However, little is known about potential mediating effects of an unhealthy lifestyle on the socioeconomic gradient in depressive symptoms, particularly in older persons. ${ }^{14}$ Depressive symptoms are common in older adults and associated with high societal costs due to associated morbidity and high utilization of health services. ${ }^{23,24}$ Since unhealthy lifestyles are amenable to change, indications for a mediating effect of an unhealthy lifestyle on SES-specific risks of incident depressive symptoms would offer new perspectives on prevention or treatment of this potentially debilitating mental disorder and the socioeconomic differences therein.

In the present study, nine years of follow-up data from the Health ABC study in American black and white men and women aged 70 to 79 years, initially free of depression, will be used to study: 1) pathways between SES and lifestyle factors at baseline, 2) pathways between lifestyle factors at baseline and incident depressive symptoms, and 3 ) the relationship between SES at baseline and incident depressive symptoms. Additionally, the potentially mediating effect of unhealthy lifestyle factors on this relationship will be evaluated. A simplified model of the relationships under study is shown in Figure 1.

3

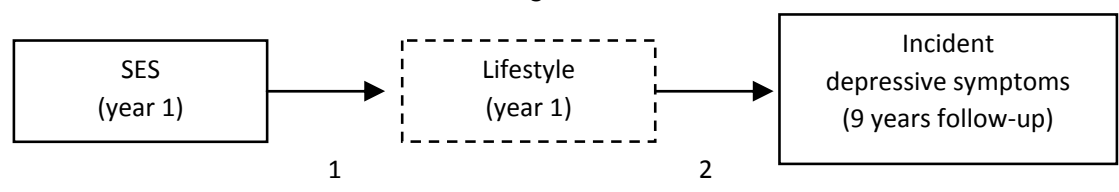

Figure 1 Conceptual model

${ }^{1}$ Association between year 1 SES and year 1 lifestyle factors; ${ }^{2}$ Relation between year 1 lifestyle factors and incident depressive symptoms, over a period of 9 years of follow-up; ${ }^{3}$ Relation between year 1 SES and incident depressive symptoms, over a period of 9 years of follow-up, potentially mediated by lifestyle factors. 


\section{METHODS}

\section{Design and study population}

The Health, Aging and Body Composition (Health $A B C$ ) study is a longitudinal cohort study consisting of 3,075 well-functioning 70 to 79-year old, black and white men and women. Participants were identified from a random sample of white Medicare beneficiaries and all age-eligible community-dwelling black residents in designated ZIP code areas surrounding Memphis, Tennessee and Pittsburgh, Pennsylvania.

Participants were eligible if they reported no difficulty in either walking one quarter of a mile, going up 10 steps without resting, or performing basic activities of daily living. Participants were excluded if they reported a history of active treatment for cancer in the prior three years, planned to move out of the study area in the next three years, or were currently participating in a randomized trial of a lifestyle intervention. Baseline data were collected between April 1997 and June 1998 and included an in-person interview and a clinic-based examination, with evaluation of socioeconomic status and material adversity, body composition, lifestyle, clinical and subclinical diseases, and depressive symptoms.

The present study uses 9 years of follow-up data, collected between 1997 and 2007. Data on socioeconomic status and lifestyle factors were collected at baseline. Data on depressive symptoms were collected at all years of follow-up, except for years seven and nine. In order to study the onset of depression, respondents with depressive symptoms at baseline (short CES-D score $>10$ or use of antidepressant medication) were excluded ( $n=263$ ). Furthermore, 31 persons with missing values on education and/or assets and 24 persons with missing data on lifestyle factors were excluded, leaving 2,757 participants (mean age 73.6, SD=2.87, 1,363 men and 1,394 women) for the present analyses. All participants signed informed written consent approved by the institutional review boards of the clinical sites.

\section{Measures}

\section{Depressive symptoms}

Depressive symptoms were assessed at baseline (year 1 ) and at years 3, 4, 5, 6, 8 and 10, with the short form of the Center for Epidemiologic Studies-Depression (CES-D 10) scale. ${ }^{25,26}$ This 10 -item self-report scale is designed to measure depressive symptoms during the previous week. Scores ranged from 1 to 30, with higher scores indicating more depressive symptoms. A cut-off score of 11 was used as a criterion for depressive symptoms. ${ }^{25}$ In addition, self-reported use of antidepressant medication (prescribed for the treatment of depression or depressive symptoms) during the previous two weeks was recorded at years $1,2,3,5,6,8$, and 10 . Participants were classified with depressive symptoms when the cut off score of 11 was 
crossed $(n=702)$ and/or when use of antidepressant medication was reported $(n=290)$.

\section{Socioeconomic status}

Four indicators of SES at baseline were used: education, family income, perceived adequacy of income, and ownership of financial assets. Categories for completed education were: less than high school, high school graduate, and college graduate and beyond. Net family income was defined as: wages, salaries, social security or retirement benefits, financial help from relatives, and rent from property. Five categories of family income from the year prior to interview (i.e. 1996-1997) were distinguished: $<\$ 10,000, \$ 10,000-<\$ 25,000, \$ 25,000-<\$ 50,000, \geq \$ 50,000$, and missing $(n=347)$. Furthermore, persons were asked to indicate whether they perceive their income adequate to meet essential needs. Categories for perceived adequacy of income were: poorly, fairly well, and very well. Finally, the number of financial assets a person reported was used as a SES measure. Assets included: money market account, saving bonds or treasury bills, home ownership or investment property or housing; a business or farm, stock or stock mutual funds, individual retirement (IRA) or KEOGH accounts, or other investments. Three categories were created: none, one or two, and three to seven. ${ }^{27}$

\section{Lifestyle factors}

Lifestyle factors included smoking, alcohol use, physical activity, and body mass index (BMI). Four categories of smoking were created: current smokers, recent quitters (within 10 years), long time quitters (over 10 years), and non-smokers. Categories of alcohol consumption were: abstinence, moderate drinkers (1-14 units per week), and heavier drinkers ( $>14$ units per week). Physical activity pattern was based on energy expenditure doing household chores, care giving, walking and climbing stairs, and exercise and recreation and was estimated by kilocalorie expenditure per week. ${ }^{28}$ Categories were: inactive $(<1000 \mathrm{kcal}$ of exercise and $<2719$ of total physical activity per week), active lifestyle $(<1000$ of exercise and $>2718$ of total physical activity per week), and exercise ( $>1000$ of exercise alone). BMI was calculated as weight in kilograms divided by height in meters squared $\left(\mathrm{kg} / \mathrm{m}^{2}\right)$. Three categories were created: $<25$ (because of small numbers this category also includes persons who were underweight), $25-<30$, and $\geq 30$.

\section{Covariates}

Sociodemographics included age, sex, race (black or white), study site (Memphis or Pittsburgh), and marital status (never married, previously married including widowers, and married). For the analyses with family income, we also controlled for whether the household included anyone in addition to the participant and his or her spouse. Presence of lung, heart and cerebrovascular disease, diabetes mellitus, 
osteoarthritis, and cancer at baseline was determined using standardised algorithms considering self-report, use of specific medications, and, when available, as for diabetes, the results of screening tests conducted in the cohort.

\section{Analyses}

All analyses were performed using SPSS, version 15.0.1 and were stratified by race and sex ( $p$ : $<0.05$ for all sex and race interaction with indicators of SES). Differences in main characteristics between black and white, men and women were determined using chi-square tests for categorical variables and t-test statistics for continuous variables. Cross tabulations of lifestyle factors among the different SES strata were calculated to study the association between SES and lifestyle factors.

To evaluate the relationship between lifestyle factors and incident depressive symptoms, Cox proportional hazard regression models were fitted, adjusting for age, site, marital status and, to avoid confounding and a possible selection effect on socioeconomic status, prevalent diseases. If a person developed deppresive symptoms, person time (in months) was set at the interview during which the person reported depressive symptoms (24, 36, 48, 60, 84, 108 months). Persons surviving with no evidence of deppresive symptoms were censored at the last follow-up measurement (108 months). Those who died ( $n=722)$ with no evidence of depressive symptoms were censored at time of death (months from baseline), and those lost to follow-up were censored at their last follow-up measurement $(0,24,36,48$, 60, 84 months).

To determine if there were differences in (time to) incidence of deppresive symptoms between SES groups, Cox Proportional Hazard regression models were fitted. The first model included age, site, marital status, and prevalent diseases at baseline. The analyses for income were also adjusted for the number of persons in the household other than spouse. The second model was additionally adjusted for all lifestyle variables. A percentage reduction in hazard ratio from model 1 was computed using: $\left(\mathrm{HR}_{\text {model } 1}-\mathrm{HR}_{\text {model }} 2\right) /\left(\mathrm{HR}_{\text {model }} \mathrm{-}-1\right) * 100 \%$. Mediation was considered present when imputation of the lifestyle variable(s) in the logistic regression analyses caused at least a $10 \%$ decrease in relative risk compared with the original relative risk associated with SES on incident depressive symptoms. ${ }^{29}$ The proportional hazards assumption was investigated by testing the constancy of the log hazard ratio over time by means of log-minus-log survival plots and interactions with time (log transformed). According to the tests, the proportional hazard assumption was not violated $(p>0.05)$. 


\section{RESULTS}

Table 1 shows how covariates, baseline SES factors and lifestyle factors were distributed among black and white men and women. Black participants were less well educated, reported less income than needed, and fewer assets compared with white participants. In general, women reported lower incomes and fewer assets, compared with men. Furthermore, black men and women were significantly more likely than whites to be obese and to report unhealthy lifestyles, such as smoking and being inactive. However, they more often reported alcohol abstinence $(69 \%$ of black women), while white men more often reported heavier drinking (13.3\%). In general, black and white men were more likely to have ever smoked in life and to drink alcohol, while women were more likely to be inactive.

All indicators of SES were consistently associated with lifestyle factors (not tabulated). Black and white men and women from lower SES groups were more likely to have unhealthy lifestyle factors at baseline, such as smoking, inactivity, and obesity. These associations were strongest in black men and women. More than $35 \%$ of black women with a low educational level reported an inactive physical activity pattern, in contrast with only $18 \%$ of black women with higher educational levels. Opposite associations for alcohol intake were found, with white men from high SES groups reporting the highest alcohol intake. For example, $16 \%$ of white men with high levels of education reported heavier alcohol intake, in contrast to only $8 \%$ of white men with lower levels of education.

Table 2 shows the relationship between lifestyle factors and incident depressive symptoms over nine years. While the magnitude of the relationships was fairly consistent across all the four race-sex groups, significant relationships were found for white women only. In this group, inactive physical activity pattern ( $\mathrm{HR}=1.59,95 \% \mathrm{Cl}$ : 1.08-2.33) and being a current smoker $(\mathrm{HR}=1.65,95 \% \mathrm{Cl}: 1.09-2.51)$ predicted depressive symptoms, even after adjusting for age, site, marital status, and prevalent diseases. 
Table 1 Distribution of covariates, baseline SES, and lifestyle factors among study participants ${ }^{\mathrm{a}}$

\begin{tabular}{|c|c|c|c|c|c|c|c|}
\hline & \multicolumn{3}{|c|}{ Men } & \multicolumn{3}{|c|}{ Women } & \multirow{2}{*}{$\begin{array}{l}\text { Men vs } \\
\text { Women } \\
\text { p-value }\end{array}$} \\
\hline & $\begin{array}{l}\text { White } \\
(n=850)\end{array}$ & $\begin{array}{c}\text { Black } \\
(n=513)\end{array}$ & $\mathrm{p}$-value & $\begin{array}{l}\text { White } \\
(n=735)\end{array}$ & $\begin{array}{c}\text { Black } \\
(n=659)\end{array}$ & p-value & \\
\hline \multicolumn{8}{|l|}{ Covariates } \\
\hline Mean age (SD) & $73.9(2.93)$ & $73.5(2.78)$ & 0.008 & $73.6(2.76)$ & $73.4(2.94)$ & 0.166 & 0.016 \\
\hline Pittsburgh (\%) & 49.2 & 50.5 & 0.639 & 44.9 & 53.9 & 0.001 & 0.781 \\
\hline Married (\%) & 73.4 & 62.2 & $<0.001$ & 44.8 & 22.9 & $<0.001$ & $<0.001$ \\
\hline$\geq 1$ prevalent chronic diseases (\%) & 68.6 & 63.7 & 0.027 & 68.0 & 59.8 & 0.019 & 0.021 \\
\hline Mean CES-D score at baseline (SD) & $2.11(2.20)$ & $2.40(2.47)$ & 0.032 & $2.72(2.46)$ & $2.66(2.48)$ & 0.679 & $<0.001$ \\
\hline \multicolumn{8}{|l|}{ Education (\%) } \\
\hline Low & 13.8 & 49.3 & $<0.001$ & 10.3 & 37.9 & $<0.001$ & $<0.001$ \\
\hline Middle & 25.6 & 24.0 & & 41.9 & 35.4 & & \\
\hline High & 60.6 & 26.7 & & 47.8 & 26.7 & & \\
\hline \multicolumn{8}{|l|}{ Income (\%) } \\
\hline$<10.000$ & 1.1 & 16.6 & $<0.001$ & 6.0 & 27.3 & $<0.001$ & $<0.001$ \\
\hline $10.000-<25.000$ & 24.8 & 44.1 & & 31.3 & 43.4 & & \\
\hline $25.000-<50.000$ & 37.9 & 23.0 & & 33.7 & 13.8 & & \\
\hline$\geq 50.000$ & 26.6 & 8.2 & & 14.4 & 1.8 & & \\
\hline Missing & 9.6 & 8.2 & & 14.6 & 13.7 & & \\
\hline \multicolumn{8}{|l|}{ How well does income fit need? (\%) } \\
\hline Poorly & 1.9 & 8.8 & $<0.001$ & 1.8 & 10.9 & $<0.001$ & 0.001 \\
\hline Fairly well & 36.5 & 54.6 & & 36.5 & 60.4 & & \\
\hline Very well & 58.6 & 34.3 & & 57.0 & 25.6 & & \\
\hline Missing & 3.1 & 2.3 & & 4.8 & 3.0 & & \\
\hline \multicolumn{8}{|l|}{ Assets (\%) } \\
\hline 0 & 6.2 & 21.2 & $<0.001$ & 12.0 & 31.6 & $<0.001$ & $<0.001$ \\
\hline $1-2$ & 28. & 59.5 & & 29.5 & 54.3 & & \\
\hline $3-7$ & 65.6 & 19.3 & & 58.5 & 14.1 & & \\
\hline \multicolumn{8}{|l|}{ Smoking (\%) } \\
\hline Current & 5.1 & 20.1 & $<0.001$ & 7.6 & 12.3 & 0.004 & $<0.001$ \\
\hline Former, stopped $\leq 10$ years ago & 57.2 & 39.2 & & 26.8 & 23.4 & & \\
\hline Former; stopped $>10$ years ago & 8.1 & 9.9 & & 6.3 & 8.8 & & \\
\hline Never & 29.6 & 30.8 & & 59.3 & 55.5 & & \\
\hline \multicolumn{8}{|l|}{ Alcohol consumption (\%) } \\
\hline Heavier & 13.3 & 9.2 & $<0.001$ & 4.9 & 1.7 & $<0.001$ & $<0.001$ \\
\hline Abstinence & 35.8 & 53.8 & & 47.2 & 69.3 & & \\
\hline Moderate & 50.9 & 37.0 & & 64.8 & 29.0 & & \\
\hline \multicolumn{8}{|l|}{ Physical activity (\%) } \\
\hline Inactive & 16.4 & 28.7 & $<0.001$ & 22.7 & 27.2 & 0.002 & $<0.001$ \\
\hline Lifestyle active & 42.2 & 50.5 & & 57.4 & 59.6 & & \\
\hline Exercise & 41.4 & 20.9 & & 19.9 & 13.2 & & \\
\hline \multicolumn{8}{|l|}{ BMI (\%) } \\
\hline Obese $(\geq 30.0)$ & 19.1 & 25.9 & 0.001 & 16.7 & 43.9 & $<0.001$ & $<0.001$ \\
\hline Overweight $(25.0-<30.0)$ & 51.3 & 41.5 & & 38.8 & 35.7 & & \\
\hline Normal weight $(<25.0)$ & 29.6 & 32.6 & & 44.5 & 20.5 & & \\
\hline
\end{tabular}

${ }^{a}$ Differences between groups were tested using 2-tailed t-tests for continues measures, and Chi-square tests for categorical variables. 
Table 2 Hazard Ratios (HR) and 95\% confidence intervals (Cl) for incident depressive symptoms by lifestyle factors $^{\text {a }}$

\begin{tabular}{|c|c|c|c|c|}
\hline \multirow{4}{*}{ Cases $(\%)^{b}$} & \multicolumn{2}{|c|}{ Men } & \multicolumn{2}{|c|}{ Women } \\
\hline & White $(n=850)$ & Black $(n=513)$ & White $(n=735)$ & Black (n=659) \\
\hline & $236(27.8 \%)$ & $160(31.2 \%)$ & $273(37.1 \%)$ & $234(35.5 \%)$ \\
\hline & $\mathrm{HR}(95 \% \mathrm{Cl})$ & $\mathrm{HR}(95 \% \mathrm{Cl})$ & $\mathrm{HR}(95 \% \mathrm{Cl})$ & $\mathrm{HR}(95 \% \mathrm{Cl})$ \\
\hline \multicolumn{5}{|l|}{ Smoking } \\
\hline Current & $1.37(0.74-2.55)$ & $1.23(0.77-1.96)$ & $1.65(1.09-2.51)$ & $1.04(0.68-1.58)$ \\
\hline Former, stopped $\leq 10$ years ago & $1.25(0.93-1.69)$ & $1.09(0.75-1.59)$ & $1.11(0.84-1.46)$ & $0.84(0.61-1.16)$ \\
\hline Former; stopped >10years ago & $1.46(0.86-2.50)$ & $1.42(0.82-2.45)$ & $1.26(0.74-2.15)$ & $0.95(0.60-1.51)$ \\
\hline Never ${ }^{c}$ & Ref & Ref & Ref & Ref \\
\hline \multicolumn{5}{|l|}{ Alcohol consumption } \\
\hline Heavier & $0.69(0.44-1.08)$ & $0.76(0.39-1.49)$ & $0.87(0.45-1.66)$ & $0.52(0.13-2.15)$ \\
\hline Abstinence & $1.05(0.79-1.38)$ & $0.89(0.64-1.23)$ & $1.18(0.92-1.52)$ & $0.96(0.72-1.27)$ \\
\hline Moderate $^{c}$ & Ref & Ref & Ref & Ref \\
\hline \multicolumn{5}{|l|}{ Physical activity } \\
\hline Inactive & $1.29(0.89-1.87)$ & $1.36(0.87-2.40)$ & $1.59(1.08-2.33)$ & $1.43(0.93-2.19)$ \\
\hline Lifestyle active & $1.15(0.86-1.53)$ & $1.16(0.77-1.75)$ & $1.26(0.90-1.77)$ & $0.94(0.64-1.39)$ \\
\hline Exercise $^{c}$ & Ref & Ref & Ref & Ref \\
\hline \multicolumn{5}{|l|}{ Body Mass Index } \\
\hline Obese (BMI $\geq 30)$ & $1.25(0.87-1.80)$ & $1.27(0.85-1.96)$ & $1.02(0.73-1.42)$ & $1.26(0.89-1.80)$ \\
\hline Overweight $(25-<30)$ & $0.94(0.70-1.28)$ & $0.97(0.67-1.41)$ & $0.94(0.72-1.22)$ & $1.05(0.73-1.52)$ \\
\hline Normal $(<25)^{c}$ & Ref & Ref & Ref & Ref \\
\hline
\end{tabular}

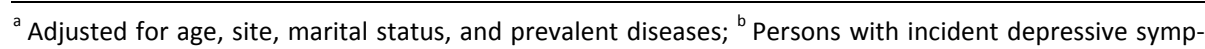
toms; ${ }^{c}$ Category of reference in analysis.

Tables 3 and 4 show the relationship between SES and incident depressive symptoms for white and black men and women, respectively. For white men, hazard ratios for incident depressive symptoms, adjusted for all covariates were significantly higher in the lowest income groups and those reporting inadequate income. These relationships remained statistically significant after adjustment for all lifestyle factors ( $\mathrm{HR}=3.14 ; 95 \% \mathrm{Cl}: 1.23-8.02$ and $\mathrm{HR}=2.63 ; 95 \% \mathrm{Cl}: 1.33-5.21$, respectively). In black men, adjusted hazard ratios of depressive symptoms by income were even higher ( $\mathrm{HR}=5.32,95 \% \mathrm{Cl}: 2.21-12.83)$. Low education and fewer assets were also significant predictors of depressive symptoms in black men, with adjusted hazard ratios of 2.36 (95\% $\mathrm{Cl}: 1.56-3.57)$ and $1.70(95 \% \mathrm{Cl}: 1.01-2.85)$ respectively.

For white women, hazard ratios for incident depressive symptoms, adjusted for all covariates, were significantly higher in those with low education. When additionally adjusted for lifestyle factors, this relation remained statistically significant ( $\mathrm{HR}=1.73 ; 95 \% \mathrm{Cl}: 1.19-2.50)$. For black women, hazard ratios were higher for middle and low educated women $(\mathrm{HR}=2.32 ; 95 \% \mathrm{Cl}: 1.60-3.37$ and $\mathrm{HR}=1.94,95 \% \mathrm{Cl}$ 
1.32-2.83, respectively). Also in black women, compared with those who perceived their income as 'very well' and had three to seven assets, those with poorly perceived income and fewer assets had higher rates of depressive symptoms with adjusted hazard ratios of 2.05 (95\% $\mathrm{Cl}: 1.32-3.17)$ and 1.65 (95\% $\mathrm{Cl}: 1.05-2.60)$ respectively.

Overall, no relevant reductions $(\geq 10 \%)$ of the hazard ratios were found when lifestyle factors were introduced into the model.

Table 3 Hazard Ratio's (HR) and 95\% confidence intervals (Cl's) of incident depressive symptoms according to SES strata in men $(n=1,375)$

\begin{tabular}{|c|c|c|c|c|}
\hline \multirow{4}{*}{ Cases (\%) } & \multirow{2}{*}{\multicolumn{2}{|c|}{$\begin{array}{c}\text { White }(n=850) \\
236(27.8 \%)\end{array}$}} & \multirow{2}{*}{\multicolumn{2}{|c|}{$\begin{array}{c}\text { Black }(n=513) \\
160(31.2 \%)\end{array}$}} \\
\hline & & & & \\
\hline & Model $1^{a}$ & Model $2^{b}$ & Model $1^{\mathrm{a}}$ & Model $2^{b}$ \\
\hline & $\mathrm{HR}(95 \% \mathrm{Cl})$ & HR $(95 \% \mathrm{Cl})$ & $\mathrm{HR}(95 \% \mathrm{Cl})$ & $\mathrm{HR}(95 \% \mathrm{Cl})$ \\
\hline \multicolumn{5}{|l|}{ Income } \\
\hline 1 (Low) & 2.99 (1.18-7.57) & $3.14(1.23-8.02)$ & $5.32(2.21-12.76)$ & $5.32(2.21-12.83)$ \\
\hline 2 & $1.43(1.00-2.05)$ & $1.41(0.99-2.03)$ & $3.69(1.60-8.52)$ & $3.71(1.60-8.63)$ \\
\hline 3 & $1.29(0.86-1.66)$ & $1.20(0.86-1.67)$ & $2.13(0.88-5.13)$ & $2.16(0.89-5.23)$ \\
\hline 4 (high) $^{c}$ & Ref & Ref & Ref & Ref \\
\hline \multicolumn{5}{|l|}{ Education } \\
\hline Low & $1.01(0.67-1.51)$ & $0.98(0.65-1.47)$ & $2.37(1.57-3.57)$ & $2.36(1.56-3.57)$ \\
\hline Middle & $0.95(0.70-1.29)$ & $0.92(0.67-1.26)$ & $1.46(0.84-2.37)$ & $1.43(0.87-2.33)$ \\
\hline $\mathrm{High}^{\mathrm{c}}$ & Ref & Ref & Ref & Ref \\
\hline \multicolumn{5}{|l|}{ Perc income } \\
\hline Poorly & $2.68(1.36-5.28)$ & $2.63(1.33-5.21)$ & $1.75(0.98-3.10)$ & $1.65(0.92-2.97)$ \\
\hline Fairly well & $1.31(1.00-1.72)$ & $1.29(0.98-1.69)$ & $1.41(0.99-2.03)$ & $1.41(0.98-2.03)$ \\
\hline Very well $^{c}$ & Ref & Ref & Ref & Ref \\
\hline \multicolumn{5}{|l|}{ Assets } \\
\hline 0 & $0.85(0.47-1.54)$ & $0.81(0.45-1.46)$ & $1.78(1.07-2.97)$ & $1.70(1.01-2.85)$ \\
\hline $1-2$ & $0.99(0.73-1.33)$ & $0.96(0.71-1.30)$ & $1.57(1.01-2.42)$ & $1.51(0.98-2.34)$ \\
\hline $3-7^{c}$ & Ref & Ref & Ref & Ref \\
\hline
\end{tabular}

${ }^{a}$ Adjusted for age, site, marital status, and prevalent diseases; analyses for income are also adjusted for the number of persons in the household other than spouse; ${ }^{b}$ Adjusted for the variables listed under ${ }^{1}$ and for smoking, drinking, physical activity and $\mathrm{BMI}$; ${ }^{\mathrm{c}}$ Category of reference in analysis. 
Table 4 Hazard Ratio's (HR) and 95\% confidence intervals ( $\mathrm{Cl}$ 's) of incident depressive symptoms according to SES strata in women $(n=1,411)$

\begin{tabular}{|c|c|c|c|c|}
\hline \multirow{4}{*}{ Cases (\%) } & \multirow{2}{*}{\multicolumn{2}{|c|}{$\begin{array}{c}\text { White }(n=735) \\
273(37.1 \%)\end{array}$}} & \multirow{2}{*}{\multicolumn{2}{|c|}{$\begin{array}{c}\text { Black }(n=659) \\
234(35.5 \%)\end{array}$}} \\
\hline & & & & \\
\hline & Model $1^{\mathrm{a}}$ & Model $2^{b}$ & Model $1^{\mathrm{a}}$ & Model $2^{b}$ \\
\hline & $\mathrm{HR}(95 \% \mathrm{Cl})$ & $\mathrm{HR}(95 \% \mathrm{Cl})$ & $\mathrm{HR}(95 \% \mathrm{Cl})$ & $\mathrm{HR}(95 \% \mathrm{Cl})$ \\
\hline \multicolumn{5}{|l|}{ Income } \\
\hline 1 (Low) & $1.23(0.66-2.29)$ & $1.11(0.59-2.07)$ & $1.16(0.50-2.70)$ & $1.04(0.44-2.48)$ \\
\hline 2 & $1.48(0.98-2.24)$ & $1.38(0.91-2.09)$ & $1.07(0.47-2.45)$ & $0.97(0.42-2.25)$ \\
\hline 3 & $1.31(0.88-1.97)$ & $1.25(0.83-1.89)$ & $0.72(0.30-1.76)$ & $0.67(0.28-1.64)$ \\
\hline 4 (high) $^{c}$ & Ref & Ref & Ref & Ref \\
\hline \multicolumn{5}{|l|}{ Education } \\
\hline Low & $1.80(1.26-2.59)$ & $1.73(1.19-2.50)$ & $1.95(1.35-2.82)$ & $1.94(1.32-2.83)$ \\
\hline Middle & $1.14(0.88-1.48)$ & 1.15 (0.89-1.49) & $2.25(1.57-3.24)$ & $2.32(1.60-3.37)$ \\
\hline $\mathrm{High}^{\mathrm{c}}$ & Ref & Ref & Ref & Ref \\
\hline \multicolumn{5}{|l|}{ Perc income } \\
\hline Poorly & $0.89(0.33-2.42)$ & $0.80(0.29-2.17)$ & $2.04(1.32-3.13)$ & $2.05(1.32-3.17)$ \\
\hline Fairly well & $1.16(0.90-1.49)$ & $1.13(0.88-1.45)$ & $1.27(0.92-1.74)$ & $1.27(0.92-1.76)$ \\
\hline Very well $^{c}$ & Ref & Ref & Ref & Ref \\
\hline \multicolumn{5}{|l|}{ Assets } \\
\hline 0 & $0.96(0.65-1.44)$ & $0.88(0.59-1.33)$ & $1.68(1.07-2.63)$ & $1.65(1.05-2.60)$ \\
\hline $1-2$ & $1.15(0.88-1.51)$ & $1.09(0.83-1.43)$ & $1.58(1.04-2.40)$ & $1.55(1.01-2.37)$ \\
\hline $3-7^{c}$ & Ref & Ref & Ref & Ref \\
\hline
\end{tabular}

${ }^{a}$ Adjusted for age, site, marital status, and prevalent diseases; analyses for income are also adjusted for the number of persons in the household other than spouse; ${ }^{b}$ Adjusted for the variables listed under ${ }^{a}$ and for smoking, drinking, physical activity and $\mathrm{BMI}$; ${ }^{\mathrm{C}}$ Category of reference in analysis.

\section{DISCUSSION}

This study in older black and white men and women showed that low SES predicted an increased incidence of depressive symptoms over nine years. In black men, socioeconomic differences in depressive symptoms were especially strong ( $H R=5.32)$. Although unhealthy lifestyle factors were inversely associated with SES levels at baseline in all groups, unhealthy lifestyle factors were only weakly related to depressive symptoms during follow-up. Furthermore, lifestyle factors did not substantially reduce the hazard ratios for depressive symptoms by SES.

Our results confirm the presence of a social gradient in depressive symptoms among initially healthy older persons in their seventies. We showed not only considerable socioeconomic differences in the incidence of depressive symptoms, but also racial and sex differences herein ( $p$-values for interaction all<0.05). The absolute prevalence and incidence of depressive symptoms was highest in white women 
(see Tables 1 and 4). In contrast, black men with low incomes had a risk of incident depressive symptoms in excess of five times the risk in black men with high incomes.

We also showed differences in the relevance of the individual SES measures in predicting depressive symptoms. Income was an important predictor of incident depressive symptoms in men but not women, whereas in women educational level was important. Comparing black and white men, perceived income seemed to have more importance predicting depressive symptoms in white men, while a more absolute measure on the number of financial assets had more predictive power in black men. Perceived income and the number of financial assets seemed to have more importance in predicting depressive symptoms in black women, compared with white women.

The relationship between SES and depressive symptoms was only weakly mediated by lifestyle factors, in all four race/sex subgroups. These findings agree with earlier studies examining the role of lifestyle factors on the relationship between SES and depression. ${ }^{13,14}$ For example, Koster et al found that lifestyle factors explained less than $5 \%$ of the association between SES and incident depression in Dutch older adults. ${ }^{14}$ Furthermore, in the Whitehall II study among male and female civil servants in London, UK, Stansfeld et al found that lifestyle factors were an important explanatory factor for the gradient in physical functioning but not for the gradient in depressive symptoms. ${ }^{13}$ Alternative explanations for socioeconomic, racial, and sex differences in depressive symptoms may have a psychosocial background. For example, exposure to major life stressors and low levels of social support and social integration are good candidates for mediation between SES and depression. ${ }^{30,31}$ Moreover, it has been suggested that the experience of low social status itself can program a 'defensive' phenotype, which is marked by sustained activation of stress-related autonomic and neuro-endocrine responses. ${ }^{32}$ These stress responses may contribute to the onset of depressive symptoms later in life. Further research on explanation for socioeconomic differences in depressive symptoms in otherwise healthy older persons is recommended to develop effective interventions in the near future.

\section{Strengths and limitations}

The strengths of this study include the use of a relatively long follow-up period to study the onset of depressive symptoms. The ability to exclude cases with prevalent depressive symptoms at baseline allowed for extensive longitudinal analyses to study the causal pathway between SES and depressive symptoms over a period of nine years time. This study has a few limitations, however.

First, the definition of depression is classically a fluctuating condition. The concept of 'incidence' might not fit well with its natural history. Although we have used 
a relatively healthy older population, initially free of mobility limitations and depressive symptoms, there is an unknown period preceding the window of observation, as well as in between measurements. Therefore, it is likely that a number of depressive symptoms cases have been missed in our analyses. It is unclear how this misclassification may have affected the results of our study.

Second, the study relied on self-reports for data on SES, lifestyle factors, and depressive symptoms. Individuals with a general tendency towards negative perceptions of material well-being (e.g. perceived income, assets) may also over-report depressive symptoms. ${ }^{33}$ This may have led to an overestimation of the presented relations. However, by excluding persons with prevalent depressive symptoms at baseline from the analyses, this potential bias should be minimal. ${ }^{34,35}$

Third, because of the observational nature of this study, we cannot exclude that lifestyle modifications may have attenuated the impact of low SES on depression. Furthermore, controlling for prevalent disease at baseline may be considered as over-adjustment and might also have attenuated the effect of lifestyle factors. In this respect, pathways linking lifestyle factors to depression, mediated by disease might also be plausible. Additional analyses, in which we have looked at the role of prevalent and incident diseases in separate models, however, yielded similar results with regard to the lifestyle factors.

Fourth, our research may be limited by potential selection biases. The goal of recruitment for the Health $A B C$ study was not to have a representative sample but rather enrollment of a high-functioning cohort to examine onset of functional limitations. Hence, the study sample was restricted to a relatively healthy subset of the older population, with a low prevalence of depressive symptoms at baseline $(n=263$, $8.6 \%$ ). Consequently, our findings may not be generalisable to a more frail older population.

Finally, attrition (between 1997 and 2006, 1,411 participants (51.2\%) were lost to follow-up due to death or other reasons) was higher for black men and persons with lower SES $(p<0.05)$. Missing value analyses showed that persons with missing scores on variables of interest were significantly more likely to be from lower SES groups $(p<0.05)$ and to have higher scores on the CES-D10 at baseline $(p<0.05)$. This pattern of missing values and attrition also may have led to an underestimation of key associations.

\section{CONCLUSION}

This study showed considerable socioeconomic, racial and sex differences in the incidence of depressive symptoms in a relatively healthy subsample of older persons in the United States. Black men with low perceived income in particular were at heightened risk of depressive symptoms. The mediating effect of lifestyle factors 
on the relationship between SES and incident depressive symptoms was weak. Further research on alternative explanation for socioeconomic differences in depressive symptoms in older persons is recommended to help develop effective interventions.

Acknowledgements

This research was supported by National Institute on Aging (NIA) Contracts N01-AG6-2101; N01-AG-6-2103; N01-AG-6-2106; NIA grant R01-AG028050, and NINR grant R01-NR012459.

This research was supported in part by the Intramural Research Program of the National Institutes of Health, National Institute on Aging.

The researchers are indebted to the participants for their willingness to participate in the study. 


\section{REFERENCES}

1. Adler NE, Ostrove JM. Socioeconomic status and health: what we know and what we don't. Ann N Y Acad Sci. 1999;896:3-15.

2. Fein 0 . The influence of social class on health status: American and British research on health inequalities. J Gen Intern Med. 1995;10(10):577-86.

3. Galobardes B, Lynch JW, Davey Smith G. Measuring socioeconomic position in health research. Br Med Bull. 2007;81-82:21-37.

4. Kaplan GA, Keil JE. Socioeconomic factors and cardiovascular disease: a review of the literature. Circulation. 1993;88:1973-88.

5. Kitagawa EM, Hauser PM. Differential mortality in the United States: A study in socioeconomic epidemiology. Cambridge, MA: Harvard University Press; 1973.

6. Marmot M, Ryff CD, Bumpass LL, Shipley MJ, Marks NF. Social inequalities in health: next questions and converging evidence. Soc Sci Med. 1997;44(6):901-10.

7. Marmot MG, Shipley MJ, Rose G. Inequalities in death--specific explanations of a general pattern? Lancet. 1984;1(8384):1003-6.

8. Pamuk ER. Social class inequality from 1921 to 1972 in England and Wales. Popul Stud. 1985;39(1):17-31.

9. Sorlie PD, Backlund E, Keller JB. US mortality by economic, demographic, and social characteristics: the National Longitudinal Mortality Study. Am J Public Health. 1995;85(7):949-56.

10. Wilkinson RG. Income distribution and life expectancy. Br Med J. 1992;304:165-8.

11. Martikainen P, Adda J, Ferrie JE, Davey Smith G, Marmot M. Effects of income and wealth on GHQ depression and poor self-rated health in white collar women and men in the Whitehall II study. J Epidemiol Community Health. 2003;57:718-23.

12. Lorant $V$, Deliège $D$, Eaton $W$, Robert $A$, Philippot $P$, Ansseau $M$. Socioeconomic inequalities in depression: a meta analysis. Am J Epidemiol. 2003;157:98-112.

13. Stansfeld SA, Head J, Fuhrer R, Wardle J, Cattell V. Social inequalities in depressive symptoms and physical functioning in the Whitehall II study: exploring a common cause explanation. J Epidemiol Community Health. 2003;57:361-7.

14. Koster A, Bosma H, Kempen GIJM, Penninx BW, Beekman AT, Deeg DJ, et al. Socioeconomic differences in incident depression in older adults: the role of psychosocial factors, physical health status, and behavioral factors. Psychosom Med. 2006;61(5):619-27.

15. Stansfeld SA, Bosma H, Hemingway $H$, Marmot MG. Psychosocial work characteristics and social support as predictors of SF-36 health functioning: the Whitehall II study. Psychosom Med. 1998;60:247-55.

16. Giskes K, Turrel G, van Lenthe FJ, Brug J, Mackenbach JP. A multilevel study of socio-economic inequalities in food choice behaviour and dietary intake among the Dutch population: the GLOBE study. Public Health Nutr. 2006;9(1):75-83.

17. Hulshof KF, Brussaard JH, Kruizinga AG, Telman J, Lowik MR. Socio-economic status, dietary intake and 10 y trends: the Dutch National Food Consumption Survey. Eur J Clin Nutr. 2003;57(1):128-37.

18. Droomers M, Schrijvers CT, Stronks K, Van de Mheen HD, Mackenbach JP. Educational differences in excessive alcohol consumption: the role of psychosocial and material stressors. Prev Med. 1999;29(1):1-10.

19. Lynch JW, Kaplan GA, Salonen JT. Why do poor people behave poorly? Variation in adult health behaviours and psychosocial characteristics by stages of the socioeconomic lifecourse. Soc Sci Med. 1997;44(6):809-19.

20. Van Gool CH, G.I.J.M. K, Bosma H, Van Boxtel MP, Jolles J, Van Eijk JTM. Associations between lifestyle and depressed mood: longitudinal results from the Maastricht Aging Study. Am J Public Health. 2007;97(5):887-94.

21. Goodwin RD. Association between physical activity and mental disorders among adults in the United States. Prev Med. 2003;36(6):698-703. 
22. Carpenter KM, Hasin DS, Allison DB, Faith MS. Relationships between obesity and DSM-IV major depressive disorder, suicide ideation, and suicide attempts: results from a general population study. Am J Public Health. 2000;90(2):251-7.

23. Welch CA, Czerwinski D, Ghimire B, Bertsimas D. Depression and costs of health care. Psychosomatics. 2009;50:392-401.

24. Unutzer J, Patrick DL, Simon G, Grembowski D, Walker E, Rutter C, et al. Depressive symptoms and the cost of health services in HMO patients aged 65 years and older. A 4-year prospective study JAMA. 1997;277(20):1618-23.

25. Andresen EM, Malmgren JA, Carter WB, Patrick DL. Screening for depression in well older adults: evaluation of a short form of the CES-D (Center for Epidemiologic Studies Depression Scale). Am J Prev Med. 1994;10:77-84.

26. Radloff LS. The CES-D scale: A self-report depression scale for research in the general population. Appl Psychol Meas. 1977;1:385-401.

27. Koster A, Penninx BW, Bosma H, Kempen GIJM, Newman AB, Rubin SM, et al. Socioeconomic differences in cognitive decline and the role of biomedical factors. Ann Epidemiol. 2005;15:564-71.

28. Ainsworth BE, Haskell WL, Whitt MC, Inwin ML, Swartz AM, Strath SJ, et al. Compendium of physical activities: an update of activity codes and MET intensities. Med Sci Sports Exerc. 2000;32(9 Suppl):498-504.

29. Baron RM, Kenny DA. The moderator-mediator variable distinction in social psychological research: conceptual, strategic, and statistical considerations. J Pers Soc Psychol. 1986;51(6):1173-82.

30. Cohen S. Social relationships and health. Am Psychol. 2004;59:676-84.

31. Berkman LF. The role of social relations in health promotion. Psychosom Med. 1995;57:245-54.

32. Miller GE, Chen E, Fok AK, Walker H, Lim A, Nicholls EF, et al. Low early-life social class leaves a biological residue manifested by decreased glucocorticoid and increased proinflammatory signaling. Proc Natl Acad Sci U S A. 2009;106(34):14716-21.

33. Macleod J, Davey Smith G, Heslop P, Metcalfe C, Carroll D, Hart C. Psychological stress and cardiovascular disease: empirical demonstration of bias in a prospective observational study of Scottish men. Br Med J. 2002;324:1247-53.

34. Kressin NR, Spiro A, Skinner KM. Negative affectivity and health related quality of life. Med Care. 2000;38(8):858-67.

35. Watson D, Pennebakker JW. Health complaints, stress, and distress: exploring the central role of negative affectivity. Psychol Rev. 1989;96(2):234-54. 



\section{ABSTRACT}

\section{Background}

Taking into account our rapidly aging population, older people are of particular interest in studying health inequalities. The aim of the present study is to examine the relation between socioeconomic status and health-related functioning in older people and to find out how material factors (e.g. the lack of basic goods) and psychosocial factors (e.g. low self-efficacy) compare regarding the explanation of these socioeconomic differences.

\section{Methods}

Data came from 5,061 Dutch men and women aged 55 years and older who participated in the longitudinal SMILE study. Baseline data were collected between November 2002 and May 2004 and respondents were followed until May 2009 (followup range: 0 to 5 years). Multilevel analyses were used to study the association between educational level and longitudinal changes in physical and mental functioning (i.e. two subscales of the SF-36) and to study the relative contribution of material and psychosocial factors to this relation.

\section{Results}

Low educational level was associated with poor initial physical and mental functioning. However, no further widening of these gradients was found during follow-up. Material factors reduced the initial educational differences by an average of $29 \%$, while psychosocial factors, mastery and self-efficacy in particular, reduced these differences by an average of $60 \%$.

\section{Conclusion}

More than material factors, psychosocial factors, mastery and self-efficacy in particular, explained a large part of the educational differences in physical and mental functioning in older people. Further research is recommended to explore the amenability to change of characteristics that hamper people from taking control over their lives. 


\section{INTRODUCTION}

Socioeconomic gradients in health and functioning are evident. ${ }^{1,2}$ Taking into account our rapidly aging population, older people are of particular interest in studying health inequalities. From previous studies, we know that socioeconomic health differences still exist in old age. ${ }^{3,4}$ Furthermore, we know that the rate of functional decline is significantly higher in older age groups. ${ }^{5}$ It is, however, less clear if older people from lower socioeconomic status (SES) groups also have higher rates of functional decline, compared with older people from higher SES groups.

Even less attention has been paid to the factors that might account for socioeconomic differences in (changes in) health-related functioning in older people. Potential determinants that have been identified include lifestyle, biological, material, and psychosocial factors. ${ }^{6-8}$ During recent years, material and psychosocial factors in particular have been subject of debate. ${ }^{9}$

According to some scholars, material factors are the most important explanation of health differences. ${ }^{7}$ Material conditions might include financial problems, adverse housing conditions, housing tenure, ownership of a car, and lack of basic goods, such as a freezer or refrigerator. ${ }^{10,11}$ The material hypothesis posits that adverse material conditions in low SES groups may have direct biological effects on health. ${ }^{9,22}$ For example, the lack of a refrigerator (i.e. the inability to store fresh food) has been shown to increase the risk of stomach cancer. ${ }^{12}$ The lack of qualitatively good food and poor housing conditions (e.g. cold and draught) might also affect health and functioning. ${ }^{7}$

On the other hand, the psychosocial hypothesis implies that inequalities are due to the direct or indirect effects of stress stemming from being at the bottom of the socioeconomic hierarchy. ${ }^{8}$ Comparisons with other individuals are argued to be a central phenomenon within human societies. ${ }^{13}$ Negative social comparisons of wealth in low SES groups might have adverse effects on subjective prestige, pride and status, affecting feelings of control, self-esteem, the quality of social contacts, and might ultimately even compromise mental and physical functioning. ${ }^{14}$ Before exploring the possibilities of more targeted health policies to reduce socioeconomic health differences, it is important to obtain an in-depth insight into the potential relevance of both material and psychosocial factors. In the present study, in which we use 5 years of follow-up data from the longitudinal SMILE study among Dutch men and women of 55 years or older, we set out to examine: 1) the relation between SES and baseline differences in health-related functioning, 2) the relation between SES and longitudinal changes in health-related functioning, and 3) whether and to what extent material and/or psychosocial factors contribute to the explanation of SES inequalities in (changes in) health-related functioning. A simplified model of the relationships under study is shown in Figure 1. 


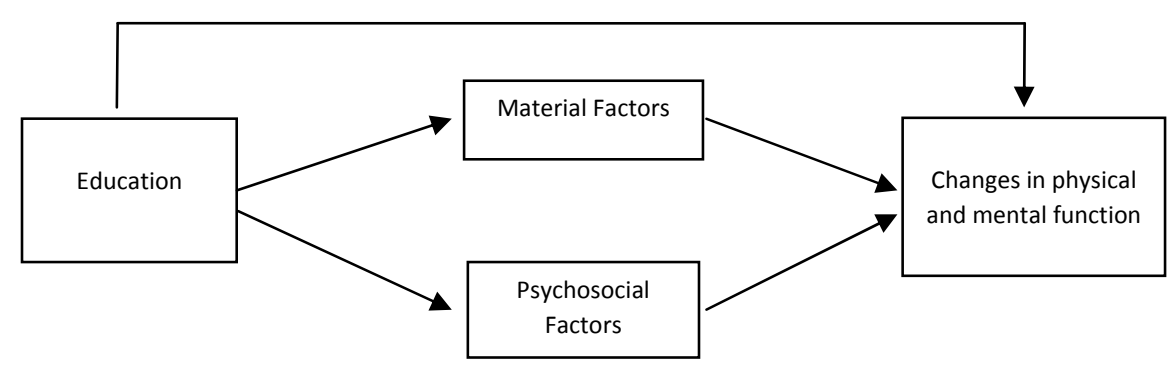

Figure 1 Hypothetical model

\section{METHODS}

\section{Design and study population}

This study is part of the longitudinal SMILE study (i.e. Study on Medical Information and Lifestyles Eindhoven), ${ }^{15}$ a large ongoing dynamic cohort study in the city of Eindhoven in the southern part of the Netherlands. This study is a joint project of Maastricht University and the Corporation of Primary Care Centres in Eindhoven. From November 2002 onwards, biannual postal questionnaires were sent to patients of the participating general practitioners (GP's) (23 GP's from eight health centres) to collect data on health and health determinants. In the Netherlands, almost the whole population is registered in general practices.

Figure 2 shows a flowchart of response and follow-up data in this study. Between November 2002 and May 2004, 10,964 persons of 55 years and older were sent self-administered questionnaires, of whom 7,059 (64.4\%) responded. Participants were included in the analyses sample if complete baseline data on educational level (1,554 missing) and on at least one measurement of physical and mental functioning (444 missing) were available. Consequently, 5,061 respondents were followed up between 0 and 5 years (mean follow-up: 2.5 years, SD 1.7). 


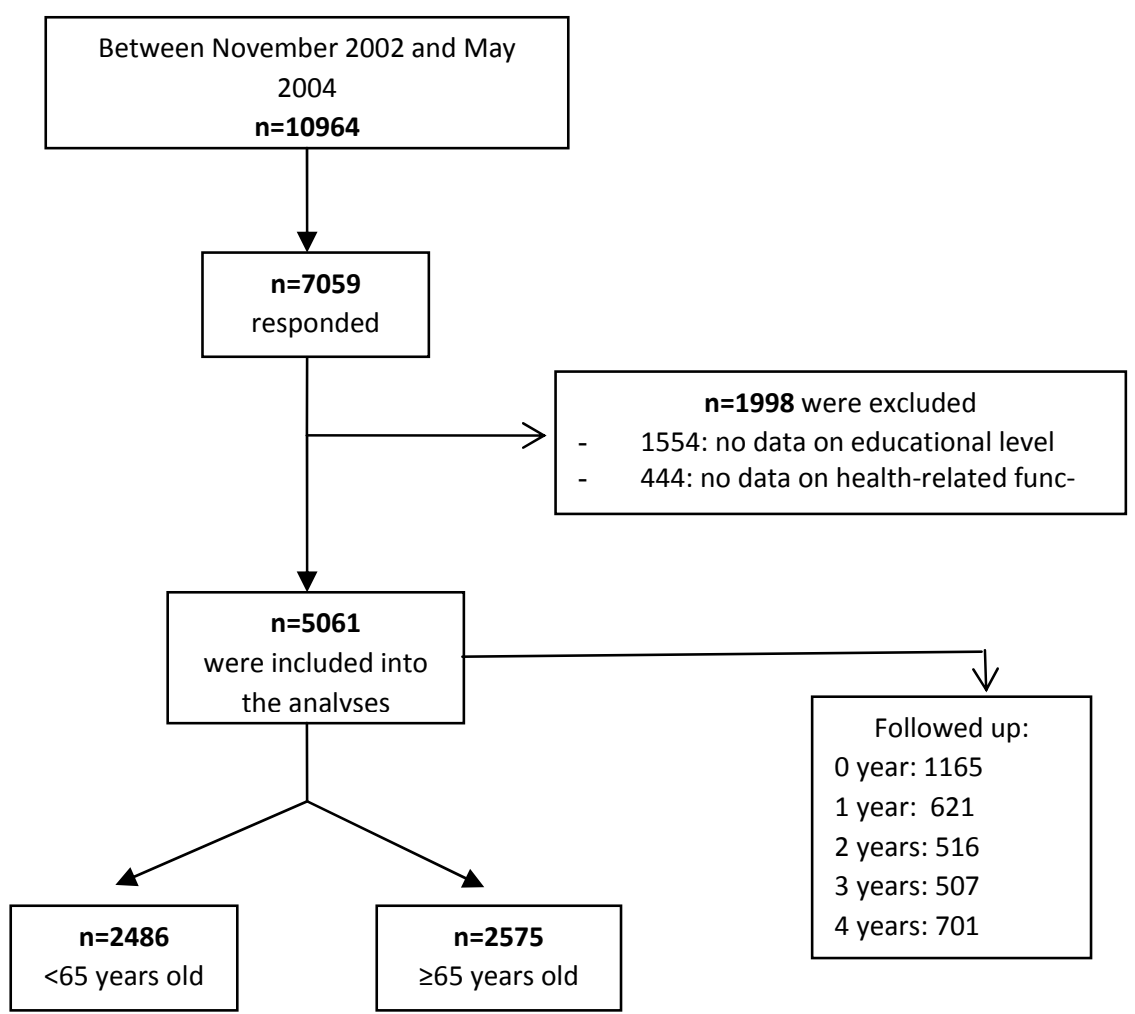

Figure 2 Flowchart response and inclusion in the analysis sample Only baseline measurement of SF-36 available.

\section{Measures}

Data on socioeconomic status, material and psychosocial factors and on covariates were assessed at baseline, using questionnaires sent between November 2002 and May 2004. Data about mental and physical functioning were assessed at baseline and all available follow-up measurements between May 2004 and May 2009.

\section{Socioeconomic status}

Education, as an indicator of socioeconomic status, was measured in November 2002 and May 2003, using a seven-point scale. In the original study sample, three categories were then created in a way that each group contained approximately a third of the sample: primary school only (lowest); lower vocational education and intermediate general education (middle); intermediate vocational education, higher general education, higher vocational education, and university (highest). 


\section{Material factors}

Material factors were measured in May 2004 using a 20-item instrument developed by the Netherlands Institute for Social Research (SCP). ${ }^{16}$ For the purpose of this study, four subscales were created: a) lack of basic goods (range: 0-7) (i.e. enforced lack of one or more of the following items: freezer, refrigerator, car, oven, washing machine, own house, and telephone), b) arrears of payment (range: 0-3) (i.e. one or more of the following arrears of payments: mortgage or rent, utility bills, and hire purchase instalments), c) economic strain (range: 0-6) (i.e. could not afford one or more of the following items or activities: week long holiday away from home, meal with meat, chicken or fish every second day, keep home adequately warm, buy new furniture when needed, buy new clothes when needed, invite family or friends for dinner), and d) perceived financial problems (range: 0-3) (i.e. living expenses are considered heavy or very heavy and/or managing with household income is considered moderately difficult to very difficult and/or reimbursement of debts is considered heavy to very heavy).

In addition, one item concerned poverty in childhood. ${ }^{17}$ Originally, this item consisted of four potential answers ranging from "in the past we constantly lacked money to buy food or new clothes/shoes when necessary" to "we never lacked money in the past". This item was dichotomised, dividing persons with poverty from those without (regularly to always insufficient money versus the rest).

\section{Psychosocial factors}

Psychosocial factors were defined as: 'relating to the interrelation of social factors and individual thought and behaviour' ${ }^{18,19}$ Consequently, psychosocial factors may include characteristics of the self (i.e. personality and psychological factors) and characteristics of the social environment (i.e. social support and social network). Psychosocial factors included self-efficacy, ${ }^{20}$ neuroticism, ${ }^{21}$ mastery, ${ }^{20}$ social support, $^{5}$ and social network. ${ }^{5}$

Self-efficacy, i.e. the extent to which people believe that they can perform a certain behaviour, (16 items, range 16-80, Cronbach's $\alpha=0.85$ ) was measured in November 2002 using the Dutch version of Sherer's General Self-Efficacy Scale. ${ }^{20,22}$ One of the items is: "When trying to learn something new, I soon give up if I am not initially successful". Neuroticism (12 items; range $0-12$; Cronbach's $\alpha=0.85$ ) was measured in May 2003 using the Dutch version of the Eysenck Personality Questionnaire. ${ }^{23}$ Neuroticism is considered a stable personality trait characterized by high levels of negative affect such as depression and anxiety. One of the items is: "Do you consider yourself a worrier?". The Dutch version of Pearlin and Schooler's Mastery scale (seven items; range 7-35; Cronbach's $\alpha=0.83$ ) was used to measure the extent to which people believe that their behaviour matters for the events that occur in their environment in May 2003. ${ }^{20,24}$ One of the items is: "Sometimes I feel that I am being pushed around in life". Social support and social network were both 
measured in November 2002. Social support was measured using the Social Support List of Interactions (SSL12_I), a short scale for measuring received social support in the elderly (12 items; range 12-48; Cronbach's $\alpha=0.91$ ). ${ }^{25}$ One of the items is: "Does it ever happen to you that people invite you to a party or to dinner?". Social network was measured using two questions, assessing how many friends or family members (except for housemates) were available with whom private issues can be discussed or who can provide help, and with whom the participant has contact at least a few times a month. Four categories were created: nobody, 1-4 contacts, 5-9 contacts, and 10 or more contacts.

\section{Health-related functioning}

Data about mental and physical functioning was derived from the Dutch version of the MOS SF36, ${ }^{26}$ annually assessed from May 2004 to May 2009. The SF36 is a shortform health survey of 36 questions, clustered in eight subscales relating to functional health and well-being. The eight scales can be recoded in two distinct higherordered components: physical and mental functioning. ${ }^{27}$

\section{Covariates}

Covariates were age, sex, and follow-up time in years. Furthermore, respondents were asked whether or not they had any of the severe (chronic obstructive pulmonary disease, heart disease, bowel disease, liver disease, kidney disease, diabetes, cancer, epilepsy, and stroke) and less severe (migraine, joints, rheumatoid arthritis, arthrosis, back, injury, and other) chronic diseases. ${ }^{28}$ The number of diseases was measured in May 2003 and May 2004.

\section{Statistical analyses}

All analyses were performed using SPSS, version 17.0.2. The Multiple Imputation (MI) procedure in SPSS was used to replace any missing values for the mediating variables of interest (i.e. material and psychosocial factors). Data were assumed to be Missing At Random (MAR) (i.e. the probability that a value is missing does only depend on values or variables that were measured). ${ }^{29}$ Including a larger set of predictors in the imputation model decreases the likelihood that the MAR assumption is violated. ${ }^{30}$ Our MI model therefore included educational level, health-related functioning outcome measures, severe and less severe diseases, age, sex and material and psychosocial factors. The MI procedure allowed analysis of the entire sample $(n=5,061)$.

Differences in baseline characteristics between educational levels were determined using Chi-square test for categorical variables and t-test and F-test statistics for continuous variables. Two level linear regression analyses (i.e. observations nested within subjects), using the linear mixed models option in SPSS, were per- 
formed to account for the dependency in data. A random intercept model was fitted to examine the educational differences in baseline physical and mental functioning (i.e. intercept estimates) and the longitudinal change in physical and mental functioning over time (i.e. slope estimates, the interaction of educational level with longitudinal time), in which the higher educated group was used as a reference category. Three models were fitted. The first model was adjusted for sex, age, severe and less severe diseases at baseline, and follow-up time in years. Because diseases were not the main focus of the analyses they were included to equalize disease status at baseline. In model 2, material factors were introduced into the first model. Model 3 separately introduced psychosocial factors into the first model. Educational differences in mean scores on physical and mental functioning at baseline (i.e. intercept estimates) and educational differences in changes in mean scores of physical and mental functioning over time (i.e. slope estimates), using the highest educational level as a reference category, will be presented.

A percentage reduction in intercept and slope estimates due to material and psychosocial factors was calculated using:

and

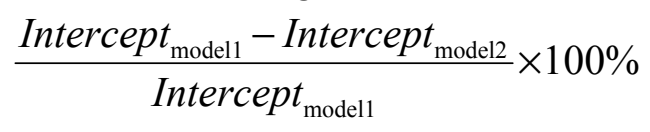

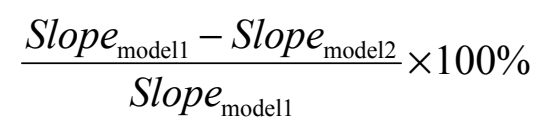

in which model 1 represents the unadjusted model and model 2 the adjusted model. ${ }^{31}$ Mediation was considered present when the introduction of the psychosocial or material factors in the multilevel analyses caused at least a $10 \%$ decrease in estimates of intercept or slope compared with the original intercept and slope of educational level on physical and mental functioning.

Analyses indicated significant interactions between education and age and between follow-up time and age (not tabulated). All analyses were, therefore, performed in two age groups: 55 to 64 years and 65 years and older.

\section{RESULTS}

Table 1 shows baseline characteristics of the study population by educational level and age group. In general, persons with a lower educational level were more likely to report lower physical and mental functioning than persons with higher educational levels. They were also significantly more likely to report lower levels of psychosocial functioning and higher levels of material deprivation, compared with persons with higher educational levels. 
Older persons ( $\geq 65$ years old) were more likely to report poorer physical functioning and severe diseases, compared with persons younger than 65 years old. Moreover, these older persons were somewhat more likely to report lower levels of selfefficacy and mastery, and to report a lack of basic goods. However, they were less likely to report financial problems and to have suffered from poverty in the past, compared with younger persons.

Tables $2 \mathrm{a}$ and $2 \mathrm{~b}$ show the result of the multilevel linear regression analyses. Educational differences in baseline physical and mental functioning as well as educational differences in changes in physical and mental functioning during follow up, in two age groups are shown. In both age groups, persons with lower educational levels had significantly worse physical and mental functioning scores at baseline, compared with persons with the highest educational level. For physical dysfunction in particular, this difference was somewhat higher in the younger age group $(b=-$ $4.18)$, as compared with the higher age group $(b=-3.43)$. In both age groups, however, there was no indication of a steeper longitudinal decline of functioning in lower educational levels and thus no indication of a further longitudinal widening of the socio-economic differences in health-related functioning over time (see Figure 3).

In models 2 and 3 of Tables $2 a$ and $2 b$, material and psychosocial factors were introduced into the model. Material factors reduced the educational differences in baseline physical functioning by an average of $19 \%$, while psychosocial factors reduced these baseline differences by an average of $30 \%$. Material factors reduced the educational differences in baseline mental functioning by an average of $38 \%$. In both age groups, educational differences in baseline mental functioning even lost their statistical significance when psychosocial factors were adjusted for.

When examining the role of the individual psychosocial and material factors (not displayed), mastery accounted for the highest reduction of educational baseline differences in physical functioning, with an average reduction of $31 \%$. Selfefficacy accounted for the highest reduction of educational baseline differences in mental functioning, with an average reduction of $69 \%$.

When the analyses were performed both with and without additional adjustment for severe and less severe diseases, similar patterns of findings were found. 
Table 1 Baseline characteristics of the study population by educational level and age group ${ }^{a}$

\begin{tabular}{|c|c|c|c|c|c|c|c|c|c|c|c|c|}
\hline & & & $<65 y$ & years & 186) & & & $\geq 65$ & years $(n=$ & $=2575)$ & & $<65$ vs \\
\hline & $\begin{array}{c}\% \\
\text { Missing }^{n}\end{array}$ & $\begin{array}{l}\text { Sub } \\
\text { total }\end{array}$ & $\begin{array}{c}\text { Low } \\
n=308\end{array}$ & $\begin{array}{c}\text { Middle } \\
n=999\end{array}$ & $\begin{array}{c}\text { High } \\
n=1179\end{array}$ & $\mathrm{P}$ & $\begin{array}{l}\text { Sub } \\
\text { total }\end{array}$ & $\begin{array}{c}\text { Low } \\
n=690\end{array}$ & $\begin{array}{l}\text { Middle } \\
n=1006\end{array}$ & $\begin{array}{c}\text { High } \\
n=879\end{array}$ & $P$ & $P$ \\
\hline Women (\%) & - & 53.2 & 66.2 & 67.6 & 37.6 & $<0.001$ & 54.3 & 70.9 & 61.6 & 33.0 & $<0.001$ & 0.430 \\
\hline Age (mean) & - & 58.8 & 61.0 & 60.3 & 60.1 & $<0.001$ & 72.9 & 74.8 & 74.0 & 74.7 & 0.005 & $<0.001$ \\
\hline Physical functioning (mean) & - & 48.4 & 45.2 & 48.2 & 49.5 & $<0.001$ & 43.7 & 41.1 & 43.3 & 46.1 & $<0.001$ & $<0.001$ \\
\hline Mental functioning (mean) & - & 51.9 & 48.9 & 51.8 & 52.7 & $<0.001$ & 50.9 & 48.8 & 50.3 & 53.0 & $<0.001$ & 0.178 \\
\hline$\geq 1$ severe diseases $^{\mathrm{b}}(\%)$ & - & 21.2 & 24.4 & 19.7 & 21.7 & 0.190 & 29.9 & 30.9 & 30.8 & 28.0 & 0.325 & $<0.001$ \\
\hline$\geq 1$ less severe diseases ${ }^{c}(\%)$ & - & 44.0 & 39.6 & 43.3 & 45.6 & 0.145 & 44.5 & 43.8 & 43.7 & 46.0 & 0.564 & 0.713 \\
\hline Self-efficacy ${ }^{d}$ (mean) & 31.1 & 58.0 & 53.5 & 57.0 & 60.3 & $<0.001$ & 56.2 & 53.0 & 55.6 & 59.2 & $<0.001$ & 0.002 \\
\hline Mastery ${ }^{\mathrm{e}}$ (mean) & 18.6 & 25.6 & 23.6 & 25.3 & 26.3 & $<0.001$ & 24.0 & 23.0 & 23.7 & 25.1 & $<0.001$ & $<0.001$ \\
\hline Neuroticism ${ }^{f}$ (mean) & 17.2 & 2.8 & 3.7 & 3.0 & 2.5 & $<0.001$ & 2.9 & 3.5 & 3.1 & 2.1 & $<0.001$ & 0.116 \\
\hline Social support ${ }^{\mathrm{g}}$ (mean) & 36.1 & 28.4 & 27.8 & 28.9 & 28.4 & 0.013 & 28.1 & 28.8 & 28.5 & 27.9 & 0.008 & 0.354 \\
\hline Small social network ${ }^{\mathrm{h}}(\%)$ & 26.8 & 13.1 & 15.0 & 13.5 & 10.8 & $<0.001$ & 15.6 & 14.9 & 14.2 & 15.2 & 0.002 & 0.020 \\
\hline$\leq 4$ basic goods ${ }^{i}(\%)$ & 30.0 & 14.4 & 25.2 & 22.1 & 20.3 & $<0.001$ & 18.0 & 34.4 & 25.6 & 19.3 & $<0.001$ & $<0.001$ \\
\hline$\geq 1$ arrears of payment ${ }^{j}(\%)$ & 30.2 & 26.2 & 34.0 & 33.0 & 30.3 & 0.356 & 20.3 & 27.7 & 22.4 & 21.0 & 0.002 & 0.001 \\
\hline Economic strain ${ }^{\mathrm{k}}(\%)$ & 30.2 & 34.8 & 44.4 & 30.5 & 24.1 & $<0.001$ & 34.1 & 41.9 & 29.6 & 22.5 & $<0.001$ & 0.020 \\
\hline Living expenses' (\%) & 30.0 & 35.4 & 44.9 & 34.6 & 28.4 & $<0.001$ & 27.7 & 32.7 & 27.8 & 18.7 & $<0.001$ & $<0.001$ \\
\hline Poverty in the past ${ }^{\mathrm{m}}(\%)$ & 30.6 & 12.0 & 19.0 & 12.2 & 9.7 & $<0.001$ & 9.7 & 16.4 & 9.0 & 5.9 & $<0.001$ & 0.060 \\
\hline
\end{tabular}

${ }^{a}$ For the purpose of presentation, variables on the number of severe and less severe diseases, social network, and material factors were dichotomised; ${ }^{b}$ Percentage of participants that have one or more severe diseases, including chronic obstructive pulmonary disease, heart disease, bowel disease, liver disease, kidney disease, diabetes, cancer, epilepsy, and stroke; ${ }^{c}$ Percentage of participants that have one or more less severe diseases, including migraine, joints, rheumatoid arthritis, arthrosis, back, injury, and other diseases; ${ }^{d}$ Lower scores indicate a lower sense of control; ${ }^{\text {e }}$ Lower scores indicate a lower sense of control; ${ }^{f}$ Higher scores indicate neuroticism; ${ }^{g}$ Lower scores indicate lower levels of social support; ${ }^{\mathrm{h}}$ Percentage of participants that do not have any family or friends with whom he/she has contact at least once a month; ' Percentage of participants that reported to have 4 or less of the following items: freezer, refrigerator, car, oven, washing machine, own house, and telephone; ${ }^{j}$ Percentage of participants that reported to have one or more arrears of payment, including arrears of payment of mortgage or rent, utility bills, and hire purchase instalments; ${ }^{k}$ Percentage of participants that reported not being able to afford one or more of the following items or activities: week long holiday away from home, meal with meat, chicken or fish every second day, keep home adequately warm, buy new furniture when needed, buy new clothes when needed, invite family or friends for dinner; 'Percentage of participants that reported to perceive their financial situation as problematic (i.e. Living expenses are considered heavy or very heavy and/or managing with household income is considered moderately difficult to very difficult and/or reimbursement of debts is considered heavy to very heavy); ${ }^{m}$ Percentage of participants that reported having experienced poverty during upbringing (i.e. "In the past we constantly or regularly lacked the money to buy food or new clothes/shoes when necessary); ${ }^{n}$ Percentage of missing values due to item non-response or non-response in the respective year of measurement, after exclusion of missing values on variables on educational level and health-related function. 


\section{Longitudinal changes in physical functioning}

(younger than 65 years old)

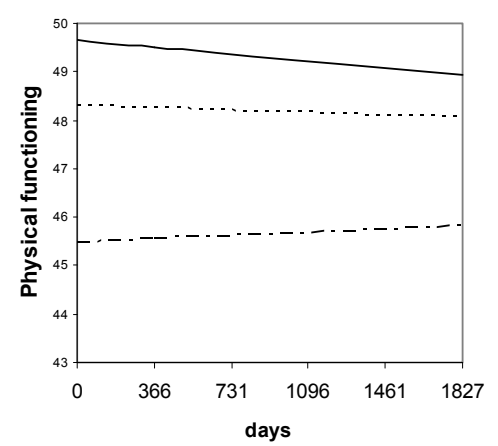

Longitudinal changes in physical functioning

(65 years and older)

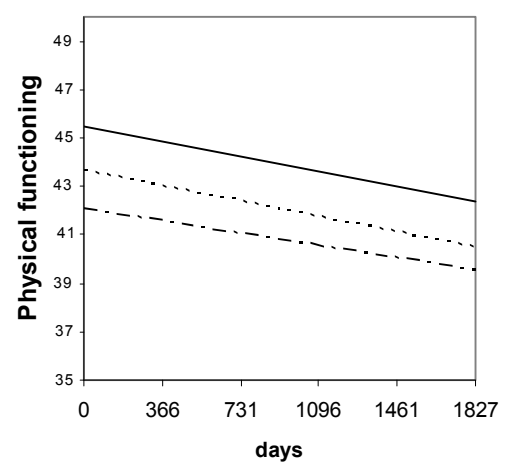

Longitudinal changes in mental functioning

(younger than 65 years old)

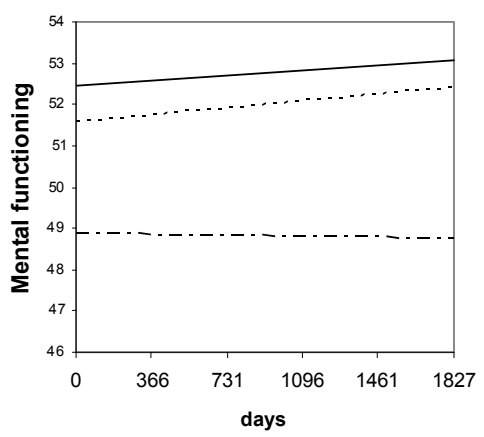

Longitudinal changes in mental functioning

(65 years and older)

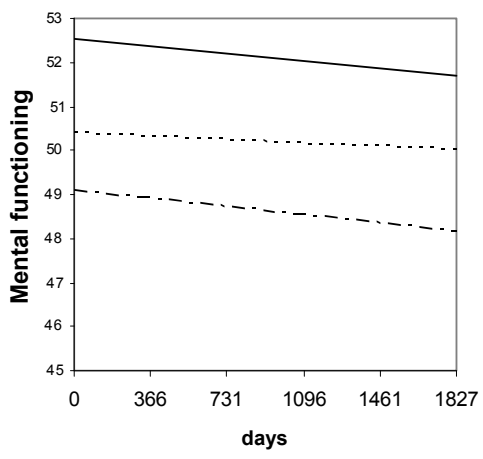

Figure 3 Longitudinal course of physical and mental functioning according to educational level in two age groups (younger than 65 years old and older than 65 years old); Adjusted for sex, age, number of severe and less severe chronic diseases.

:high : middle -...... : low 
Table 2a Educational differences in baseline physical functioning and educational differences in changes in physical functioning over a period of 5 years of follow up ( $<65$ years and $\geq 65$ years old)

\begin{tabular}{|c|c|c|c|c|c|c|c|c|c|c|}
\hline & \multicolumn{2}{|c|}{ Model 1} & \multicolumn{4}{|c|}{$\begin{array}{c}\text { Model } 2 \\
(+ \text { material factors })\end{array}$} & \multicolumn{4}{|c|}{$\begin{array}{c}\text { Model } 3 \\
\text { (+ psychosocial factors) }\end{array}$} \\
\hline & Baseline & Change & Baseline & $\%$ red & Change & $\%$ red & Baseline & $\%$ red & Change & $\%$ red \\
\hline \multicolumn{11}{|c|}{$<65$ years old } \\
\hline \multicolumn{11}{|l|}{ Education } \\
\hline Low & $-4.18 * *$ & 0.20 & $-3.53 * *$ & 15.6 & 0.20 & 0 & $-3.07 * *$ & 26.6 & 0.20 & 0 \\
\hline Medium & $-1.38 * *$ & 0.10 & $-1.15^{*}$ & 16.7 & 0.10 & 0 & $-0.87 *$ & 37.0 & 0.10 & 0 \\
\hline High & Ref & Ref & Ref & & Ref & & Ref & & Ref & \\
\hline \multicolumn{11}{|c|}{$\geq 65$ years old } \\
\hline \multicolumn{11}{|l|}{ Education } \\
\hline Low & $-3.43 * *$ & 0.10 & $-2.62 * *$ & 23.6 & 0.09 & 10 & $-2.58 * *$ & 24.8 & 0.08 & 20 \\
\hline Medium & $-1.86 * *$ & -0.04 & $-1.45^{*}$ & 22.0 & -0.04 & 0 & $-1.28 *$ & 31.2 & -0.04 & 0 \\
\hline High & Ref & Ref & Ref & & Ref & & Ref & & Ref & \\
\hline
\end{tabular}

Table $\mathbf{2 b}$ Educational differences in baseline mental functioning and educational differences in changes in mental functioning over a period of 5 years of follow up ( $<65$ years and $\geq 65$ years old)

\begin{tabular}{|c|c|c|c|c|c|c|c|c|c|c|}
\hline & \multicolumn{2}{|c|}{ Model 1} & \multicolumn{4}{|c|}{$\begin{array}{c}\text { Model } 2 \\
\text { (+ material factors) }\end{array}$} & \multicolumn{4}{|c|}{$\begin{array}{c}\text { Model } 3 \\
\text { (+ psychosocial factors) }\end{array}$} \\
\hline & Baseline & Change & Baseline & $\%$ red & Change & $\%$ red & Baseline & $\%$ red & Change & $\%$ red \\
\hline \multicolumn{11}{|c|}{$<65$ years old } \\
\hline \multicolumn{11}{|l|}{ Education } \\
\hline Low & $-3.62 * *$ & -0.11 & $-2.25 *$ & 37.8 & -0.12 & +9 & -0.07 & 98.1 & -0.16 & +46 \\
\hline Medium & $-0.91 * *$ & 0.05 & -0.37 & 59.3 & 0.04 & 20 & $0.68 *$ & $>100$ & 0.04 & 20 \\
\hline High & Ref & Ref & Ref & & Ref & & Ref & & Ref & \\
\hline \multicolumn{11}{|c|}{$\geq 65$ years old } \\
\hline \multicolumn{11}{|l|}{ Education } \\
\hline Low & $-3.44 * *$ & 0.02 & $-2.45^{* *}$ & 28.8 & -0.01 & $>100$ & -0.72 & 79.1 & -0.05 & $>100$ \\
\hline Medium & $-2.09 * *$ & 0.07 & $-1.56^{*}$ & 25.4 & 0.07 & 0 & -0.33 & 84.2 & 0.08 & +14 \\
\hline High & Ref & Ref & Ref & & Ref & & Ref & & Ref & \\
\hline
\end{tabular}

$*_{*}^{*}=p<0.001 * p<0.05$; Baseline: Beta coefficients of baseline mental functioning in lower and middle educated groups, relative to the higher educated group (i.e. intercept differences); Follow-up: Beta coefficients of changes in mental functioning over time of the lower and middle educated groups, relative to the higher educated group (i.e. slope differences, follow-up time*education); \% red: Percentage reduction of intercept and slope estimates, respectively. (Not adjusted model - Adjusted model)/Not adjusted model)*100\%; Model 1: adjusted for age, sex, severe and less severe diseases and follow-up time; Model 2: adjusted for age, sex, severe and less severe diseases, follow-up time and additionally for material factors; Model 3: adjusted for age, sex, severe and less severe diseases, follow-up time and additionally for psychosocial factors. 


\section{DISCUSSION}

This longitudinal study examined the relation between SES and baseline differences in health-related functioning and the relation between SES and longitudinal changes in health-related functioning in older people. Moreover, the role of material and psychosocial factors on these relations was studied. Results showed that low educational level was associated with initial poor physical and mental functioning. However, no further widening of these gradients was found during a follow-up of a few years. More than material factors, psychosocial factors, mastery and self-efficacy in particular, explained a large part of the educational differences in initial healthrelated functioning.

In general, studies show that socioeconomic gradients persist in old age. ${ }^{32-34}$ In our population, we also found considerable educational differences in initial healthrelated functioning but no further widening during follow-up. It is possible that the initial differences have their origin prior to the baseline measurement when people were 55 years old or older. This supports a life course perspective on health in which it is argued that not only exposures during later adulthood but also in earlier adulthood and even childhood are important for health in old age. ${ }^{35}$ As the followup period of our study was relatively short and the number of people who were followed up was relatively small, we cannot yet exclude, however, a further widening of the socioeconomic gap in health in older age. Moreover, our data might also be indicative of a selective survivor effect, in which those in the most disadvantaged circumstances died prior to the baseline study. The remaining people from lower socioeconomic groups might be relatively protected against further functional decline, possibly because of favourable environmental, social, or genetic resources. ${ }^{36}$

In the present study we showed that educational level is strongly associated with both psychosocial and material factors. For example, material deprivation and poor psychosocial functioning was more common in the lower educated groups. More than material factors, psychosocial factors, mastery and self-efficacy in particular, explained a considerable amount of educational differences in physical and mental functioning. Both mastery and self-efficacy are constructs of control. ${ }^{37} \mathrm{Sev}$ eral authors have addressed low control beliefs as a major mediator of the association of low socioeconomic status with health. ${ }^{34,38,39}$ It is argued that low socioeconomic status in childhood or adult life socialises individuals to emphasise environmental rather than personal causation of behaviour (i.e. "socialized fatalism"). ${ }^{40}$ This lower sense of control undermines coping mechanisms in problem situations, which via psychobiological (e.g. neuro-endocrine) pathways and unhealthy lifestyles will result in adverse health outcomes and physical and mental dysfunction. ${ }^{14}$ The relatively strong role of mastery and self-efficacy in explaining socioeconomic health differences in older people suggests that potential interventions should focus on enabling all persons to take control over their lives. ${ }^{41}$ Taking into account the life 
course perspective of socioeconomic health differences, these interventions should have their origin in early life. ${ }^{41}$ However, increasing control beliefs in those not experiencing the environmental conditions (e.g. control at work and living circumstances) needed for taking control over their lives might be futile. Further research is recommended to explore the exact mechanisms explaining why persons from low SES groups experience a lower sense of control and to what extent these factors are amenable to change.

\section{Methodological considerations}

The strengths of this study include the possibility to use longitudinal data, the use of advanced statistical analyses techniques and the use of various measures of psychosocial and material factors. However, this study also has several limitations.

First, our study has a high number of missing values on material and psychosocial factors. Under the assumption of MAR, they were imputed using MI procedures. However, MI might not perform well in circumstances where the pattern of missing data is not MAR (e.g. Missing not at Random; missing values depend on factors that were not measured in the study). This might have distorted the results of our study.

Second, the conclusions drawn from this study are mainly based upon crosssectional findings, as the analyses of changes over time did not reach statistical significance. Moreover, material and psychosocial factors were measured only once. Consequently, any causal inferences about explanatory pathways could not be firmly made. This issue needs further examination in future longitudinal research.

Third, important indicators of material circumstances such as physical housing, neighbourhood and working conditions were not measured, and are therefore lacking in our study. Simultaneously, it is also not clear whether all psychosocial factors (e.g. job stress) were appropriately covered. This might have biased the full impact of material and psychosocial factors on the relation between educational level and changes in health-related functioning.

Finally, our research may be limited by possible selection biases. Older persons living in convalescent homes were not included, which restricts the generalisability of our findings. Furthermore, the most disadvantaged older persons may be underrepresented in our research because of premature mortality and non-response. Missing value analyses revealed that persons with missing values on educational level at baseline ( $n=1,554$, excluded from analyses sample) were more likely to report lower scores on physical and mental functioning $(p<0.001)$. Moreover, people of whom only baseline data were available $(n=1,165$, included into the analyses in order to better estimate intercept differences) also reported lower scores on functioning $(p<0.001)$ and lower educational levels $(p<0.001)$. This pattern of nonresponse and attrition may have led to a lack of significance of the relation between 
educational level and changes in health-related functioning and to an underestimation of the role of material and psychosocial factors.

\section{CONCLUSION}

Low educational level was associated with poor physical and mental functioning in older age. However, no further widening of these gradients was found during follow-up. More than material factors, psychosocial factors, mastery and self-efficacy in particular, explained a large part of the educational differences in baseline health-related functioning. Further research is recommended to explore the amenability to change of characteristics that hamper people from taking control over their lives.

\section{Acknowledgements}

The longitudinal SMILE study is carried out by the Department of General Practice of Maastricht University, in collaboration with the Eindhoven Corporation of Primary Care Centres. The researchers are indebted to the participants for their willingness to participate in the study. 


\section{REFERENCES}

1. Adler NE, Ostrove JM. Socioeconomic status and health: what we know and what we don't. Ann N Y Acad Sci. 1999;896:3-15.

2. Marmot M, Ryff CD, Bumpass LL, Shipley MJ, Marks NF. Social inequalities in health: next questions and converging evidence. Soc Sci Med. 1997;44(6):901-10.

3. Ramsay SE, Whincup PH, Morris RW, Lennon LT, Wannamethee SG. Extent of social inequalities in disability in the elderly: results from a population-based study of British men. Ann Epidemiol. 2008;18:896-903.

4. Huguet N, Kaplan MS, Feeny D. Socioeconomic status and health-related quality of life among elderly people: results from the Joint Canada/United States Survey of Health. Soc Sci Med. 2008;66(4):80310.

5. Stuck AE, Walthert JM, Nikolaus T, Bula CJ, Hohmann C, Beck JC. Risk factors for functional status decline in community-living elderly people: a systematic literature review. Soc Sci Med. 1999;48:44569.

6. Van Lenthe FJ, Schrijvers CT, Droomers M, Joung IM, Louwman MJ, Mackenbach JP. Investigating explanations of socio-economic inequities in health. Eur J Public Health. 2004;14:63-70.

7. Lynch JW, Davey Smith G, Kaplan GA, House JS. Income inequality and mortality: importance to health of individual income, psychosocial environment, or material conditions. $\mathrm{Br}$ Med J. 2000;320:1200-4

8. Adamson JA, Ebrahim S, Hunt K. The psychosocial versus material hypothesis to explain observed inequality in disability among older adults: data from the West of Scotland Twenty-07 Study. J Epidemiol Community Health. 2006;60:974-80.

9. Marmot MG, Wilkinson RG. Psychosocial and material pathways in the relation between income and health: a response to Lynch et al. Br Med J. 2001;322:1233-6.

10. Groffen DAI, Bosma H, Akker van den M, Kempen GIJM, Eijk van JTM. Lack of basic and luxury goods and health-related dysfunction in older persons; Findings from the SMILE study. BMC Public Health. 2008;8:242.

11. Pikhart H, Bobak M, Rose R, Marmot M. Household item ownership and self-rated health: material and psychosocial explanations. BMC Public Health. 2003;3(38).

12. Boeing $\mathrm{H}$. Epidemiological research in stomach cancer: progress over the last ten years. J Cancer Res Clin Oncol. 1991;117(2):133-43.

13. Festinger L. A theory of social comparison processes. Hum Relat. 1954;7(2):117-40.

14. Kristenson M, Eriksen HR, Sluiter JK, Starke D, Ursin H. Psychobiological mechanisms of socioeconomic differences in health. Soc Sci Med. 2004;58:1511-22.

15. Van den Akker M, Spigt MG, de Raeve L, van Steenkiste B, Metsemakers JFM, van Voorst EJ, et al. The SMILE study: A Study of Medical Information and Lifestyles in Eindhoven. The rationale and contents of a large prospective dynamic cohort study. BMC Public Health. 2008;8(19).

16. Jehoel-Gijsbers G. Sociale uitsluiting in Nederland/Social exclusion in the Netherlands. The Hague: Netherlands Institute for Social Research/SCP; 2003.

17. Van Lenthe FJ, Gevers E, Joung IM, Bosma H, Mackenbach JP. Material and behavioral factors in the explanation of educational differences in incidence of acute myocardial infarction: the Globe study. Ann Epidemiol. 2002;12(8):535-42.

18. Martikainen P, Bartley M, Lahelma E. Psychosocial determinants of health in social epidemiology. Int J Epidemiol. 2002;31:1091-3.

19. "Psychosocial". OED Online. [cited 201024 March]; March 2008: [Available from: http://dictionary.oed.com

20. Bosma H, van Jaarsveld CH, Tuinstra J, Sanderman R, Ranchor AV, van Eijk JT, et al. Low control beliefs, classical coronary risk factors, and socio-economic differences in heart disease in older persons. Soc Sci Med. 2005;60:737-45. 
21. Wilson RS, Krueger KR, Gu L, Bienias JL, Mendes de Leon CF, Evans DA. Neuroticism, extraversion, and mortality in a defined population of older persons. Psychosom Med. 2005;67:841-5.

22. Sherer M, Maddux JE, Mercandante B, Prentice-Dunn S, Jacobs B, Rogers RW. The self-efficacy scale: construction and validation. Psychol Rep. 1982;51:663-71.

23. Eysenck HJ, Eysenck SGB. Personality structure and measurement. Londen: Routledge; 1969.

24. Pearlin II, Schooler C. The structure of coping. J Health Soc Behav. 1978;19:2-21.

25. Kempen GIJM, van Eijk LM. The psychometric properties of the SSL12-I, a short scale for measuring social support in the elderly. Soc Indic Res. 1995;35:303-12.

26. Ware JE, Sherbourne CD. The Rand-36 Short-form Health Status Survey 1: Conceptual framework and item selection. Med Care. 1992;30(6):473-81.

27. Ware JE, Kosinski M. Interpreting SF-36 summary health measures: a response. Qual Life Res. 2001;10:415-20.

28. Koster A, Bosma H, Kempen GI, Van Lenthe FJ, Van Eijk JT, Mackenbach JP. Socioeconomic inequalities in mobility decline in chronic disease groups (asthma/COPD, heart disease, diabetes mellitus, low back pain): only a minor role for disease severity and comorbidity. J Epidemiol Community Health. 2004;58:862-9.

29. Rothman KJ, Greenland S. Modern Epidemiology. 2nd ed. Philadelphia, PA: Lippincott Williams \& Wilkins; 1998.

30. Van Buuren S, Brand JPL, Groothuis-Oudshoorn CGM, Rubin DB. Fully conditional specification in multivariate imputation. J Stat Comput Simul. 2006;76(12):1049-64.

31. Baron RM, Kenny DA. The moderator-mediator variable distinction in social psychological research: conceptual, strategic, and statistical considerations. J Pers Soc Psychol. 1986;51(6):1173-82.

32. Breeze E, Fletcher AE, Leon DA, Marmot MG, Clarke RJ, Shipley MJ. Do socioeconomic disadvantages persist into old age? Self-reported morbidity in a 29-year follow-up of the Whitehall study. Am J Public Health. 2001;91(2):277-83.

33. Huisman M, Kunst AE, Mackenbach JP. Socioeconomic inequalities in morbidity among the elderly: a European overview. Soc Sci Med. 2003;57(5):861-73.

34. Koster A, Bosma H, Broese van Groenou MI, Kempen GI, Penninx BW, van Eijk JT, et al. Explanations of socioeconomic differences in changes in physical function in older adults; results from the Longitudinal Aging Study Amsterdam. BMC Public Health. 2006;6(1):244.

35. Kuh D, Ben-Shlomo Y, Lynch JW, Hallqvist J, Power C. Life course epidemiology. J Epidemiol Community Health. 2003;57:778-83.

36. Beckett M. Converging health inequalities in later life--An artifact of mortality selection. J Health Soc Behav. 2000;41(2):106-19.

37. Skinner EA. A guide to constructs of control. J Pers Soc Psychol. 1996;71(3):549-70.

38. Bosma H. Socio-economic differences in health: are control beliefs fundamental mediators? In: Siegrist J, Marmot M, editors. Social inequalities in health; new evidence and policy implications. Oxford: Oxford University Press; 2006. p. 153-66.

39. Barbareschi G, Sanderman R, Kempen GIJM, Ranchor AV. The mediating role of perceived control on the relationship between socioeconomic status and functional changes in older patients with coronary heart disease. J Gerontol B Psychol Sci Soc Sci. 2008;63B(6):353-61.

40. Wheaton B. The sociogenesis of psychological disorder: an attributional theory. J Health Soc Behav. 1980;21:100-24.

41. Marmot M. Fair society, healthy lives. Strategic review of health inequalities in England post 2010. London: The Marmot Review; 2010. 



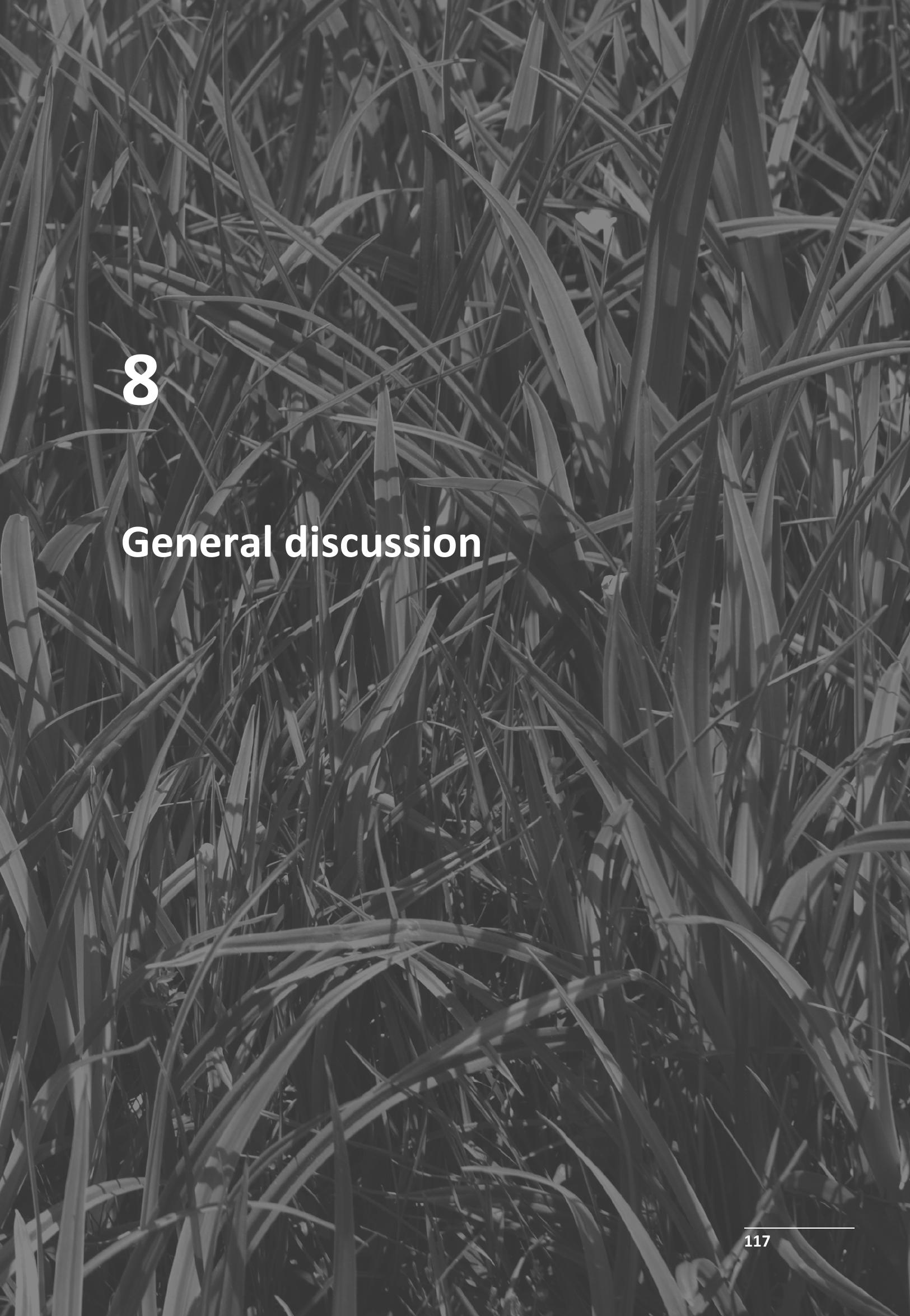




\section{INTRODUCTION}

Socioeconomic health differences are still a disturbing problem in generally wealthy Western countries. Overall, people from lower socioeconomic status (SES) suffer from higher levels of morbidity, mortality and functional limitations and a lower quality of life, compared with people from higher SES. ${ }^{1,2}$ Identifying the fundamental explanations of these health differences is likely to be the first step in the development of targeted interventions to reduce these health differences. Taking into account our rapidly aging population, and the fact that socioeconomic health differences and its explanations in older people remain unclear, older people are of particular interest in studying health inequalities. ${ }^{3}$ The main explanations of socioeconomic health differences that have been identified include selection effects, behavioural, material and psychosocial factors. ${ }^{4-6}$ Definitions of these explanatory factors can be found in the Introduction section (Chapter 1) of this thesis.

The aim of the present thesis was to explore these explanations of socioeconomic health differences in older people. To gain more insight into the fundamental determinants of socioeconomic health differences, the individual contribution of material and psychosocial factors to the relation between SES and health-related functioning in older people was studied in particular. For this purpose, four main research questions were formulated:

1. What is the influence of socioeconomic status on physical and mental functioning in older people?

2. What is the influence of material factors on physical and mental functioning in older people?

3. What is the influence of psychosocial factors on physical and mental functioning in older people?

4. What is the relative contribution of psychosocial factors and material factors to the relation between SES and physical and mental functioning in older people?

In addition, the reversed influence from health-related dysfunction to low socioeconomic status (i.e. direct selection) and between psychosocial factors and low socioeconomic status (i.e. indirect selection), as well as the mediating role of behavioural factors (i.e. behavioural factor hypothesis) were considered to gain more insight in the underlying relations and explanations of socioeconomic differences in healthrelated function. Answers on these research questions were addressed in the different chapters of this thesis.

In this chapter, the main findings of this thesis will be discussed. Next, a discussion on what this thesis adds to previous research and some conceptual and methodological considerations will be summarised. Finally, recommendations for future research and policy implications will be provided, as well as a general conclusion. 


\section{MAIN FINDINGS}

\section{Socioeconomic differences in old-age functioning}

The first research question of this thesis was to assess the influence of socioeconomic status on old-age physical and mental functioning. This question was explicitly addressed in Chapters 4, 6, and 7.

In the AGES-Reykjavik study, we studied the effects of midlife socioeconomic status on mobility limitations, walking speed and depressed mood almost three decades later. Before the recent economic crisis, Iceland was considered to be one of the wealthiest countries in the world with an egalitarian distribution of resources, as assessed by the Gini-coefficient. ${ }^{7}$ Consequently, socioeconomic health differences were expected to be relatively small. ${ }^{8,9}$ Classic SES measures in midlife, such as education and occupation, however, turned out to be important predictors of health-related dysfunction in older people. Men and women with primary or secondary education had a risk of reporting a depressed mood that was more than twice as high as compared with men and women with college or university education. Looking at mobility limitations and walking speed, coefficients were less extreme, but clearly showed a socioeconomic gradient, in which men and women with the lowest levels of education and occupation (e.g. homemakers and manual workers) showed the highest risk of dysfunction three decades later.

In the Health $A B C$ study, the effects of socioeconomic adversity on depressive symptoms over a nine year time period were studied. Due to the political climate in the United States, socioeconomic health differences were expected to be more pronounced as compared with the situation in the Netherlands and Iceland. In addition to the classic measures of socioeconomic status, i.e. education and income, also the effects of perceived income (i.e. "How well does the amount of money you and your family receive, fits your needs?") and possession of financial assets (i.e. money market accounts, saving bonds or treasury bills, home ownership or investment property or housing, a business or farm, stock or stock mutual funds, individual retirement accounts, or other investments) on depressive symptoms were assessed. Results showed that low SES predicted an increased incidence of depressive symptoms over nine years time. In black men, socioeconomic differences in depressive symptoms were especially strong, with black men with lower income levels having a risk of depressive symptoms that was more than five times as high as compared with black men with higher income levels. We also showed differences in the relevance of the individual SES measures in predicting depressive symptoms. Income was an important predictor of incident depressive symptoms in men but not women, whereas in women educational level was important. Comparing black and white men, perceived income seemed to have more importance predicting depres- 
sive symptoms in white men, while a more absolute measure on the number of financial assets had more predictive power in black men.

In the Dutch longitudinal SMILE study, we studied the effects of educational level on physical and mental functioning over an average of 2.5 years (follow-up range: 0-5 years). Results showed that low educational level was associated with initial poor physical and mental functioning. However, no further widening of these gradients was found during this relatively short follow-up.

These findings indicate that socioeconomic health differences are still a major problem, also in older people. Moreover, socioeconomic health differences seem consistent across countries and are independent of the specific cultural and economic characteristics of the different study populations.

\section{Material factors and old-age functioning}

The second research question of this thesis addressed the influence of material factors on old-age physical and mental functioning. This question could be answered by looking at the results of Chapters 2, 3, and 4 .

Cross-sectional results from the SMILE study showed that material deprivation and poverty are not uncommon in Dutch older people. For example, almost $29 \%$ of our study population perceived at least one financial problem, including arrears of payment, not being able to afford new furniture or clothes when needed or to eat a meal with meat, chicken or fish every other day. Those reporting material deprivation had more than twice the risk of physical and mental dysfunction compared with non-deprived persons.

Taking a closer look at the basic goods a household can possess, the SMILE study showed that a lack of these basic goods, including a car, freezer or house ownership, is also not uncommon in Dutch older people. The lack of basic goods (lacking three or more items out of list of seven) was significantly related to both incident mental and physical dysfunction, even when additionally adjusted for relevant covariates, such as educational level. People lacking three or more items out of a list of seven, had a risk of physical and mental dysfunction that was more than twice as high as compared with people possessing all seven basic goods.

In the AGES-Reykjavik Study we examined the effects of early life and midlife material factors on mobility limitations, walking speed and depressed mood almost three decades later, independently of the classic measures of SES. Material factors included the possession of basic goods, such as a car, but also housing age and quality and availability of food in childhood. Although not all material factors were consistently related to all outcome measures in both sexes, some measures such as home or car ownership, age of housing, home features, and report of not having enough to eat when growing up, turned out to be important determinants related to dysfunction in older people, independently of the classis SES measures. 
These results indicate the importance of material factors as predictors of healthrelated functioning in older people. Even accounting for the classic SES measures, material life circumstances continue to affect health in older people.

\section{Psychosocial factors and old-age functioning}

The third research question of this thesis was to assess the influence of psychosocial factors on old-age physical and mental functioning. This question was addressed in Chapter 3. Chapter 5 and 7, however, also give important clues about the importance of psychosocial factors.

In Chapter 3 the possession of luxury goods was associated with physical and mental functioning. The possession of luxury goods was hypothesised to be an indicator of the psychosocial factor hypothesis on socioeconomic health differences. Luxury goods cannot have a direct, biological, effect on health, but may rather affect health via indirect mechanisms related to the stress resulting from negative social comparisons. Cross-sectional results from the SMILE study, however, showed that the lack of luxury good was not associated with physical and mental dysfunction in older people.

In Chapter 5 the effects of personality factors on future changes in income were studied. Results of the longitudinal SMILE study showed that personality factors, social anxiety in particular, have an important role in maintaining one's socioeconomic position in older Dutch people. Via indirect selection mechanisms (see below), psychosocial factors appear to be important predictors of health-related functioning in older people.

In Chapter 7 the independent effect of psychosocial factors on socioeconomic health differences in older people was studied. Conclusions about the role of psychosocial factors in predicting health-related functioning could also be made (not shown); results from the longitudinal SMILE study showed that especially constructs of control (i.e. mastery and self-efficacy) are important in explaining health-related functioning in older people.

\section{Material versus psychosocial explanations of socioeconomic differences in old-age functioning}

The fourth research question of this thesis aimed to assess the relative contribution of both material and psychosocial factors to the relation between SES and old-age physical and mental functioning. This question was explicitly addressed in Chapter 7 of this thesis.

In previous chapters, we have already seen that material deprivation and poverty are not uncommon in generally wealthy Western countries (Chapters 2, 3, 4). These material factors have strong effects on health. Moreover, we have been given 
an indication that the effect of adverse material circumstances accumulates along the life course, making older people an especially vulnerable population. Consequently, material factors may be considered an important explanation of socioeconomic differences in health-related functioning in older people.

Using data from the longitudinal SMILE study, the individual contribution of material and psychosocial factors to the relation between educational level and physical and mental dysfunction was assessed. Material factors reduced the educational differences in physical and mental functioning by an average of $29 \%$. Psychosocial factors, mastery and self-efficacy in particular, reduced these differences by an average of $60 \%$. These results indicate the relative importance of psychosocial factors, especially of constructs of control, in explaining socioeconomic health differences in older people.

Summarising these results in light of the ongoing debate between material and psychosocial explanations of socioeconomic health differences, ${ }^{10-13}$ we conclude that material and psychosocial explanations may not be mutually exclusive, but rather are complementary. It seems important to enable all persons to maximise their self-management capabilities and control over their lives. However, these factors can probably only be modified if the wider material context in which they occur is taken into account. ${ }^{14}$

\section{Additional explanations of socioeconomic differences in old-age functioning}

To gain more insight in the underlying relations and explanations of socioeconomic differences in health-related functioning in older people, two additional pathways were studied.

\section{Selection mechanisms}

The reversed relation between health-related dysfunction and low socioeconomic status and between psychosocial factors and low socioeconomic status was assessed in Chapter 5 of this thesis.

Three years of follow-up data from the longitudinal SMILE study were used to study the independent effects of physical and mental dysfunction and severity of chronic diseases on decreases in income (direct selection hypothesis) and the independent effects of adverse personality factors on decreases in income (indirect selection hypothesis). Results showed that social anxiety, physical dysfunction and severe diseases were significant predictors of decreases in income three years later. These results indicate the additional importance of both the direct and indirect selection hypothesis of socioeconomic health differences. 


\section{Behavioural factors}

The mediating role of behavioural factors in the relation between low socioeconomic status and mental dysfunction was assessed in Chapter 6 of this thesis. Nine years of follow-up data from the Health $A B C$ study were used to study the relative contribution of individual lifestyle factors, including smoking, alcohol use, body mass index, and physical activity, to the relation between socioeconomic adversity and depressive symptoms. Although unhealthy lifestyle factors were consistently associated with low SES, lifestyle factors did not significantly reduce hazard ratios for depressive symptoms by SES. The mediating effect of lifestyle factors on the relationship between SES and depressive symptoms was therefore considered to be weak to non-existent. It should, however, be mentioned that these findings are only valid within a population of relatively healthy older American people. However, previous research on behavioural explanations of socioeconomic differences in mental functioning showed similar results in Dutch older people. ${ }^{15}$ Behavioural factors, however, might have a role in explaining socioeconomic differences in physical functioning in people aged younger than 70 years. ${ }^{16}$

\section{WHAT THIS THESIS ADDS}

The studies described in this thesis have important theoretical and methodological strengths which add to previous research undertaken in this field.

\section{Contribution to theory development}

Theoretically, the results presented in this thesis contribute to the debate between advocates of the material and psychosocial factor hypothesis. ${ }^{10,12,13}$ We have found evidence for both perspectives, indicating that both material and psychosocial factors may not be mutually exclusive but complement each other. The role of psychosocial factors might even be more important than the role of material factors. This knowledge is especially of importance for future intervention development.

Second, this thesis includes a selection perspective on socioeconomic health differences. In recent years, it is increasingly becoming clear that socioeconomic status not only affects future health outcomes, but that also health problems in early life may be followed by a lower social position in later life. ${ }^{17}$ Chapter 5 of this thesis shows that severe health problems in older people may cause downward social mobility, i.e. decreases in income. These findings are supportive of the direct selection hypothesis, even in older age. In addition, other qualities of a person, for example personality and $\mathrm{IQ}$, may affect where a person ends up in terms of future health and socioeconomic status. ${ }^{18}$ We also found supportive evidence for this indirect selection hypothesis' by showing how social anxiety was related to future de- 
creases in income. Simultaneously, social anxiety is related to future health outcomes.

Third, we used relatively new theoretical concepts and measurement instruments, luxury goods and social anxiety in particular. In Chapter 3, we have looked at the role of luxury goods in predicting health related functioning in older adults. Luxury goods were hypothesised to be an indicator of the psychosocial factor hypothesis on socioeconomic health differences. Luxury goods cannot have a direct, biological effect on health, but rather affect health via indirect mechanisms related to the stress resulting from negative social comparisons. Results, however, showed no significant effects of these luxury goods. Additional research, using the same 21item instrument but looking at different subgroups, showed that particularly people from low socioeconomic status still may benefit from the possession of luxury goods. ${ }^{19}$ These results pave the way to future research examining the reasons for and consequences of 'conspicuous consumption' ${ }^{20}$ in low SES groups. Furthermore, we have looked at relatively new measures for personality factors, like social anxiety. Although the concept of 'social anxiety' is explicitly mentioned as an important psychological pathway through which income inequality may affect health, ${ }^{21}$ it has rarely been studied in empirical studies. Similar to well-known concepts as mastery and self-efficacy, social anxiety or social inadequacy might reflect beliefs of low control in social circumstances.

Finally, we have looked beyond the classic measures of socioeconomic status. In the Health $A B C$ study we used predictor variables like perceived income and the possession of financial assets. In the AGES-Reykjavik study, several material factors related to housing quality, housing assets, car ownership, and financial situation in childhood were used. Even when adjusting for the classic measures of SES, these factors turned out to be important (additional) predictors of health-related functioning in older people.

\section{Methodological strengths}

One of the methodological strengths of this thesis comprises the use of three different international datasets to answer our research questions. Data from the Netherlands, Iceland and the United States were analysed. Consequently, our main finding that socioeconomic differences in health-related functioning in older people still exist is independent of culture and the politic climate of a specific research sample. Although the socioeconomic health differences are strongest in a heterogeneous American population and more subtle in an egalitarian Icelandic population, classic measures of SES are consistent predictors of health-related functioning across countries. People with lower levels of education, occupation or income have a consistent higher risk of physical and mental dysfunction in older people. 
A second methodological strength of this study is the use of longitudinal data. Following the same individuals over time allows for causal inference. ${ }^{22}$ Moreover, it helps to deal with the bias resulting from using self-reported data. For example, individuals with a general tendency towards negative perceptions of material wellbeing may also over-report symptoms of health-related dysfunction (i.e. negative affectivity). ${ }^{23-25}$ However, by excluding prevalent dysfunction cases from the longitudinal analyses, persons with negative affectivity will also be excluded. In the Dutch SMILE study, five years of follow-up data were available for analyses. Every year, the participant's self-reported health-related functioning was measured. This repeated measurements allowed us to study the changes in socioeconomic health differences in older people over time. In the Health ABC study, nine years of followup data were available, which enabled us to study the onset of depressive symptoms over time. Furthermore, in the AGES-Reykjavik Study, an average of almost 30 years of follow up was available. Despite of using chronic diseases as a proxy for poor health-related functioning at baseline, the long follow-up period allowed us to study the effects of midlife and early life factors on health-related functioning in older people, employing a life course perspective on socioeconomic health differences. In recent years, a life course perspective has been given increased attention in the field of socioeconomic health differences. ${ }^{26}$ In this perspective, accumulation of adverse socioeconomic circumstances and causation and selection operating simultaneously over the course of life may cause a downward spiral of health. ${ }^{17}$

\section{LIMITATIONS}

Some conceptual and methodological issues should be considered in order to better interpret the results of the studies described in this thesis. This section reports on these limitations and their implications.

\section{Material factors}

In this thesis, material factors were defined as factors related to the physical (living and working) environment, the possession of goods and the household's financial situation. They are hypothesised to have direct biologically damaging effects on health and functioning. In the SMILE study, a scale on material deprivation was used. Material deprivation was defined as a financial strain and/or the enforced lack of material resources. ${ }^{27,28}$ This scale included questions on the possession of basic goods and having arrears of payment. ${ }^{27}$ However, the individual's perception of his or her financial situation was also asked for (e.g. "do you have problems managing with your monthly household income?"). Consequently, these variables might not only reflect a material mechanism but -at least partly- might also reflect psychoso- 
cial mechanisms. Due to this misinterpretation, the results of our studies with regard to the role of material factors with direct biological effects on health might thus have been overestimated to some unknown extent.

Second, we have to acknowledge that certain important material factors were not measured in our studies. For example, hygienic housing conditions, neighbourhood conditions and physical working conditions were not part of the questionnaire in all three datasets. Although these measures might have been implicitly assessed, the lack of these data may have resulted in an underestimation of the role of material factors.

A third issue regarding material factors includes the conceptual similarities with SES itself. Instead of looking at material factors as a mediator between SES and health, they might even be considered as the most toxic component of a person's social status itself. In our studies, we have shown that the association between material factors and classic measures of SES is very high indeed (e.g. Chapters 2, 3, 4). People with lower levels of education and income are more likely to suffer from a lack of basic goods, adverse housing conditions, and problems with managing the household income. Although all analyses examining the role of material factors on health-related functioning were (additionally) adjusted for education or income, it is not possible to disentangle the causal (i.e. mediating or independent) role of material factors itself. Future research (e.g. principal component analyses) is necessary to disentangle which factors are involved in shaping a person's social status (e.g. education and income, but also IQ and cultural factors).

Finally, macroeconomic factors, which are strongly related to the distribution of material resources in a country, are neglected in this thesis. ${ }^{29,30}$ The presented analyses took place in relatively rich and wealthy populations within countries with social democratic (i.e. the Netherlands, Iceland) and liberal (i.e. United States) welfare state regimes. Some scholars propose that in social democratic welfare regimes, with egalitarian distribution of resources, socioeconomic health differences tend to be smaller, whereas in (neo) liberalistic policies, which include competitive market principles and conservative policies, these health differences may be more strong. ${ }^{31}$ Although most evidence shows that the magnitude of health inequalities in

different countries does not consistently reflect the different welfare regimes, ${ }^{32-34}$ it remains important to acknowledge that macroeconomic factors may affect socioeconomic health inequalities. In the current thesis, we found socioeconomic health differences to be most strong in the United States, while they were more subtle in Iceland and the Netherlands. However, had Eastern European or Third World countries been included, this would perhaps have resulted in a fuller insight into the role of material factors. 


\section{Psychosocial factors}

Our studies included several personality and psychological factors (e.g. social anxiety, social dominance, mastery, self-efficacy, hostility, neuroticism) as well as questions on the social environment (e.g. social support and social network). Moreover, questions on the possession of a list of 21 luxury goods were included. These factors might affect health via psychosocial pathways. However, it is very likely that certain aspects of the psychosocial factor hypothesis were not covered in this thesis. Therefore, it is still not clear which psychological and social factors mostly impede older people from low SES groups to successfully function in society.

First, although they might be of minor interest in this older age groups, factors related to psychosocial work stress might also be important mediators in the relation between SES and health. ${ }^{35}$ Second, personality factors like social reactivity or rebelliousness, ${ }^{36}$ vigilance, socialised fatalism and operationalisations of shame might also be of interest. ${ }^{37}$ The lack of data on these psychosocial factors might have resulted in an underestimation of the role of the psychosocial factor hypothesis in explaining socioeconomic health differences in older people. Future research is needed to develop appropriate questionnaires to assess these factors. Particularly research that questions perceptions and opinions of individuals from different SES groups, preferably by using mixed -quantitative and qualitative- methods ${ }^{38}$, is recommended. The latter might also be of interest in assessing individual's perceptions of material circumstances and relative deprivation, for example on the causes of income decrease.

\section{Attrition and selection bias}

Attrition and loss to follow-up are common problems in longitudinal cohort studies, especially when older people are involved. In this thesis, data from three studies were used. In the longitudinal SMILE study, more than $60 \%$ of participants were lost to follow up. In the Health $A B C$ study more than $50 \%$ were lost to follow-up due to death or other reasons. The AGES-Reykjavik study consisted of survivors from the original Reykjavik study (ca. 19\%). Overall, attrition was higher among lower SES groups. Furthermore, people who were lost to follow-up often had poorer physical and mental functioning compared with those who remained in the study. In addition to this selective loss to follow-up, all three studies suffered from considerable amounts of missing values on the variables of interest. In general, these participants were excluded from the analyses (25\% in the SMILE study, $17 \%$ in the AGESReykjavik Study and $10 \%$ in the Health $A B C$ study). Missing value analyses revealed that persons with missing values on one or more of the variables of interest were more likely to report lower levels of education and lower scores on physical and mental functioning. The most disadvantaged older persons may be underrepresented due to premature mortality or other reasons for drop-out, i.e. the 'healthy 
survivor effect'. These biases may have led to an underestimation of the relation between SES and health-related functioning.

\section{RECOMMENDATIONS}

\section{Policy implications}

The primary aim of the studies presented in this thesis was to explore the explanations of socioeconomic differences in health-related function in older people, focusing on material and psychosocial explanations in particular. Identifying and understanding the pathways and mechanisms that contribute to socioeconomic health differences might provide more insight in the possible factors that offer the most important startingpoint for action. This information could then be used to identify priorities for future intervention, implementation and evaluation studies. In the following, the Dutch political situation is used as an example to structure recommendations and implications for policy actions. Despite the difficulty to make crosscountry generalisations, depending on the political climate of a country, these recommendations could also be of interest for other Western populations.

The existence and reduction of socioeconomic health differences is a recurring issue in Dutch policy. A programme focussing on developing and evaluating interventions to reduce socioeconomic health differences formulated four targets: ${ }^{39}$

1. Reducing the structural inequalities in income, education, and materials (i.e. redistribution of resources). For example by providing supplementary benefits to people living in poverty.

2. Reducing the effects of health on SES (i.e. direct selection effects). For example by providing disability benefits and stimulating re-integration trajectories.

3. Reducing the effects of socioeconomic disadvantage on health (i.e. related to mediating factors, such as lifestyle and personal characteristics). For example by lifestyle interventions and empowerment programmes for lower SES groups.

4. Improving accessibility and quality of healthcare services for all SES groups. For example by the introduction of practice nurses in deprived areas and improving communication with ethnic minorities.

In November 2008, the Ministry of Public Health, Welfare and Sports launched a new policy plan. ${ }^{40}$ This plan emphasises individual responsibility, rather than prioritising inequalities in structural resources. Preferred instruments included provision of information, advising and counselling, stimulating self-regulation, fiscal instruments, and prohibitions to make people aware of their choices. ${ }^{40}$ The initial four target points are not easily recognised. However, the results of the current thesis still underline the importance of, at least part of, these original target points. 
First, our findings do not support the hypothesis that the poorer mental functioning of low SES groups is solely the result of their higher rates of unhealthy lifestyles. Other research findings support this statement, also for physical health outcomes. ${ }^{15,41}$ Many of the current interventions to reduce the socioeconomic gradient in health are, however, aimed at the prevention of unhealthy lifestyles. ${ }^{42}$ While it is not always clear if these interventions succeed in improving health in the general population, it is even more difficult to assess their impact on the socioeconomic gradient in health. ${ }^{42}$ Often, unhealthy lifestyles are formed in the context of an individual's material and cultural environment and norms. Stimulating healthy lifestyle choices by stressing individual responsibility will probably not be enough in reducing the socioeconomic gradient in health.

Instead, the current thesis provides evidence for a material factor hypothesis on socioeconomic health differences. Our studies suggest that relative deprivation is not uncommon in relatively wealthy Western countries. These factors strongly affect physical and mental functioning in older people. Increasing government interference by reducing structural inequalities in income and housing and working conditions might thus be necessary to reduce socioeconomic health differences. However, in addition to material explanations of socioeconomic health differences, our research findings strongly suggest that psychosocial factors might also be at work, constructs of control in particular. Hence, interventions aimed at reducing socioeconomic health differences should not only focus on structural determinants and the factors that have their origin in the material world, but also on interventions to enable all persons to maximize their capabilities and have control over their lives. ${ }^{14}$ For example, by teaching self-management skills in order to improve self-efficacy and low mastery in low SES groups ${ }^{43}$ (e.g. empowerment training programmes). The latter might also be of interest in improving accessibility to health care services. In the Netherlands, equal access to the health care system for all SES groups in general performs well. However, research shows that there are some noticeable differences in utilisation between SES groups (e.g. the contact with GP's and physicians and consequently the choice of the best treatment option differs for lower and higher SES groups) which may be due to differences in communication and cultural aspects, rather than the financial aspect. ${ }^{44}$ This underlines the importance of investing in psychosocial factors in lower SES groups.

Next, this thesis also provides evidence for selection effects as explanation of socioeconomic health differences in older people. Not only a poor health, but also adverse personality factors might be of interest in predicting social mobility in older people. In addition, they might affect future health status. This finding may stress the importance of disability benefits, but also of the previously mentioned psychosocial interventions. Taking into account the life-course perspective on health, these interventions should already focus on factors in early life, preferably starting in early childhood, to prevent accumulation of disadvantage into old age. ${ }^{14}$ 
In addition to these recommendations, it is important to acknowledge that health follows a gradient. Not only the poorest have poor health, but there is an improvement in health status at each successive step on the socioeconomic ladder up to the very top. ${ }^{2}$ Hence, interventions to reduce socioeconomic health differences should not only focus on the poorest of society. However, interventions that work for middle and higher class individuals, might not work as well for people on the bottom of the socioeconomic ladder. ${ }^{45}$ It might, thus, still be important to develop different approaches for each group.

Moreover, research, interventions, as well as all policy plans and programmes should consider socioeconomic differences from the beginning (i.e. mainstreaming). All health and policy professionals must have knowledge and awareness of the ways socioeconomic status affects health. Policies aimed at reducing socioeconomic health differences should involve not only the public health care sector but also other relevant sectors, such as the education, social affairs and environmental planning sectors. Consequently, an integrated approach may be more effective in reducing socioeconomic health differences. ${ }^{46}$

To summarise, it can be stated that socioeconomic health differences do not have one single explanation. Consequently, there is also no single solution. Interventions should include aspects of both the material and psychosocial factor hypothesis, as well as on selection mechanisms. Of course, we cannot prevent people from becoming ill. Instead, we have to focus on the unequal distribution of disease and dysfunction across SES groups. In order to reduce socioeconomic health differences, this issue deserves attention in all policies.

\section{Future research}

In this thesis, we have studied the independent contribution of material and psychosocial factors to socioeconomic differences in health-related functioning in older people. Neither material nor psychosocial factors alone could fully account for these health inequalities. It is, however, likely that these factors complement each other. Hence, it is preferable to conduct research that allows each to be tested in the context of the other. ${ }^{10}$ In addition to studying main effects, interactions may be informative. They could tell us, for example, whether material factors have different effects for individuals with varying psychosocial profiles. This might elucidate, for example, what it is about car ownership that leads to better functioning or what material conditions are critical to maintain a sense of control. Such information could further help target policy and interventions.

With regard to the psychosocial factor hypothesis, it would also be of interest to study the possible biological mechanisms underlying the relation between psychosocial stress and poor health outcomes. Biochemical markers of stress responses, 
such as salivary cortisol and inflammatory markers in blood serum might provide more information on these pathways. ${ }^{47-50}$

Other factors that were not subject of the current research might also be of interest in explaining socioeconomic health differences in older people. For example, genetic factors might be associated with both poor health outcomes and low SES. Because a person's genotype precedes his or her socioeconomic status and is related to individual disease susceptibility, ${ }^{51}$ genetic factors can be seen to operate within a selection perspective on socioeconomic health differences, possibly via personality factors like neuroticism and social anxiety and intelligence. ${ }^{18,52,53}$

There is a growing body of evidence that shows how area effects, such as neighbourhood circumstances (e.g. social capital) and family roles, explain or interact with the influence of an individual's socioeconomic status on their health. ${ }^{54-56}$ In this thesis, only individual-level factors were considered. However, individual-level factors such as personality factors and lifestyle choices generally do no arise in a vacuum. For example, social anxiety is, at least partly, likely to have arisen from family and childhood experiences and the influence of role models. Food choices and smoking behaviour, too, are formed in the context of an individual's cultural environment (e.g. friends, neighbourhood). ${ }^{57,58}$ Future research is recommended to assess the impact of group and area-related cultural factors on the relationships that were found.

Finally, the information obtained from the present thesis can be used to identify priorities for future research. However, intervention-, implementation, and evaluation studies are necessary to study which factors are actually amenable to change and which interventions are effective in reducing socioeconomic health differences and to whom.

\section{CONCLUSION}

We conclude that low SES is strongly related to physical and mental functioning in older people. Moreover, relative deprivation is not uncommon in generally wealthy Western countries. These factors are important determinants of health-related dysfunction in older people. In addition, psychosocial factors are also -or even more- of importance in explaining socioeconomic health differences, constructs of control in particular. Hence, material and psychosocial factors may not be mutually exclusive but may be complementary. Building on the strengths of both perspectives provides a more complete understanding of the causes of health inequalities. The material perspective provides insight into the physical and environmental determinants of health. Identifying material factors can inform social policy regarding the distribution of resources. The psychosocial perspective provides information on more proximal processes, including individual responses to stress. It seems impor- 
tant to enable all persons to maximise their capabilities and control over their lives. These psychosocial pathways to poor health may possibly be more effectively modified if the material context in which they occur is taken into account.

Our research findings can be used to identify priorities for both new research and policy. For example, we need to get insight into the factors that are amenable to change, which interventions are effective and for whom and how can they be implemented. These research questions require intervention-, implementation- and evaluation- studies of interventions that address the socioeconomic, material and psychosocial determinants of health. 


\section{REFERENCES}

1. Adler NE, Ostrove JM. Socioeconomic status and health: what we know and what we don't. Ann N Y Acad Sci. 1999;896:3-15.

2. Marmot MG, Shipley MJ, Rose G. Inequalities in death specific explanations of a general pattern? Lancet. 1984;8384:1003-6.

3. Artazcoz L, Rueda S. Social inequalities in health among the elderly: a challenge for public health research. J Epidemiol Community Health. 2007;61:466-7.

4. Townsend P, Davidson N. The Black Report. In: Townsend P, Davidson N, Whitehead M, editors. Inequalities in health. London: Penguin Books; 1988.

5. Mackenbach JP, van de Mheen HD, Stronks K. A prospective cohort study investigating the explanation of socio-economic inequalities in health in the Netherlands. Soc Sci Med. 1994;38(2):299-308.

6. Van Lenthe FJ, Schrijvers CT, Droomers M, Joung IM, Louwman MJ, Mackenbach JP. Investigating explanations of socio-economic inequities in health. Eur J Public Health. 2004;14:63-70.

7. Yitzhaki S. Relative deprivation and the Gini Coefficient. Q J Econ. 1979;93(2):321-4.

8. Jonsson PV. Letter from Reykjavik. Ann Intern Med. 1998;128(11):941-5.

9. Hardarson T, Gardarsdottir M, Gudmundsson KT, Thorgeirsson G, Sigvaldason H, Sigfusson N. The relationship between educational level and mortality. The Reykjavik Study. J Intern Med. 2001;249:495-502.

10. Adler NE. When one's main effect is another's error: Material vs psychosocial explanations of health disparties. A commentary on Macleod et al. Soc Sci Med. 2006;63(4):846-50.

11. Macleod J, Davey Smith G. Psychosocial factors and public health: a suitable case for treatment? J Epidemiol Community Health. 2003;57:565-70.

12. Macleod J, Davey Smith G, Metcalfe C, Hart C. Is subjective social status a more important determinant of health than objective social status? Evidence from a prospective observational study of Scottish men. Soc Sci Med. 2005;61(9):1916-29.

13. Macleod J, Davey Smith G, Metcalfe C, Hart C. Subjective and objective status and health: a response to Adler. Soc Sci Med. 2006;63(4):851-7.

14. Marmot M. Fair society, healthy lives. Strategic review of health inequalities in England post 2010. London: The Marmot Review; 2010.

15. Koster A, Bosma H, Kempen GIJM, Penninx BW, Beekman AT, Deeg DJ, et al. Socioeconomic differences in incident depression in older adults: the role of psychosocial factors, physical health status, and behavioral factors. J Psychosom Res. 2006;61(5):619-27.

16. Koster A, Bosma H, Broese van Groenou MI, Kempen GI, Penninx BW, van Eijk JT, et al. Explanations of socioeconomic differences in changes in physical function in older adults; results from the Longitudinal Aging Study Amsterdam. BMC Public Health. 2006;6(1):244.

17. Van de Mheen HD, Stronks K, Mackenbach JP. A lifecourse perspective on socio-economic inequalities in health: the influence of childhood socio-economic conditions and selection processes. Sociol Health IIIn. 1998;20 (5):754-77.

18. Mackenbach JP. Genetics and health inequalities: hypotheses and controversies. J Epidemiol Community Health. 2005;59:268-73.

19. Bosma H, Groffen DAI, Van den Akker M, Kempen GIJM, Van Eijk JTM. Better health reports when the grass is greener on your side of the fence? A cross-sectional study in older persons. Int J Public Health. 2010; In press.

20. Charles KK, Hurst E, Roussanov N. Conspicuous consumption and race. Q J Econ. 2009;124(2):425-67.

21. Wilkinson RG. Health, hierarchy and social anxiety. Ann N Y Acad Sci. 1999;896:48-63.

22. Rothman KJ, Greenland S. Modern Epidemiology. 2nd ed. Philadelphia, PA: Lippincott Williams \& Wilkins; 1998.

23. Kressin NR, Spiro A, Skinner KM. Negative affectivity and health related quality of life. Med Care. 2000;38(8):858-67. 
24. Macleod J, Davey Smith G, Heslop P, Metcalfe C, Carroll D, Hart C. Psychological stress and cardiovascular disease: empirical demonstration of bias in a prospective observational study of Scottish men. Br Med J. 2002;324:1247-53.

25. Watson D, Pennebakker JW. Health complaints, stress, and distress: exploring the central role of negative affectivity. Psychol Rev. 1989;96(2):234-54.

26. Kuh D, Ben-Shlomo Y, Lynch JW, Hallqvist J, Power C. Life course epidemiology. J Epidemiol Community Health. 2003;57:778-83.

27. Jehoel-Gijsbers G. Sociale uitsluiting in Nederland. The Hague: Netherlands Institute for Social Research/SCP; 2003.

28. Vrooman C, Dirven H, Soede A, Trimp R. Armoede monitor 2005. The Hague: Netherlands Institute for Social Research (SCP) and Statistics Netherlands (CBS); 2005.

29. Esping-Andersen G. The three worlds of welfare capitalism. Cambridge: Polity Press; 1990.

30. Esping-Andersen G. Social foundations of postindustrial economies. Oxford: Oxford University Press; 1999.

31. Sekine M, Chandola T, Martikainen P, Marmot M, Kagamimori S. Socioeconomic inequalities in physical and mental functioning of British, Finnish, and Japanese civil servants: role of job demand, control and work hours. Soc Sci Med. 2009;69(10):1417-25.

32. Bosma H. A critical reflection on the role of social democracy in reducing socioeconomic inequalities in health: a commentary on Sekine, Chandola, Martikainen, Marmot and Kagamimori. Soc Sci Med. 2009;69(10):1426-8.

33. Eikemo TA, Bambra C, Joyce K, Dahl E. Welfare state regimes and income-related health inequalities: a comparison of 23 European countries. Eur J Public Health. 2008;66(6):2281-95.

34. Dahl E, Fritzell J, Lahelma E. Welfare state regimes and health inequalities. Oxford: Oxford University Press; 2006.

35. Stansfeld SA, Bosma H, Hemingway H, Marmot MG. Psychosocial work characteristics and social support as predictors of SF-36 health functioning: the Whitehall II study. Psychosom Med. 1998;60:247-55.

36. Klabbers G, Bosma $H$, Van den Akker M, Van Boxtel MPJ, Kempen GIJM, McDermott MR, et al. Measuring rebelliousness and predicting health behaviour and outcomes. J Health Psych. 2009;14(6):771-9.

37. Lundberg J, Kristenson M, Starrin B. Status incongruence revisited: associations with shame and mental wellbeing. Sociol Health IIIn. 2009;31(4):478-93.

38. Polit DF, Beck CT. Nursing research. Principles and methods. 7 ed. Philadelphia: Lippincott Williams \& Wilkins; 2004.

39. Mackenbach JP, Stronks K. A strategy for tackling health inequalities in the Netherlands. Br Med J. 2002;325:1029-32.

40. Klink A. Naar een weerbare samenleving. Beleidsplan aanpak gezondheidsverschillen op basis van sociaaleconomische achtergronden. The Hague: Ministry of Public Health, Welfare and Sports; 2008.

41. Van Lenthe FJ, Gevers E, Joung IM, Bosma H, Mackenbach JP. Material and behavioral factors in the explanation of educational differences in incidence of acute myocardial infarction: the Globe study. Ann Epidemiol. 2002;12(8):535-42.

42. Bambra C, Gibson M, Sowden A, Wrigth K, Whitehead M, Petticrew M. Tackling the wider social determinants of health and health inequalities: evidence from systematic reviews. J Epidemiol Community Health. 2010;64:284-91.

43. Smeulders ESTF, Van Haastregt JCM, Ambergen T, Stoffers HEJH, Janssen-Boyne JJJ, Uszko-Lencer NHKM, et al. Heart failure patients with a lower educational level and better cognitive status benefit most from a self-management group programme. Patient Educ Couns. 2010; In Press.

44. Smits JPJM, Droomers M, Westert GP. Sociaal-economische status en toegankelijkheid van zorg in Nederland. Bilthoven: RIVM; 2002. 
45. Ogilvie D, Fayter D, Petticrew M, Sowden A, Thomas S, Whitehead M, et al. The harvest plot: A method for synthesising evidence about the differential effects of interventions. BMC Med Res Methodol. 2008;8(8).

46. Schrijvers CTM, Storm I. Naar een integrale aanpak van gezondheidsachterstanden. Een beschrijving van beleidsmaatregelen binnen en buiten de volksgezondheidssector. Bilthoven: Rijksinstituut voor Volksgezondheid en Milieu (RIVM); 2009.

47. Kristenson M, Eriksen HR, Sluiter JK, Starke D, Ursin H. Psychobiological mechanisms of socioeconomic differences in health. Soc Sci Med. 2004;58:1511-22.

48. Steptoe A, Kunz S, Owen N, Feldman PJ, Willemsen G, Kirschbaum C, et al. Socioeconomic status and stress-related biological responses over the working day. Psychosom Med. 2003;65:461-70.

49. Koster A, Bosma H, Penninx BWJH, Newman AB, Harris TB, Van Eijk JTM, et al. Association of inflammatory markers with socioeconomic status. J Gerontol A Biol Sci Med Sci. 2006;61:284-90.

50. Miller GE, Chen E, Fok AK, Walker H, Lim A, Nicholls EF, et al. Low early-life social class leaves a biological residue manifested by decreased glucocorticoid and increased proinflammatory signaling. Proc Natl Acad Sci U S A. 2009;106(34):14716-21.

51. Evans RG, Barer ML, Marmor TR. Why are some people healthy and others not? The determinants of health populations. New York: Walter de Gruyter, Inc.; 1994.

52. Ramos E, Rotimi C. The A's, G's, C's, and T's of health disparities. BMC Med Genomics. 2009;2(29).

53. Collins FS. What we do and don't know about 'race', 'ethnicity', genetics and health at the dawn of the genome era. Nature, Genetics Supplement. 2004;36(11):S13-S5.

54. Fone D, Dunstan F, Lloyd K, Williams G, Watkins J, Palmer S. Does social cohesion modify the association between area income deprivation and mental health? A multilevel analysis. Int J Epidemiol. 2007 February 28, 2007:1-8.

55. Diez-Roux AV. Investigating neighborhood and area effects on health. Am J Epidemiol. 2001;91:17839.

56. Mansyur C, Amick BC, Harrist RB, Franzini L. Social capital, income inequality, and self-rated health in 45 countries. Soc Sci Med. 2008;66:43-56.

57. Siahpush M, Borland R, Taylor J, Singh GK, Ansari Z, Serraglio A. The association of smoking with perception of income inequality, relative material well-being, and social capital. Soc Sci Med. 2006;63:2801-12.

58. Beard JR, Tomaska N, Earnest A, Summerhayes R, Morgan M. Influence of socioeconomic and cultural factors on rural health. Aust J Rural Health. 2009;17:10-5. 

Summary

Samenvatting

Co-authórs and affiliations

Dankwoord

About the author

\section{Publications}





\section{SUMMARY}

Socioeconomic health differences are a major public health problem in wealthy Western countries. Generally, people of lower socioeconomic status (SES) suffer from higher levels of morbidity, mortality, functional limitations, and a lower quality of life, compared with people with higher SES. Although there is ample evidence about the existence of a socioeconomic gradient in health, its fundamental explanations are less clear. Identifying the main explanation of socioeconomic health differences could be the first step in the development of targeted interventions to reduce these differences. Until now, the main explanations of socioeconomic health differences that have been identified include selection effects, behavioural, material and psychosocial factors.

In the selection perspective, healthy people are believed to reach higher positions on the social hierarchy than people who are less healthy (i.e. direct selection). Moreover, other qualities of an individual (e.g. personality, IQ) might also affect both where one ends up in the social hierarchy as well as the future health status (i.e. indirect selection). In general, more evidence exists for the causation perspective on socioeconomic health differences. In this perspective, SES is causally related to future health outcomes via behavioural, material or psychosocial factors. The behavioural factor explanation of SES differences in health implies that people from lower SES groups have poorer health because of their higher rates of unhealthy lifestyles, for example smoking, poor diet, and being physical inactive. In the material factor hypothesis, material factors (i.e. relative deprivation, possession of basic goods, physical housing and working conditions) are associated with exposures that are damaging and protective to health, which provide the explanation for social inequalities in health. Finally, the psychosocial factor hypothesis implies that inequalities are due to the direct and indirect effects of stress stemming from being in a socioeconomic hierarchy. Psychosocial factors, such as personality and social support, may determine individual susceptibility to stress.

The aim of the current thesis is to explore these explanations of socioeconomic health differences in older people. Taking into account our rapidly ageing population and a lack of evidence on the existence and explanation of socioeconomic health differences in older people, older people are of particular interest in studying health inequalities. To gain more insight into the fundamental determinants of socioeconomic health differences, the individual contribution of material and psychosocial factors to the relation between SES and health-related functioning in older people will be studied in particular. For this purpose, four main research questions were formulated: 
1. What is the influence of socioeconomic status on physical and mental functioning in older people?

2. What is the influence of material factors on physical and mental functioning in older people?

3. What is the influence of psychosocial factors on physical and mental functioning in older people?

4. What is the relative contribution of psychosocial factors and material factors to the relation between SES and physical and mental functioning in older people?

In addition, the reversed influence from health-related dysfunction to low socioeconomic status (i.e. direct selection) and between psychosocial factors and low socioeconomic status (i.e. indirect selection), as well as the mediating role of behavioural factors (i.e. behavioural factor hypothesis) are considered to gain more insight in the underlying relations and explanations of socioeconomic differences in healthrelated function. Answers on these research questions are addressed in the different chapters of this thesis.

Chapter 1 comprises a general introduction to the research subject. It reports on the existence and current explanations of socioeconomic health differences. Moreover, the aim and research questions of this thesis are outlined.

Using cross-sectional data from the Dutch Study on Medical Information and Lifestyles Eindhoven (SMILE), Chapter 2 reports on the prevalence of material deprivation and the association between material deprivation and health-related dysfunction in persons aged 55 years and older. Material deprivation was defined as a financial strain and/or the enforced lack of material resources. Results showed that almost $29 \%$ of subjects experienced at least one financial problem. Those reporting material deprivation had more than twice the risk of physical and mental dysfunction compared with non-deprived persons. These results support the hypothesis that even in a generally wealthy country such as the Netherlands, material deprivation is not uncommon among older people and is strongly related to both mental and physical dysfunction.

Chapter 3 presents the outcomes of the analyses on the relation between a lack of basic and luxury goods and health-related function. Both cross-sectional and longitudinal data from the Dutch SMILE study were used. The lack of basic goods was considered to be an indicator of the material factor hypothesis, while the lack of luxury goods was considered to be an indicator of the psychosocial factor hypothesis. Results showed that the lack of basic goods was closely related to incident physical and mental dysfunction, even when traditional measures of SES were taken into account. A lack of luxury goods was, however, not related to dysfunction. 
In Chapter 4 results from the Age, Gene/Environment Susceptibility (AGES)Reykjavik study are presented in which material factors were related to physical dysfunction and depressed mood almost three decades later. Independent of classic SES measures, not owning a house or car and living in older or poorer quality housing were important determinants of self-reported mobility limitations, depressed mood, and lower walking speed. Similarly, recalled shortages of food in childhood were related to health outcomes. These findings support the hypothesis that even accounting for the classic SES measures, other material life circumstances continue to affect health status in old age.

Chapter 5 presents analyses in which the direct and indirect selection perspective on socioeconomic health differences is tested. Three years of follow-up data from the longitudinal SMILE study were used to study the independent effects of physical and mental dysfunction and severity of chronic disease and adverse personality factors on subsequent decreases in income. Results showed social anxiety, physical dysfunction and severe diseases to be significant predictors of decrease in income three years later. The findings suggest that these factors are important for socioeconomic mobility in older people, and thus support the selection hypothesis on socioeconomic health differences.

Chapter 6 reports on the analyses in which the behavioural factor hypothesis was tested. Results from the Health, Aging, and Body Composition (Health $A B C$ ) Study among older American black and white men and women are presented. Nine years of follow-up data were used to test independent relations between SES, lifestyle factors, and incident depressive symptoms. People from low SES groups more often suffered from incident depressive symptoms. Strongest relations were found for black men. Although unhealthy lifestyle factors were consistently associated with low SES, lifestyle factors were only weakly related to incident depressive symptoms. In the Health $A B C$ study, the mediating effect of lifestyle factors on the relationship between SES and depressive symptoms in older people was considered to be weak to non-existent.

Chapter 7 addresses a comparison between both material and psychosocial explanations of socioeconomic differences in health-related functioning in older people. Longitudinal data from the SMILE study were used to study the relation between SES and longitudinal changes in physical and mental functioning and to study the relative contribution of material and psychosocial factors to this relation. Low SES was associated with poor initial physical and mental functioning in older people. No further widening of this gradient was found during follow-up. Material factors reduced the initial SES differences by an average of $29 \%$, while psychosocial factors, mastery and self-efficacy in particular, reduced these differences by an average of 
$60 \%$. More than material factors, these findings support a psychosocial explanation of socioeconomic health differences in older people.

Chapter 8 summarises and discusses the main findings of this thesis. Furthermore, the methodological and conceptual strengths and limitations of this thesis are considered. Moreover, recommendations for future research and policy implications are provided. Despite some limitations, we conclude that low SES is strongly associated with physical and mental functioning in older people. Moreover, material deprivation and relative poverty are not uncommon in generally wealthy Western countries. These factors are important determinants of health-related dysfunction in older people. In addition, psychosocial factors are also relevant in explaining socioeconomic health differences, constructs of perceived control in particular. Hence, material and psychosocial factors are not mutually exclusive but are complementary. Building on the strengths of both material and psychosocial perspectives might provide a more complete understanding of the causes of health inequalities in older people. For example, psychosocial pathways to poor health can possibly be more effectively modified if the material context in which they occur is also taken into account.

Our research findings can be used to identify priorities for new research. For example, we need to get insight into the factors that are amenable to change, which interventions are effective and for whom and how they can be implemented. These research questions require intervention-, implementation- , and evaluation-studies of interventions that address the socioeconomic, material and psychosocial determinants of health in older people. 


\section{SAMENVATTING}

Sociaal-eonomische gezondheidsverschillen zijn nog steeds een belangrijk volksgezondheidsprobleem in de meeste welvarende, westerse landen. Mensen uit lagere sociale klassen hebben hogere sterftecijfers, krijgen vaker te maken met (chronische) ziekten en beperkingen in het dagelijks functioneren en rapporteren een lagere kwaliteit van leven, in vergelijking met mensen uit hogere sociale klassen. Terwijl er al veel bewijs is over het bestaan van een sociaal-economische gradiënt in gezondheid, zijn de fundamentele verklaringen hiervoor nog steeds onduidelijk. Het identificeren van de belangrijkste verklaringen van sociaal-economische gezondheidsverschillen is waarschijnlijk de eerste stap bij de ontwikkeling van gerichte interventies om deze gezondheidsverschillen te verkleinen. De belangrijkste factoren die de laatste jaren zijn aangevoerd als mogelijke verklaring voor sociaaleconomische gezondheidsverschillen zijn: selectie effecten, gezondheidsgedrag, materiële en psychosociale factoren.

Uitgaande van een selectie perspectief hebben gezonde mensen meer mogelijkheden om hoger op de sociale ladder terecht te komen (directe selectie). Ook andere eigenschappen van een persoon, bijvoorbeeld persoonlijkheid of intelligentie, kunnen bepalen waar iemand terecht komt op de sociale ladder maar kunnen ook de toekomstige gezondheid voorspellen (indirecte selectie). Echter, over het algemeen is er meer bewijs dat sociale status gezondheid bepaalt (sociale causatie) dan andersom. Hierin kan gezondheidsgedrag een rol spelen. Aanhangers van deze hypothese geloven dat mensen uit lagere klassen een slechtere gezondheid hebben omdat zij er vaker een ongezonde levensstijl op nahouden, bijvoorbeeld door roken, ongezond eten en weinig beweging. Materiële factoren, zoals bezit van goederen en fysieke woon- en werkomstandigheden, zijn geassocieerd met een hogere blootstelling aan schadelijke stoffen of omstandigheden die slecht zijn voor de gezondheid. Over het algemeen komt dit vaker voor in de lagere sociale klassen. Ten slotte zegt de psychosociale factor hypothese dat sociaal-economische gezondheidsverschillen kunnen worden verklaard door de directe of indirecte effecten van chronische stress. Het leven in een sociale hiërarchie, waarin mensen zichzelf altijd vergelijken met anderen, kan een belangrijke bron van stress zijn, in het bijzonder voor mensen onderaan de ladder. Psychosociale factoren zoals persoonlijkheid en sociale steun kunnen de individuele gevoeligheid voor stress beïnvloeden.

Het doel van dit proefschrift is het verkrijgen van inzicht in de verklaringen van sociaal-economische verschillen in gezondheidsgerelateerd functioneren bij ouderen. Rekening houdend met onze snel vergrijzende samenleving, en een gebrek aan bewijs over het bestaan en de verklaringen van sociaal-economische gezondheidsverschillen bij ouderen, is het van groot belang deze gezondheidsverschillen te be- 
studeren in oudere populaties. Om meer inzicht te krijgen in de fundamentele verklaringen van sociaal-economische gezondheidsverschillen wordt, in het bijzonder, naar de individuele bijdrage van materiële en psychosociale factoren op de relatie tussen sociaal-economische status (SES) en gezondheidsgerelateerd functioneren bij ouderen gekeken. Om dit doel te bereiken zijn vier vraagstellingen geformuleerd:

1. Wat is de invloed van sociaal-economische status op fysiek en mentaal functioneren op oudere leeftijd?

2. Wat is de invloed van materiële factoren op fysiek en mentaal functioneren op oudere leeftijd?

3. Wat is de invloed van psychosociale factoren op fysiek en mentaal functioneren op oudere leeftijd?

4. Wat is de relatieve bijdrage van materiële en psychosociale factoren op de relatie tussen sociaal-economische status en fysiek en mentaal functioneren op oudere leeftijd?

Naast deze vier hoofdvraagstellingen wordt ook de omgekeerde invloed van gezondheidsgerelateerd functioneren en psychosociale factoren op toekomstige sociale status onderzocht (respectievelijk directe en indirecte selectie effecten). Verder wordt de rol van gezondheidsgedrag bekeken om een meer volledig inzicht in de verklaringen te verkrijgen. Antwoorden op deze vragen worden behandeld in de verschillende hoofdstukken van dit proefschrift.

Hoofdstuk 1 omvat een algemene inleiding op het onderwerp. Het rapporteert over de omvang en huidige verklaringen van sociaal-economische gezondheidsverschillen en presenteert het doel en de vraagstellingen van dit proefschrift.

Hoofdstuk 2 beschrijft de prevalentie van materiële deprivatie en de associaties tussen materiële deprivatie en gezondheidsgerelateerd functioneren in Nederlandse ouderen van 55 jaar en ouder. Hiervoor is gebruik gemaakt van de Studie naar Medische Informatie en Leefwijzen Eindhoven (SMILE). Materiële deprivatie werd gedefinieerd als het hebben van financiële problemen en/of een gedwongen gemis van materiële goederen. Resultaten lieten zien dat bijna $29 \%$ van de onderzoekspopulatie tenminste één financieel probleem rapporteert. Fysiek en mentaal dysfunctioneren kwam meer dan twee keer zo vaak voor onder diegenen die materiële deprivatie rapporteerden, in vergelijking met mensen die dit niet deden. Deze resultaten ondersteunen de hypothese dat ook in relatieve rijke landen, zoals Nederland, materiële deprivatie niet ongebruikelijk is bij oudere mensen en dat dit sterk geassocieerd is met fysiek en mentaal dysfunctioneren.

Hoofdstuk 3 beschrijft de relatie tussen een gebrek aan basale en luxe goederen en gezondheidsgerelateerd functioneren. Cross-sectionele en longitudinale gegevens van de SMILE studie werden gebruikt. Het gebrek aan basale goederen werd gezien 
als een indicator van de materiële factor hypothese, terwijl het gebrek aan luxe goederen een indicator was van de psychosociale hypothese. Resultaten lieten zien dat het gemis van basale goederen sterk gerelateerd is aan fysiek en mentaal dysfunctioneren. Deze verbanden hielden zelfs stand als gecorrigeerd werd voor traditionele SES maten, zoals opleiding en inkomen. Het gebrek aan luxe goederen was echter niet gerelateerd aan gezondheidsgerelateerd functioneren.

Hoofdstuk 4 presenteert resultaten van de Age, Gene/Environment Susceptibility (AGES)-Reykjavik Study. Materiële factoren, gemeten op middelbare leeftijd, werden gerelateerd aan fysiek dysfunctioneren en depressieve klachten bijna 30 jaar later. Onafhankelijk van klassieke SES maten waren het niet bezitten van een koophuis of auto, het wonen in een oudere of minder goed onderhouden woning, en niet voldoende te eten hebben gehad als kind belangrijke determinanten van zelfgerapporteerde beperkingen in het dagelijks functioneren, depressieve klachten en loopsnelheid. Deze bevindingen ondersteunen de hypothese dat, onafhankelijk van de klassieke SES maten, materiële levensomstandigheden eerder in het leven, de gezondheid op oudere leeftijd sterk bepalen.

Hoofdstuk 5 rapporteert over de directe en indirecte selectie effecten van sociaaleconomische gezondheidsverschillen. Gegevens van de longitudinale SMILE studie zijn gebruikt om de onafhankelijke effecten van fysiek en mentaal functioneren, ernstige en minder ernstige chronische ziekten en persoonlijkheidseigenschappen op een daling in inkomen drie jaar later te bestuderen. Resultaten lieten zien dat een sociaal angstige persoonlijkheid, fysiek dysfunctioneren en ernstige chronische ziekten significante voorspellers zijn van een daling in inkomen drie jaar later. Dit ondersteunt een selectie perspectief op sociaal-economische gezondheidsverschillen bij ouderen.

In Hoofdstuk 6 wordt gekeken naar gezondheidsgedrag als verklaring van sociaaleconomische verschillen in depressieve klachten bij ouderen. Resultaten van de Health, Aging, and Body Composition (Health $A B C$ ) Study worden gepresenteerd. In deze studie was data beschikbaar van blanke en gekleurde Amerikaanse mannen en vrouwen tussen 70 en 79 jaar oud. Negen jaar follow-up data zijn gebruikt om de onafhankelijke relaties tussen SES, gedragsfactoren, en nieuw gerapporteerde depressieve klachten te bestuderen. Mensen uit de laagste sociale klassen kregen vaker te maken met depressieve klachten, in vergelijking met mensen uit de hogere sociale klassen. Deze relatie was het sterkst aanwezig bij gekleurde mannen. Ongezond gedrag was consistent geassocieerd met lage sociale status, maar slechts zwak gerelateerd aan nieuwe depressieve klachten. Geconcludeerd kon worden dat in de Amerikaanse Health $A B C$ studie gezondheidsgedrag nauwelijks een mediator is in de relatie tussen SES en depressieve klachten bij ouderen. 
In Hoofdstuk 7 wordt een vergelijking gemaakt tussen materiële en psychosociale verklaringen van sociaal-economische verschillen in gezondheidsgerelateerd functioneren bij oudere mensen. Longitudinale data van de SMILE studie zijn gebruikt om de associaties tussen SES en longitudinale veranderingen in fysiek en mentaal functioneren en de relatieve bijdrage van materiële en psychosociale factoren op deze relatie te bestuderen. Lage SES was geassocieerd met fysiek en mentaal dysfunctioneren op baseline. Deze relatie bleef aanwezig tijdens follow-up, maar de verschillen in functioneren tussen hoge en lage SES werden niet groter. Materiële factoren verklaarden gemiddeld $29 \%$ van de relatie tussen SES en baseline functioneren, terwijl psychosociale factoren gemiddeld 60\% verklaarden. De grootste bijdrage werd geleverd door 'mastery' en 'self-efficacy', ofwel het geloof en gevoel van controle hebben over het leven. Deze bevindingen ondersteunen een psychosociale verklaring van sociaal-economische gezondheidsverschillen bij ouderen.

In Hoofdstuk 8 wordt een samenvatting en discussie van de belangrijkste bevindingen uit dit proefschrift gegeven. Verder worden methodologische en conceptuele sterke en zwakke punten besproken. Daarnaast worden aanbevelingen voor toekomstig onderzoek en beleid geformuleerd. Ondanks een aantal beperkingen van de verschillende studies kan geconcludeerd worden dat een lage SES sterk geassocieerd is met fysiek en mentaal dysfunctioneren bij verschillende groepen ouderen in verschillende landen. Materiële deprivatie en relatieve armoede zijn niet ongebruikelijk in relatief rijke westerse landen, zoals Nederland, IJsland en Amerika. Deze materiële factoren zijn belangrijke determinanten van gezondheidsgerelateerd functioneren. Daarnaast verdienen psychosociale factoren ook aandacht, in het bijzonder concepten die te maken hebben met het hebben van een gevoel van controle over het leven. Materiële en psychosociale verklaringen staan dus niet op zich zelf, maar vullen elkaar aan in een verklaring van sociaal-economische verschillen in gezondheidsgerelateerd functioneren bij ouderen. Bij het ontwikkelen van interventies dient hiermee rekening te worden gehouden. Bijvoorbeeld, ingrijpen op psychosociale factoren is waarschijnlijk het meest effectief als ook rekening wordt gehouden met de materiële omstandigheden.

Onze onderzoeksbevindingen kunnen worden gebruikt om prioriteiten voor toekomstig onderzoek te bepalen. Het is belangrijk om inzicht te krijgen in de factoren die veranderd kunnen worden, de interventies die daadwerkelijk effectief zijn in het verkleinen van sociaal-economische gezondheidsverschillen en hoe en bij welke doelgroep deze interventies kunnen worden geïmplementeerd. Deze onderzoeksvragen kunnen alleen worden beantwoord door middel van interventie-, implementatie- en evaluatie onderzoek bij ouderen. 


\section{CO-AUTHORS AND AFFILIATIONS}

\section{Marjan van den Akker, PhD}

CAPHRI School for Public Health and Primary Care, Maastricht University, Department of General Practice, Maastricht, The Netherlands

Thor Aspelund, PhD

Icelandic Heart Association, Kopavogur, Iceland

\section{Hilsa N Ayonayon, PhD}

Department of Epidemiology and Biostatistics, University of California, San Francisco, California, USA

\section{Hans Bosma, PhD}

CAPHRI School for Public Health and Primary Care, Maastricht University, Department of Social Medicine, Maastricht, The Netherlands

\section{Jacques ThM van Eijk, PhD}

CAPHRI School for Public Health and Primary Care, Maastricht University, Department of Social Medicine, Maastricht, The Netherlands

\section{Gudny Eiriksdottir, MSc}

Icelandic Heart Association, Kopavogur, Iceland

\section{Coen H van Gool, PhD}

Centre for Public Health Forecasting, National Institute for Public Health and the Environment, Bilthoven, the Netherlands

\section{Vilmundur Gudnason, MD, PhD}

Faculty of Medicine, University of Iceland, Reykjavik, Iceland; Icelandic Heart Association, Kopavogur, Iceland

\section{Tamara B Harris, MD, MS}

Laboratory of Epidemiology, Demography, and Biometry, National Institute on Aging, National Institutes of Health, Bethesda, Maryland, USA

\section{María K Jónsdóttir, PhD}

Faculty of Psychology, University of Iceland, Reykjavik, Iceland; Icelandic Heart Association, Kopavogur, Iceland 


\section{Pálmi V Jónsson, MD}

Faculty of Medicine, University of Iceland, Reykjavik, Iceland; Icelandic Heart Association, Kopavogur, Iceland

\section{Gertrudis IJM Kempen, PhD}

CAPHRI School for Public Health and Primary Care, Maastricht University, Department of Health Care and Nursing Science, Maastricht, The Netherlands

\section{Annemarie Koster, PhD}

Laboratory of Epidemiology, Demography, and Biometry, National Institute on Aging, National Institutes of Health, Bethesda, Maryland, USA

\section{Stephen B Kritchevsky, PhD}

Sticht Center on Aging, Section on Gerontology and Geriatric Medicine, Wake Forest University School of Medicine, Winston-Salem, North Carolina, USA

\section{Lenore J Launer, PhD}

Laboratory of Epidemiology, Demography, and Biometry, National Institute on Aging, National Institutes of Health, Bethesda, Maryland, USA

\section{Marco Pahor, MD}

Department of Aging and Geriatric Research, University of Florida College of Medicine, Gainesville, Florida, USA

\section{Brenda WJH Penninx, PhD}

Department of Psychiatry/EMGO Institute fro Health and Care Research, VU University Medical Center, Amsterdam, The Netherlands

\section{Sara E Perry, MA, MPH}

Department of Epidemiology, Tulane School of Public Health and Tropical Medicine, New Orleans, Louisiana, USA

\section{Susan M Rubin, PhD}

Department of Epidemiology and Biostatistics, University of California, San Francisco, California, USA

\section{Richard Schulz, PhD}

University Center for Social and Urban Research, University of Pittsburgh, Pennsylvania 


\section{Kristín Siggeirsdóttir, MSc}

Icelandic Heart Association, Kopavogur, Iceland

\section{Eleanor M Simonsick, PhD}

Longitudinal Research Section, Clinical Research Branch, National Institute on Aging, Baltimore, Maryland, USA; Division of Geriatric Medicine and Gerontology, Department of Medicine, Johns Hopkins School of Medicine, Baltimore, Maryland, USA

\section{Frans ES Tan, PhD}

CAPHRI School for Public Health and Primary Care, Maastricht University, Department of Methodology and Statistics, Maastricht, The Netherlands 



\section{DANKWOORD}

Vele mensen hebben bijgedragen aan de totstandkoming van dit proefschrift. Ik wil hen hiervoor graag hartelijk bedanken.

Als eerste wil ik graag mijn promotieteam bedanken, te weten mijn promotoren Jacques van Eijk en Ruud Kempen en co-promotoren Hans Bosma en Marjan van den Akker. Ik ben blij dat we met zijn 5-en dit promotietraject hebben kunnen afronden!

Jacques, ik wil je bedanken voor het vertrouwen dat je in me hebt getoond om de strakke planning waar te maken. Jouw opbouwende kritieken op mijn stukken hebben hier ook echt aan bijgedragen. Mede namens jou heb ik een tijdje in de Amerika kunnen werken. Verder waardeer ik ook je betrokkenheid en warme medeleven op het persoonlijke vlak. Ik hoop dat je, na mijn promotie, nog meer kan genieten van je pensioen!

Ruud, door 'in de schoenen van de reviewers' te staan, en je scherpe commentaren op mijn documenten, heb ik geleerd zelf ook kritisch te zijn. Ik denk dat de afzonderlijke artikelen, en het proefschrift als geheel, hierdoor zeker zijn verbeterd. Ondanks je drukke schema vond je toch altijd de tijd om te vragen hoe het nu met me ging. Dit heb ik heel erg gewaardeerd.

Hans, ik denk dat ik het heel erg heb getroffen met een dagelijkse begeleider zoals jij. Je betrokkenheid bij het onderwerp, enthousiasme over de analyses en resultaten, en vertrouwen in mij, maakten de samenwerking tot een genoegen. Je hielp me altijd de stukken nog scherper op papier te zetten en moedigde me aan als het nog korter en krachtiger kon. Daar heb ik veel van geleerd, maar het belangrijkste is dat je de affiniteit ten aanzien van sociaal-economische gezondheidsverschillen op me hebt proberen over te brengen. Dat is zeker gelukt!

Marjan, ik heb jou al leren kennen tijdens het eerste jaar van de Health Sciences Research Master. Samen met prof. Onno van Schayck heb jij het onderzoeksvoorstel voor dit project al kritisch onder de loep genomen. Doordat jij vaak iets meer afstand nam van het onderwerp, was je commentaar heel verfrissend. Het dynamische karakter van SMILE maakte de analyses en formuleringen met betrekking tot het design in de artikelen redelijk complex. Gelukkig hielp je om dit duidelijk op papier te krijgen.

De leden van de beoordelingscommissie, voorzitter prof. dr. Nanne de Vries, prof. dr. Frans Feron, prof. dr. Dorly Deeg, prof. dr. Johan Mackenbach en emeritus prof. dr. Hans Philipsen, wil ik bedanken voor hun bereidheid zitting te nemen in de commissie en het concept proefschrift van commentaar te voorzien. 
Furthermore, I would like to thank all Dutch, American, and Icelandic co-authors for their cooperation and their contribution to the SMILE, Health ABC, and/or AGES Reykjavik papers. It was a pleasure working with you all. I would especially like to thank Annemarie Koster and Tamara Harris for their supervision during my visit to the National Institute on Aging in the summer of 2008. I look forward to working with you again in the near future.

In dit kader wil ik ook graag onderzoeksinstituut CAPHRI, in het bijzonder prof. dr. Onno van Schayck, bedanken voor de beurs die ik heb ontvangen om dit werkbezoek mogelijk te maken.

Ik ben mijn AiO periode begonnen bij de vakgroep medische sociologie. Ik heb dit als een hele leuke tijd ervaren, vooral de dagelijkse thee-pauzes. Alle oud-collega's van medische sociologie wil ik hierbij bedanken, in het bijzonder mijn kamergenootje Esther Smeulders. Aan het einde van mijn eerste jaar als AiO werd de vakgroep opgesplitst en ging ik samen met Hans en Jacques mee naar de vakgroep sociale geneeskunde. Vivian Braeken ging mee naar de vakgroep Verpleging en Verzorging. Vivian, gelukkig bleef je in eerste instantie nog wel dichtbij op de $4^{e}$ verdieping en konden we onze 'opstart-klets' iedere ochtend voortzetten. Een heel fijne start van de dag. In zonnige en in minder zonnige periodes heb ik heel veel steun van je gekregen. Ik vind het heel fijn dat je mijn paraymf wilde zijn en ik wil je daarvoor heel erg bedanken.

De vakgroep sociale geneeskunde heeft zijn 'ups and downs' gekend. Letterlijk boven (op de $5^{\mathrm{e}}$ verdieping) zaten de AiO's en junior onderzoekers van de afdeling, maar ook beneden zitten waardevolle collega's, waar ik veel van heb geleerd. Allemaal mensen bij wie ik m'n ei kwijt kon als dat nodig was. Hierbij wil ik alle socmeders, maar in het bijzonder Isel van Noppen, Gonnie Klabbers, Katarina Putnik, Nicole Hoefsmit, en Yvonne Goertz bedanken. Met mijn kamergenootje, Yvonne Goertz, had ik het soms iets té gezellig en we moesten onze 'kletspauzes en volume' soms een beetje inperken, hoewel onze 'fruithapjes' natuurlijk niet uit de dagplanning mochten worden geschrapt. Yvonne, ik vind het heel bijzonder hoe we elkaar hebben kunnen steunen in onze onzekere momenten. Voor dit alles mijn oprechte dank. Begin 2011 mocht ik mijn spulletjes verhuizen naar de $4^{\mathrm{e}}$ verdieping. Bij mijn nieuwe kamergenootjes, Nicole, Evelien en Angelique, heb ik mij toen ook meteen thuis gevoeld. Hartelijk dank voor jullie warme ontvangst!

Zonder de Health Sciences Research Master was deze promotie waarschijnlijk niet tot stand gekomen. Bij dezen wil ik Christel van Gool bedanken voor de goede organisatie tijdens de opleiding. Ook docenten en mede-studenten, in het bijzonder Esther Bols, Marieke Quaak en Saskia Knies, wil ik hierbij bedanken. Saskia, ik vind het jammer dat we geen ganggenootjes meer zijn, het was erg fijn om af en toe bij elkaar aan te kunnen kloppen. Dank voor alle goede tips en inzichten. Marieke, 
bedankt voor alle koffie-, thee- of chocomel-pauzes om me door moeilijke momenten heen te slepen. Ik heb je luisterend oor altijd erg gewaardeerd!

Ik had dit proefschrift niet kunnen schrijven zonder de steun van mijn familie en vrienden. Als eerste wil ik mijn ouders, zusje en schoonouders bedanken voor de 'materiële en psychosociale' steun tijdens mijn studie en het promotietraject. Mijn schoonzusje Sharona wil ik bedanken voor haar mooie inzichten en soms kritische vragen. Sharona, ik vind het heel fijn dat je één van mijn paranymfen wilde zijn op mijn promotie, letterlijk een steuntje in de rug! Fiona, de paranymf plekken waren al vergeven dus daarin moest ik je teleurstellen, maar hierbij wil ik je bedanken dat je de laatste jaren zo'n goede vriendin bent geworden en er altijd voor mij was, in goede en in slechte tijden. Wie had kunnen denken dat het viva-forum zoiets moois kon opleveren! Kristel, soms wat meer op afstand, maar je was er ook altijd in gedachten. We hebben in al die jaren al veel meegemaakt samen. Ik denk dat je altijd één van de eersten was die ik belde als ik nieuws had. Dankjewel dat je er nog steeds voor me bent.

Tot slot, een bedankje voor mijn man Michaël. Ik denk dat dit proefschrift jou net zoveel energie heeft gekost als dat het mij heeft gekost. Maar zonder jouw steun en geduld, had ik dit proefschrift waarschijnlijk niet zo snel kunnen afronden. Je bent de liefste en beste echtgenoot die een promovenda zich kan wensen, zeker gezien je kookkunsten!

Lieve Elin*, mijn kleine dappere vlindermeisje, dit proefschrift heb ik opgedragen aan jou. Je hebt me geleerd dat een proefschrift, net als het leven, niet te plannen is. Je bent het mooiste wat me ooit is overkomen en met jou in mijn hart kan ik heel de wereld aan. Ik hoop dat jij net zo trots op mama kunt zijn, als dat mama op jou is! 



\section{ABOUT THE AUTHOR}

Daniëlle Groffen was born on July 21, 1981 in Bergen op Zoom, the Netherlands. After completing her secondary education (MAVO and HAVO), she studied Medical Imaging and Radiation Oncology (HBO-MBRT) at Fontys Hogescholen in Eindhoven, for which she obtained her bachelor degree in January 2004. She then started the Master of Public Health/Health Care Studies at Maastricht University. After her graduation in September 2005, she decided to continue studying, starting with the two-year Master of Philosophy programme: the Health Sciences Research Master at Maastricht University.

In September 2007, she officially began her PhD project on material and psychosocial explanations of socioeconomic differences in health-related functioning in older people, which she conducted at the Department of Social Medicine of Maastricht University and CAPHRI School for Public Health and Primary Care, the Netherlands. From June until October 2008, she worked at the National Institute on Aging at the Laboratory of Epidemiology, Demography and Biometry in Bethesda, Maryland, USA. There she collaborated in international research networks focusing on large-scale longitudinal studies: the AGES-Reykjavik Study and the Health ABC study.

The timely accomplishment of her PhD thesis resulted in a funded research fellowship for the forthcoming years with the CAPHRI School for Public Health and Primary Care. She will further study the biomedical and psychosocial explanations of socioeconomic health differences. A grant from research school CAPHRI has allowed here to again visit the National Institute on Aging in the USA for further in-depth longitudinal research and to intensify trans-Atlantic scientific collaboration. 



\section{PUBLICATIONS}

Bosma H, Groffen DAl, van den Akker M, Kempen GIJM, van Eijk JThM. Better health reports when the grass is greener on your side of the fence? A cross-sectional study in older persons. Int J Public Health. Aug 2010 [Epub ahead of print].

Groffen D and Vervoort K. Prostaatbestraling met behulp van rectumballonnen. Gamma, Tijdschrift van de Nederlandse Vereniging Medische Beeldvorming en Radiotherapie. 2005;55:12-8.

Groffen DAI, Bosma H, van den Akker M, Kempen GIJM, van Eijk JThM. Material deprivation and health-related dysfunction in Dutch older people; Findings from the SMILE study. Eur J Public Health. 2007;18 (3): 258-63.

Groffen DAI, Bosma H, van den Akker M, Kempen GIJM, van Eijk JThM. Lack of basic and luxury goods and health-related dysfunction in older persons; Findings from the longitudinal SMILE study. BMC Public Health. 2008;8: (42).

Groffen DAI, Bosma H, van den Akker M, Kempen GIJM, van Eijk JThM. Personality and health as predictors of income decrease in old age; Findings from the longitudinal SMILE study. Eur J Public Health. 2009;19 (4): 418-23.

Groffen DAI, Bosma H, Tan FES, van den Akker M, Kempen GIJM, van Eijk JThM. Material versus psychosocial explanations of old-age educational differences in physical and mental functioning; Findings from the longitudinal SMILE study. Eur J Public Health. 2011. (accepted)

Groffen DAl, Koster A, Bosma H, van den Akker M, Aspelund T, Siggeirsdottir K, Kempen GIJM, van Eijk JThM, Eiriksdottir G, Jonsdottir MK, Jonsson PV, Launer LJ, Gudnason V, Harris TB, for the Age, Gene/Environment SusceptibilityReykjavik Study. Beyond socioeconomic status: the influence of early life and midlife material factors on old age function; Findings from the AGES-Reykjavik Study. (submitted)

Groffen DAl, Koster A, Bosma H, van den Akker M, Kempen GIJM, van Eijk JThM, van Gool CH, Penninx BWJH, Ayonayon HN, Harris TB, Perry SE, Rubin SM, Pahor M, Schulz R, Simonsick EM, Kritchevsky SB. Socioeconomic adversity and incident depressive symptoms: mediating effects of an unhealthy lifestyle. Findings from the Health-ABC study. (submitted) 
Mertens VC, Bosma H, Groffen DAI, van Eijk JThM. Good friends, high income, or resilience: what matters most for "relatively successful functioning" in depressed elderly patients with a chronic physical disease? (submitted)

\section{International presentations}

Groffen DAI, Bosma H, van den Akker M, Kempen GIJM, van Eijk JThM. Lack of basic and luxury goods and health-related dysfunction in older persons; Findings from the longitudinal SMILE study. $10^{\text {th }}$ International Congress of Behavioral Medicine 2008, Tokyo, Japan. (oral presentation)

Groffen DAI, Bosma H, van den Akker M, Kempen GIJM, van Eijk JThM. Personality and health as predictors of income decrease in old age; Findings from the longitudinal SMILE study. XIX ${ }^{\text {th }}$ IAGG World Congress of Gerontology and Geriatrics 2009, Paris, France. (oral presentation)

Groffen DAI, Koster A, Bosma H, van den Akker M, Aspelund T, Siggeirsdottir K, Kempen GIJM, van Eijk JThM, Eiriksdottir G, Jonsdottir MK, Jonsson PV, Launer LJ, Gudnason V, Harris TB, for the Age, Gene/Environment SusceptibilityReykjavik Study. Beyond socioeconomic status: the influence of early life and midlife material factors on old age function; Findings from the AGES-Reykjavik Study. XIX ${ }^{\text {th }}$ IAGG World Congress of Gerontology and Geriatrics 2009, Paris, France. (poster presentation) 